4.

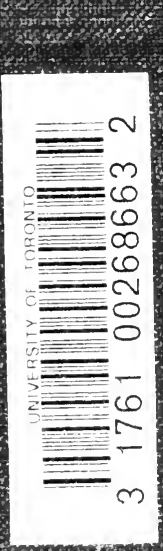

H.

in

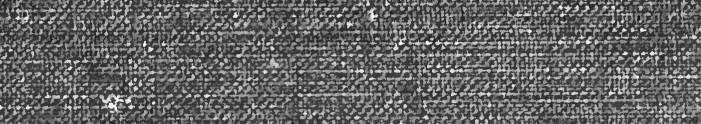

$m$

*.7. W 6. 1.

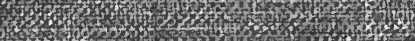

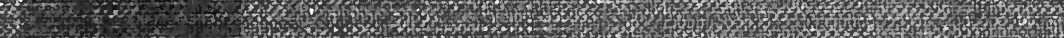

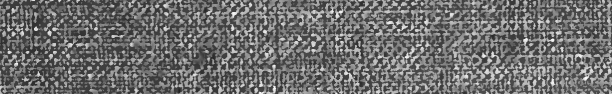
(6) 4.

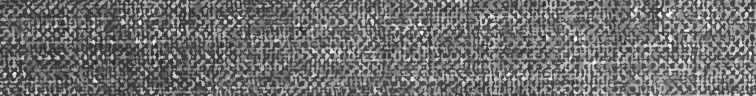

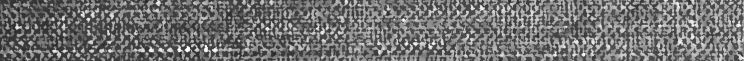
W. 13. \% (1) (3) H. P.

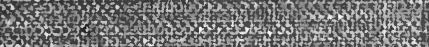
3.

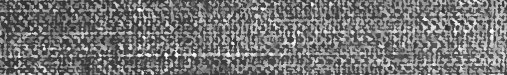




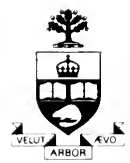

\author{
Presented to the \\ LIBRARY of the
}

UNIVERSITY OF TORONTO

by

Victoria College 
1 


THE PHILOSOPHY OF THE PRESENT IN GERMANY 



\section{THE PHILOSOPHY OF THE PRESENT IN GERMANY}

BY

OSWALD KÜLPE

PROFESSOR OF PHILOSOPHY IN THE UNIVERSITY OF BONN

TRANSLATED FROM THE FIFTH GERMAN EDITION BY MAUD LYALL PATRICK

AND

G. T. W. PATRICK

Authorized Translation

NEW YORK

THE MACMILLAN COMPANY

I9I 3 
Printed by Ballantyne, Hanson \& Co. At the Ballantyne Press, Edinburgh 


\section{PREFACE}

This little book has met with a great success in Germany. In England and America the perennial desire to follow closely the movements of German thought will, we believe, insure a welcome for the translation. Professor Külpe is well known in English-speaking countries through his other works, particularly his Introduction to Philosophy and his Outlines of Psychology, both standard works on these subjects, and both in English translations.

It has been objected that the present book is not precisely what its name implies-an account of the philosophy of the present in Germany, Die Philosophie der Gegenwart in Deutschland. This is true if by the philosophy of the present we mean the philosophy of the moment -the very last and latest philosophical fads, fancies, and effusions; but it is not true if by the philosophy of the present we mean the great representative movements which mark 
4

1 


\section{CONTENTS}

I. INTRODUCTION . $\quad . \quad+\quad . \quad$. $\quad$. 1

1. The Problem.$\quad$. $\quad . \quad$. $\quad$. 1

2. The Relation of Philosophy to the Special Sciences . . . . $\quad 8$

3. General Characteristics of the Four SchooLS . . . . . . . 18

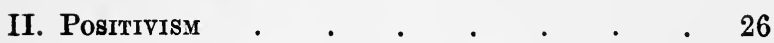

1. Ernst МасH . . . . . . 35

2. Eugen Dühring . . . . . $\quad$. 59

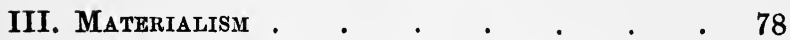

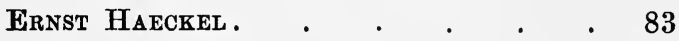

IV. NAtUralism •

Friedrich NietzSche $\quad . \quad . \quad . \quad$. 114

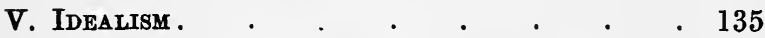

1. Gustav Theodor Fechner . . . 147

2. Hermani Lotze . . . . . 160

3. Eddard von Hartmann . . . 174

4. Wilhelm Wundt . . . . . 193

5. General Critique of Idealisi . . 222

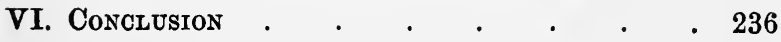

INDEX . . . ${ }_{\mathrm{ix}} \cdot{ }^{\circ} \cdot{ }^{\circ} \quad .253$ 
, 


\title{
THE PHILOSOPHY OF THE PRESENT IN GERMANY
}

\author{
I \\ INTRODUCTION \\ 1. THE PROBLEM
}

There have been times when philosophy stood in the foreground of general interest. Transcending the bounds of its legitimate field, it became a kind of public power to which everyone who laid any claim to culture was accustomed to seek as close a relation as possible. The impulse toward knowledge and science, the longing for happiness and peace, the hope for immortality and blessedness, the need of rules and regulations for conduct and action, all turned to philosophy, and were satisfied. Thus, far and wide, philosophy determined the broad orbits of the spiritual life, and was 


\section{PHILOSOPHY OF 'THE PRESENT}

regarded as unquestionably the most substantial fruit of all ideal endeavour. It was to philosophy that the arts and sciences crowded for inspiration, while culture and civilisation seemed almost to flow from it, or at least to be ennobled and consecrated through its influence. Such a period there was in Germany in the eighteenth and in the beginning of the nineteenth centuries.

At the present time philosophy holds a very different position. It has become merely one among many pursuits, and ranks in no wise above the others. Although no one would go so far as to regard philosophy simply as an inheritance of past ages, nevertheless it must now renounce its claim to the leading rôle in intellectual life. Treitschke could well say of the time succeeding the War of Liberation that a new philosophy aroused far deeper interest than a political event. Of the present times no historian could make such a statement.

Certainly the cause of this lessened interest in philosophy is not found altogether in the changed interests of the people. Nor is it true that a race of thinkers and poets (dubbed abstractionists by the first Napoleon) has been 
supplanted by a race of politicians. The change is due rather to the fact that we have to-day no philosophy which commands such profound regard. That there is a real and genuine demand in our times for philosophical reading and philosophical knowledge, is shown by the wide interest that has been taken in the works of Schopenhauer and Nietzsche.

The reproach may be made against modern philosophy, that it has itself parted with its proud title to the leading rôle in spiritual life; that it has descended to the lower region of investigation in the special sciences, and renounced altogether the development of a comprehensive theory of the universe and of life. But when there appears such a book as Haeckel's World Riddles, which with sure and expert hand offers a new standpoint for new times, its brilliant success shows that the love of philosophy is by no means extinct, but that now as ever it inspires a multitude of minds.

The situation in philosophy seems upon closer examination to be somewhat as follows: Formerly philosophical interest was directed to the more profound and difficult problems, while less attention was given to subjects of popular 


\section{PHILOSOPHY OF THE PRESENT}

interest and less merit was attributed to mere embellishment of form. It was not Gottsched and Gellert, but Christian Wolff (1679-1754), the systematiser of all knowledge, who was the philosophical hero in the first decades of the eighteenth century, while Schelling and Hegel practised but slightly the art of a Schopenhauer-the art of captivating and inspiring one's readers by means of popular language and impressive eloquence. Schopenhauer's World as Will and Idea, which appeared in 1819, although it was the chief work of the Frankfort philosopher, remained unnoticed for many decades, while the philosophically interested laity delighted to delve in the misty dialectic of Hegel and his school.

Now, however, in our own times, we discover a radically different attitude toward philosophy, well illustrated in the writings of Haeckel and Nietzsche. The happy methods of expression which make strenuous thought unnecessary, the dazzling fancies, the witty paradoxes, the artistic dress of thought, the immediate application to life and belief, and finally the close connection with scientific knowledge and hypotheses,-these are the factors which nowadays 
give a philosopher access to the reading public. Philosophy is now rather a recreation, a pleasant diversion for an idle hour, than a serious pursuit for a wide-reading public. It is not the worth of the ideas, nor the methods used in working them out, but rather a pleasing outward form, which determines in our day the choice of philosophical reading.

So it has come about that the philosophical movement of the present, in so far as it is strictly scientific, is not widely known nor fully appreciated. From this fact only can we understand the judgment that the philosophy of the present day deserves no better fate than it has received.

The first task of the modern philosopher is, therefore, as it seems to me, to determine carefully the present condition of this science, its meaning, its methods, and its goal. In the following chapters, I have sought to present very briefly the chief tendencies of modern philosophy, with the hope that we may see that it has not renounced its task of constructing a comprehensive view of the world and of life; and that in spite of its thoroughness and its carefulness, in spite of its methodological investi- 


\section{PHILOSOPHY OF 'THE PRESENT}

gations and its scientific caution, it rises to its own peculiar metaphysical views. Perhaps if I may be able to show that philosophy is at the present time pursuing its own special problems with unparalleled energy, a somewhat widely extended prejudice may in this way be removed. Perhaps also encouragement may thus be given to the study of new philosophical works, which may lay claim to a typical significance in illustrating the present achievements and the present tendencies of this science.

An essential limitation of material is of course necessary in this short sketch of the philosophy of the present. In the first place, I can scarcely go outside the limits of German plilosophy. Even in Germany it will be impossible to review all the present active philosophical tendencies and their representatives. Only the principal schools and a few typical representatives can be considered. I shall be obliged, therefore, to omit any review of the great and fruitful work in the field of the special philosophical disciplines. To be sure, it was precisely this special work which was characteristic of the close of the nineteenth century; but what I have in mind in this short discussion is the general 
tendency of thought, the general world-view, and the attitude of the several thinkers on the problem of knowledge; and on these broad questions we should gain little light from a detailed study of æsthetical, logical, ethical, or psychological problems.

While my work must necessarily be limited in the above-mentioned ways, there is one way in which it will be amplified. In speaking of the characteristics of the chief philosophical schools of the present, I shall use the word "characteristic" not simply in the sense of a description or an exposition, but also, although within very moderate limits, of a critique of the schools in question. In this way, although the difficulty of our task is increased, we shall approach it perhaps with greater interest. It is not enough merely to become acquainted with a number of pinilosophical movements; we wish also to be able to criticise them, and to gain an unprejudiced insight into their good and bad points. 


\section{PHILOSOPHY OF THE PRESENT}

2. THE RELATION OF PHILOSOPHY TO THE SPECIAL SCIENCES

It is to some extent doubtful just what is to be regarded as the chief trend of philosophy at the present. We stand too close to the events and persons, as well as to the general tendencies of our age, to be able either to comprehend them as a whole or to portray them adequately. In the following account, therefore, of the leading tendencies of the period, I should like from the first to claim the right of personal opinion, and thereby avoid all controversy over possible interpretations.

I believe four such general tendencies or schools may be distinguished: Positivism, Materialism, Naturalism, and Idealism. My task, then, will be to characterise these four schools of philosophy as to the particular form which they have at present assumed. In so doing I shall try to avoid giving a trite exposition of these theories in the usual stock phrases, treating as secondary their individual representatives. What I shall attempt, rather, will be to set forth the teaching of a few prominent 
representatives of the several schools under the form of a more thorough exposition and evaluation. In attempting in a very limited space to give a comprehensive review of the philosophical tendencies of a period, it is necessary to neglect the numerous individual differences and grasp the general standpoint, placing the main stress upon its characteristics. The individual philosophers who will receive detailed treatment win thereby the significance of types, chosen, according to the measure of their success and the respect and authority which they enjoy, to illustrate and supplement the more general exposition.

All four of the schools which we have named stand directly under the determining influence which the marvellous development of the special sciences, especially the natural sciences, exerted upon the thought of the nineteenth century. It was during this century that a final separation between philosophy and the special sciences first gained general recognition. In the great system of Christian Wolff, the natural sciences are still reckoned as empirical disciplines in philosophy. Kant also takes the same standpoint in so far as he opposes to each 


\section{PHILOSOPHY OF THE PRESENT}

other a knowledge from pure reason and a rational knowledge from empirical principles, and the latter he designates as applied philosophy. Only the former of course is to be counted as philosophy in the true sense. But in reality both philosophy and the special sciences, both the rational and the empirical disciplines, are distinguished only by their method. The former reaches its judgments by way simply of logical operations, through analysis of concepts, through conclusions and proofs, through deductive process. The latter, on the contrary, beginning with facts of perception, seeks by observation and comparison, by experimental methods and by the elaboration of judgments of experience, by induction and analogy, to arrive at scientific conclusions. The very same knowledge can, therefore, be gained in two ways: through observation or through intellectual affirmation; through investigation of empirical material or through an independent development of ideas; through the use of the senses or through the spontaneous activity of the understanding. From this it followed as a natural presupposition that the second, the rational method, was worth more 
and ranked higher than the empirical. The dominance of this view finds its expression in Goethe's Faust, in the second part of which the Baccalaureus says:

Erfahrungswesen! Schaum und Duft!

Und mit dem Geist nicht ebenbiirtig!

Although Kant had contributed greatly to subdue this arrogance of pure reason, and caused the value of empirical research to be more clearly recognised, nevertheless after his time the old view remained in favour-namely, that knowledge of a given fact could be arrived at by two different paths, the rational and the empirical, and that the former method was superior. In this spirit, Hegel (a Christian Wolff redivivus) made his great attempt to derive all knowledge of reality from pure reason by the rational method. Over experience he threw a carefully woven net of ideas. But the meshes of the net soon showed themselves to be here too narrow, there too wide. Philosophy made the claim that science is produced, like a homunculus, out of the simple ingredients of pure thought, but it produced no result capable of life and development. The dialectic method, which Hegel had used with wonderful force 


\section{PHILOSOPHY OF THE PRESENT}

and nimble mind, turned itself against him and destroyed his system. Reality showed itself unruly, and philosophy and the special sciences became involved in a violent war with each other. In this struggle, speculative philosophy, relying upon her own peculiar methods, finally succumbed. The sober, cautious, and exact work of the special sciences proved far superior and won a far more universal recognition than the abstract dialectics of the speculative philosophers, and so Hegel's whole structure, and the foundation upon which it was built, fell; and great was the fall thereof.

From this serious reverse, which philosophy suffered in the first half of the nineteenth century, it could recover only by giving up the unequal battle, the hopeless competition with the special sciences. It had to admit that its claim to an independent knowledge of reality through pure reason was a delusion; that no speculation could be tolerated which should take the place of research; that no encroachment would be permitted upon provinces which could not be subdued by the weapons of empirical investigation, nor any criticism of opinions whose empirical foundation 
one was not in position to test. Philosophy had to give up her foolish and groundless habit of disparaging and patronising the several sciences, which rested upon the fancy that she had at her service a special, quicker, and surer way by which to enter into knowledge of the whole of reality.

Originally philosophy and science coincided. So it was actually in antiquity; so it was nominally in the eighteenth century. When the special sciences began to be independent, philosophy assumed that she must still guide them and control them. But they shook off this burdensome and harmful yoke of arrogant speculation, and were quite able, unassisted, to find their own way and pursue it. The result was that a radical change took place in the relation of philosophy to science-a change which may be called characteristic of our time. Modern philosophy supplements the special sciences by a fundamental and comprehensive logic and theory of knowledge, by an amplifying and perfecting metaphysics, and, finally, by the undertaking of new investigations carried out in the spirit and by the methods of the special sciences. In this threefold sense philosophy 


\section{PHILOSOPHY OF THE PRESENT}

and science now join in the pursuit of one common end, and that end is knowledge.

All sciences rest upon certain presuppositions, which require uniform exposition and examination, as well as systematic co-ordination and confirmation. But, in the nature of things, these presuppositions cannot be found within the compass of the special disciplines, for the reason that the range of the combined sciences extends far beyond any one of them. Space and time, being and becoming, cause and effect are among these presuppositions, as well as the general methods of research and exposition which are followed by the special sciences. Thus, for instance, we are accustomed to distinguish between an inductive method, which from particular facts derives uniform relations and laws, and a deductive method advancing from general conceptions and propositions to special instances. Such presuppositions we call the fundamental principles of all science, and a philosophy which is devoted to them we call a science of principles. Epistemology and logic are the two branches of this part of philosophy, which together have been named the science of knowledge. 
But the goal of every science, which is the complete knowledge of all the facts within its sphere, lies always in infinity, and demands an unending progress. The problems increase instead of decreasing, and every vantage-point reveals new outlooks into regions before unknown. Over against this infinite task of the special sciences stands the finite circumscribed life of the inquiring man. $\mathrm{He}$ cannot wait until science has attained its goal and can give him information on all these interesting questions. It is true that every man, unless the desire has in some way been artificially suppressed, feels the need of some unifying theory of the world, some insight into the meaning, the purpose, and the worth of life and of the great mechanism of which he feels himself to be one single infinitesimal wheel: to the end that he may order his conduct in a fitting manner, that in his hopes and his aspirations he may be pursuing no deceptive fancies, and that in his willing and acting he may rest assured of a fixed order of values. But if he finds the answer which positive religion offers to all these questions concerning his fate and his destiny unsatisfying or insufficient, then 


\section{PHILOSOPHY OF THE PRESENT}

metaphysics reveals itself as a way to the desired goal. Thus the metaphysics of the present day joins on to the special sciences where they end, or where they fail the questioning human mind. Such an inductive metaphysics-that is, a metaphysics which connects itself methodologically with the positive knowledge of our time-is the new form in which modern philosophy establishes a theory of life and the world.

If we think of the special sciences as diverging rays of light, which stream out in their several directions into the infinite realm of objects of knowledge, then we may regard logic and epistemology as the disciplines which have to do with the starting-point and focus of all these rays; while, on the other hand, metaphysics is an attempt, changing naturally with the progress of time, to cause this light-force to penetrate to those distant regions hitherto inaccessible to the natural sciences, and thereby to illumine those great fields of thought which are of such supreme interest to mankind in their relation to knowledge and to conduct.

Finally, the philosophy of the present aims to take an immediate and active part in the 
work of the special sciences themselves, or, to continue our illustration, it seeks to send forth new light-rays or cause the old ones to penetrate into further regions. Philosophy was indeed the original central fire which kindled the separate, relatively independent, lights ; and it is still in like manner creative, for it opens new fields of research or gives new life to those already existing.

In this way philosophy has come into peaceful and harmonious relations with the special sciences. Not to pass them by, but to work in and through them, is its new watchword. It is true that the facts gained through the special sciences are only fragments; but it is equally true that they are at the same time the necessary building stones for the construction of a comprehensive and satisfactory theory of life and the world, if such a structure is to offer a safe dwelling, secure in times of need and danger. So philosophy has given up the speculative method and gone to school to the special sciences; while the latter, for their part, seem now to be ready and eager to recognise in philosophy a necessary and helpful supplement to their activities. Thus it has come about that 


\section{PHILOSOPHY OF THE PRESENT}

the sciences are animated by the principle of the equal rights of all; and it is undoubtedly true that such a principle will be able to satisfy their inherent striving after knowledge far better than the old hierarchy.

\section{GENERAL CHARACTERISTICS OF THE FOUR SCHOOLS}

Although the whole philosophical movement of the present is dominated by the need of a working partnership with the several sciences, nevertheless this relationship shapes itself in a special manner in each of the four different schools. In the first place, Positivism stands, in this respect, in opposition to the other three schools. It renounces absolutely any system of metaphysics supplementing the special sciences, and cultivates philosophy only from the standpoint of its other two divisions-that is, logic and epistemology. On the contrary, the other three schools hold it as an especially important part of their work to arrive at some comprehensive theory of life and the world. Again, Idealism may be contrasted with the other three schools. It does not regard reality and the 
science of reality as the final end of wisdom, but seeks and finds an ideal meaning in all knowledge. As opposed to this view, Positivism, Materialism, and Naturalism unite in the opinion that such an ideal interpretation, or any philosophy of life and the world connecting itself with our religious needs, is neither possible nor necessary. All our theories of the universe, all our practical work and aims should not, as they think, depart from the simple foundation of experience and empirical science, but should be determined strictly and exclusively by them.

These three schools, again, are closely allied in another way. Materialism, Naturalism, and Positivism are accustomed to make their appearance regularly whenever a speculative period in philosophy ends and a new one has not yet dawned. For instance, at the close of the first speculative period of Greek philosophy, we find the Materialism of Democritus, the Positivism of the Sophists, and the Naturalism of the Cynics united in opposing the rational cosmological tendencies of the first philosophers and in bringing them to a speedy end. When, however, in Plato and Aristotle, a new compre- 


\section{PHILOSOPHY OF THE PRESENT}

hensive theory of life and the world appeared, then again the Materialism and Naturalism of the Stoics and Epicureans and the Positivism of the Skeptics marked the decline of the brilliant period of Greek philosophy. Quite analogous tendencies are found in the eighteenth century, when the age of the great systems had outlived itself. We are met in England by the Positivism of Hume, in France by the Materialism of Lamettrie and the Systeme de la nature, and by the Naturalism of Rousseau. Thus, generally, the high tide of a philosophical movement, which flows beyond experience and the sciences of reality, is followed by an ebb, in which these sciences set a limit to the waves of philosophical thought. At such times, positive scientific knowledge serves as a norm by which we must govern our thinking and willing. All assertions which pass beyond these bounds are forbidden, or are represented as superfluous or untenable, and conduct is made dependent upon real knowledge-that is, upon knowledge empirically determined, and all that we need to know is what is of immediate worth for our conduct.

The Materialism, Naturalism, and Positivism of to-day all strive to be pure philosophy of 
reality. They are the outcome of that distinction between science and speculation, between certainty and personal conviction, which has come about from the powerful uprising of the special sciences. They are radically opposed to any system of metaphysics which attempts to supplement or enlarge the sciences or to discover the nature of things-in-themselves. Their object is merely to fix and to generalise what the natural sciences have achieved, to determine its range, and make it as fruitful as possible. But they define reality differently among themselves. By reality, Materialism and Naturalism understand natural reality, the sensuous, that which may be apprehended by the senses. According to Materialism, everything which is an object of knowledge must be conceived and interpreted as it is apprehended by the natural sciences. Man himself, according to Naturalism, is and remains just a part of nature, an object of sensuous knowledge; even the highest and most ideal thoughts and aspirations of which he is capable are only signs of his natural constitution, only forms of his mortal earthly destiny. Materialism and Naturalism stand to each other in the relation of a theory and its 


\section{PHILOSOPHY OF THE PRESENT}

practical application. The former rests entirely upon natural science, and allows natural science to prescribe all that shall be thought or said with reference to either the material or the mental world. The latter likewise accepts this view, but regards it more particularly as a norm determining all practical endeavour, especially the moral living and striving of mankind. Naturalism thus gives us directions how to order our being and development, if we would conform to the teachings of natural science.

Positivism, on the contrary, refrains from this one-sided recognition and superlative regard for natural science and for outward experience and reality. All experience and all the special sciences, the totality of reality and of knowledge, are its foundations. But whatever goes beyond this, whatever leaves the safe path of inductive research to the end of adding provisional assumptions and opinions to what is actually known, is, according to the harsh and rigorous teaching of Positivism, simply poetry. Thus Positivism labours to maintain a kind of status integer, to establish, as it were, a base of information, from which the way to new philosophical movements may be paved. 
It is the quiet before the storm and struggle of opinions, the critical revision of what has already been gained, the purposeful and necessary preparation for new speculative attempts appropriate to the age. Philosophy becomes in Positivism a kind of servant to the special sciences, losing almost wholly its independent worth. Thus we see, under the rule of the Positive school, a complete reversal of the former relation between philosophy and the special sciences. The latter were at one time dependent upon philosophy, whose high destiny they unhesitatingly recognised; now, according to Positivism, it becomes the only task of philosophy to support and further the researches of the sciences. 'The reserve, which this school preaches, is of course only for those easily satisfied people who make no claim to a view of life and the world scientifically expressed, or for those who, rendered shrewd by experience and instructed by the constant fluctuations and uncertainty of speculative knowledge, prefer to renounce it altogether than to follow its deceptive allurements. While Materialism and Naturalism proclaim the glory of our achievements when we give all honour to natural 


\section{PHILOSOPHY OF THE PRESENT}

reality, Positivism points out that all speculation is vain, an idle play of words and images, harmless at the best, but in any case unbecoming to the disciples of science.

In opposition to these three schools, Idealism proposes to apply new methods to the old efforts of speculative philosophy. It proposes to call to its aid the special sciences themselves, and through these to attain to a comprehensive and reliable idealistic view of life and the world. It differs from the former idealistic schools not so much in tendency as in method. It rises, to be sure, beyond the knowledge of reality; it seeks to penetrate into the realm of things-in-themselves; but in this overstepping of the bounds fixed by experience, it still observes the critical precaution and circumspection of Positivism, and preserves that regard for the natural sciences which characterises Materialism and Naturalism. It avoids the one-sidedness of these schools, limiting themselves as they do to outward experience and the knowledge of nature, and turns toward the totality of empirical interpretation and research. But it does not consider it necessary to stop where these have paused for the time, but regards it as the per- 


\section{INTRODUCTION}

fect right of philosophy to complete their work, although it may be only provisionally and within definite bounds. Just as in the plastic arts and in the poetry of our day, naturalistic and idealistic tendencies alternate as we begin again to trust to the guidance of the imagination, so also in philosophy, the new Idealism, which in this respect has learned something from Positivism, finds itself again called to take up the old problems of philosophy. Thus there has dawned a new era of ideas and systems. 


\section{II}

\section{POSITIVISM}

The Absolute Philosophy of a Schelling and Hegel succumbed, as we have seen, to the assaults of the special sciences. Their dazzling success was followed by a downfall most complete. To make a virtue of this necessity seemed to Materialism and Positivism to be just their mission-that is, to make philosophy primarily dependent upon the special sciences; the former by cultivating certain of the sciences, and, without more ado, turning their results to account to form a theory of the world; the latter by subordinating philosophy outright to the special sciences. It was from Positivism, however, that there came the most effective opposition to Hegel. This was because it did not dispute in particular any Hegelian conclusion, nor attempt to replace the whole system by another, nor even to transfer the struggle to a practical field, but simply because it cast 
effective doubt upon the methods and presuppositions of the whole Absolute Philosophy. According to Positivism, there are in philosophy no other methods of research and exposition than the methods practised and approved by the special sciences; and the limits of knowledge which exist for these disciplines are also the limits of philosophy. In these two propositions we have the whole creed of Positivism. But the limits of the special sciences, in so far as they are not merely of a formal nature, are determined by experience, and by all that is necessary to make experience intelligible and clear. Therefore, according to Positivism, philosophy, in so far as it wishes to be a science, must be limited by experience-that is, it must be an empirical science like the others, or else it must be a theory of empirical science.

Positivism originated in France and England. The noted mathematician and philosopher, d'Alembert (1717-1783), as well as the statesman and economist, Turgot (1727-1781), may be regarded as the founders of this school. In the mathematical sciences, ever since Newton's proud declaration, "Hypotheses non fingo," it had been thought necessary to do away with all 


\section{PHILOSOPHY OF THE PRESENT}

metaphysical obscurities in order to be able to give an exact description of natural phenomena. Only the perceptual matter-of-fact is accessible to us; the forces working in it remain concealed. According to d'Alembert, the universe resembles an unexplored ocean, on whose surface we discern separate islands without connection with the mainland. All speculation concerning metaphysical realities are entangled in difficulties and contradictions. Philosophy must be simply a science of facts. It must give unity and connection to all isolated knowledge, because facts everywhere form a connected unity. In the development which the exact sciences have undergone, Turgot discovers a universal law of three stages of knowledge. The first stage in the explanation of natural phenomena is religion, where the gods, conceived as mighty men, bring about the changes which we see in nature. Then follows the metaphysical stage, which speaks of essences and faculties and finds nature grounded in abstract ideas. The last stage is that of mathematical science, which simply describes phenomena and unfolds their laws. This is the Positive method, the method of science. 
Nominally Positivism goes back to the nineteenth century, to Auguste Comte (1798-1857), whose principal work, Cours de philosophie positive, ${ }^{1}$ appeared in six volumes between the years 1830 and 1842. In this celebrated source of Positivism, Comte distinguishes more carefully than Turgot the three stages in the development of the human mind-the Theological, the Metaphysical, and the Positive (the law of the three stages). The mythological explanation by means of divine powers, together with the hypothesis of universal forces, yield gradually and of necessity to a Positive conception and treatment of all the problems of our knowledge. In this stage we perceive the impossibility of arriving at absolute knowledge ; we give up, therefore, the attempt to discover the origin and destiny of the universe and to discern the inner causes of phenomena. Instead, we hope by means of observation and reason to find out the laws of things - that is, to discover the relations which exist between them in their temporal and qualitative reference. The explanation of facts consists here only in the

1 The Positive Philosophy of Auguste Comte, translated by Harriet Martineau. London, 1896 : G. Bell and Sonnenschein. (Tr.) 


\section{PHILOSOPHY OF THE PRESENT}

connection of separate phenomena with certain universal laws, whose number the progress of science seeks steadily to lessen. The completion of the Positive system would be attained, if it should succeed in proving all phenomena to be particular cases of one general law, such, for instance, as the law of gravitation. This Positive method, which renounces theological and metaphysical explanations of phenomena, is the method used in the special sciences, although, to be sure, it cannot yet be completely carried out in every case. It alone makes possible an anticipation of coming events and in this way gains a mastery over nature. The purpose of science is thus the discovery of nature's laws, and their reduction to the simplest possible form. The task of a Positive philosophy is, therefore, simply to advance and enlarge these positive sciences. A real enlargement, indeed, was offered by Comte through his project of a sociology, a science of human society. Thereby, according to his view, a systematic conclusion of scientific knowledge was reached in principle. In exhibiting the general organisation of the sciences, in outlining the uniform connection and purpose 
which exists for all of them, Comte believed that he could show the serviceable activity of philosophy in the interest of the special sciences. So here we find united the two distinctive features of the Positive school of thought: on the one hand, philosophy is a theory of science; on the other hand, it is itself a science.

In England, Positivism has existed in its beginnings since the time of Francis Bacon (1561-1626). As early as Bacon's time, the attempt was made, by developing appropriate methods and by planning a complete system of the sciences, to place philosophy at the service of scientific activity. Certain distinguishing features of this school are clearly illustrated in the case of Hume (1711-1776), inasmuch as we find in him a perfect expression of the anti-metaphysical tendency of Positivism. With respect to single metaphysical ideas, such as substance and causality, Hume sought to carry out a Positive conception, which, abstracting entirely from inner forces and real relations, took for its starting-point the phenomena of the knowing mind and reduced these concepts to psychological laws. A more definite form of Positivism appeared in England in the nine- 


\section{PHILOSOPHY OF THE PRESEN'T}

teenth century. John Stuart Mill (1806-1873), the friend and admirer of Comte, became, particularly through his Logic (first edition, 1843), the English representative of the Positive school of thought. This logic is essentially a doctrine of method, and has rendered distinguished service to the theory of induction, the method of research commonly used in the empirical sciences. In the following quotation Mill sets forth with remarkable clearness the fundamental doctrines of the Positive philosophy:- "We have no knowledge of anything but phenomena; and our knowledge of phenomena is relative, not absolute. We know not the essence, nor the real mode of production of any fact, but only its relations to other facts in the way of succession or of similitude. These relations are constant; that is, always the same in the same circumstances. The constant resemblances which link phenomena together, and the constant sequences which unite them as antecedent and consequent, are termed their laws. The laws of phenomena are all we know respecting them. Their essential nature, and their ultimate causes, either efficient or final, are unknown and inscrutable to us." 
A little later Herbert Spencer (1820-1903), from the standpoint of evolution, founded a comprehensive system, dominated in all its parts by the development theory. Since, however, he admits the existence of an Absolute as a limiting idea but denies that this is knowable, and inasmuch as he limits all our knowledge to ideas and their association, his philosophy has been called Agnosticism, following Huxley, the distinguished naturalist. Spencer's conception of philosophy is fundamentally very similar to Comte's. Like the latter, he entrusts philosophy with the task of uniting the separate facts of knowledge, of presenting the general truths of the different branches of science in their relation to each other, and of deriving them, if possible, from a single comprehensive truth. Matter, motion, and force are the ultimate notions by which we must abide; but they are only symbols of an absolute unknowable reality. "The utmost possibility for us is an interpretation of the process of things as it presents itself to our limited consciousness; but how this process is related to the actual process, we are unable to conceive, much less to know." 


\section{PHILOSOPHY OF THE PRESENT}

In Germany, the philosophy of the present bears largely the character of Positivism. During the decline of philosophy in the second half of the nineteenth century there was a return to Kant, particularly to his theory of knowledge; and in connection with this there arose the so-called neo-Kantianism, whose chief representatives are Friedrich Albert Lange (18:8-1875), Hermann Cohen, Otto Liebmann, Alois Richl, Panl Satorp. and others.

That our knowledge, in so far as it deserves the name, is limited to the sphere of possible experience; that we camnot make any scientific affirmations concerning the transcendent, concerning the things-in-themselves which lie beroud the bounds of possible experience,this riew of kant's was taken up by neoKantianism and connected with another, namely, that the chief task of philosophy consists in developing a critique and theory of knowledge, and that it is concerned primarily with the presuppositions of science. To this was added later the Immanent Philosophy, resting not only upon hant but upon Hume, in which philosophy was entrusted with the task of carrying out an analysis of that which is 
given in consciousness. In this way, Wilhelm Schuppe, Max Kauffimann, Richard von SchubertSoldern, and others have taken a position opposed to metaphysics as the philosophy of the transcendent. Here belongs likewise the Empirio-criticism of Richard Avenarius (18431896), which starts from the presupposition that we find ourselves in a certain environment and make certain affirmations concerning it and its relation to us. To analyse the relations of dependence between the ego and its environment, between the affirmations and the environment as related to the ego, is the scientific task of philosophy. In another way, finally, Positivism is represented by those who, like Franz Brentano and Anton Marty, conceive of philosophy as a science of pure experience, namely, as psychology, and place it as such in opposition to the science of nature.

\section{ERNST MACH. (Bom 1838)}

In order to lend to this general survey of the meaning of Positivism in the philosophy of the present a concrete colouring, I pass now to a characterisation of the philosophical views 


\section{PHILOSOPHY OF THE PRESENT}

of two modern representatives of this school. For this purpose I choose first the physicist and philosopher, Ernst Mach, who through his able critical researches, has won for himself wide recognition in the sphere of exact science. His Positive views are expressed most fully in his very inspiring and significant work, Beiträge zur Analyse der Empfindungen ${ }^{1}$ (1886, 5th ed. 1906), the first section of which is devoted to "anti-metaphysical prolegomena." We shall attempt to give first of all a free reproduction of Mach's views, and add thereto a critique, which will deal particularly with his anti-metaphysical, that is, his specifically Positive, tendency. ${ }^{2}$

All science is, according to Mach, a portrayal of facts in thought. By facts he understands states of consciousness. Take, for instance, the proposition: The oscillations of a pendulum are isochronous; this is a mental portrayal of the fact, that is, of the perception, that the oscillations of one and the same pen-

1 Contributions to the Analysis of the Sensations. By Ernst Mach. Translated by C. M. Williams. Chicago, 1897.-(Tr.)

${ }^{2}$ Richard Hönigswald, in his helpful book entitled Zur Kritik der Machschen Philosophie, has made a critical examination of Mach's epistemological standpoint, corresponding in many respects to ours. Compare also B. Hell: Ernst Machs Philosophie (1907). 
dulum have the same duration for different elongations. Plainly we have condensed in that proposition a great many states of consciousness, namely, the so-called observations. It is not only a portrayal but a union of many similar facts, and at the same time affords the mind a sense of relief and frugality, serving the principle repeatedly set forth by Mach, of the economy of thought. As he himself has said, science is after all nothing but a business proposition: "The scientist sets himself the task of gaining the greatest possible amount of eternal, infinite truth with the least possible labour, in the shortest possible time, and with the least possible thought." In another place he says: "When thought with its limited means tries to reflect the rich life of the world of which it is just a small part and which it can never hope to exhaust, it has every reason to be sparing of its forces."

As a generalisation of observations, the proposition of the pendulum embraces, furthermore, present as well as earlier or later experiences, thus furnishing a reference a priori for all future observations of the same kind. If the proposition is once established, it does not need 


\section{PHILOSOPHY OF THE PRESENT}

to be continually proved. It can be transmitted to future generations, and in this way shared with other individuals, in order to lighten for them also the survey of facts. But the proposition contains no recognition either of a pendulum, of its oscillations, or of their duration, as realities or independent existences ; it gains its content and its significance wholly through its relation to the facts which it portrays, through its relation to experience or to the sensations from which it is abstracted. This dependence upon experience is furthermore shown in the fact that new observations are able to modify or wholly invalidate the proposition, so that it must adapt itself to these at all times.

Science, now, is built up from just such propositions. Since our experience may be analysed into purely homogeneous elements, into sensations of colours, tones, pressure, \&c., the task of philosophy consists wholly in the exposition of these elements and their mutual relations. An apple, for instance, is a thing that looks, smells, tastes, feels so and so; that is, it is an approximately constant combination of sensations of sight, smell, taste, and touch. If 
we distinguish between the apple as an object of natural science, say of botany, and the apple as an object of psychology, in the former case we take into consideration only the reciprocal dependence of the sensuous contents upon each other, let us say, the relation of the apple to the tree, to the earth, \&c.; in the latter case, on the contrary, we take into consideration its dependence upon a perceiving subject, upon his sense-organs and mental states, such as attention, emotional life, and the like. But here we should observe that the tree and earth, just as the ego and its states, are themselves again only relatively constant combinations of like elements. It is self-evident, therefore, that matter itself can be nothing else than a certain uniform connection of sensations. Science suffers no loss, according to Mach, if the stiff, sterile, unchanging, and unknown something which in the popular opinion of natural scientists passes as matter, shall be replaced by a constant law, by a relatively constant combination.

It is just such constancy of connection that is expressed by all the declarations of natural science, and to this constancy of connection 


\section{PHILOSOPHY OF THE PRESEN'T}

there corresponds that constancy of thought upon which is based the impulse to transcend individual facts. The more constant a thoughtconnection, or a law, is and remains, the greater is our confidence therein. Therefore, we endeavour to support ideas of lesser constancy, those not yet fully confirmed, by associating them with those of greater constancy, which have been established by repeated proof. Herein lies the mainspring of all scientific explanation. We shall fail to understand this if, after the manner of a naïve, fetich-like metaphysics, we connect the facts themselves in a necessary relation to each other, as if one fact proceeds from another or is caused by it. Where our concepts and judgments are sufficiently in harmony with nature to furnish a thought-inference that corresponds with observed facts, there arises the belief in an inner necessary connection between the phenomena apprehended. But here we know nothing but the necessity in the connection and agreement of our ideas, and this is a logical necessity.

In these views of Mach, we really discern two different lines of thought: first, a theory of scientific method, and second, an anti- 
metaphysical tendency. In the following critical remarks, we shall limit ourselves to the latter, and consider the former only in so far as it serves as a foundation and support for Positivism. It is, therefore, not necessary for us to emphasise the relative correctness of Mach's views. No doubt his principle of economy, his critique of naïve metaphysical assumptions, his theory of the adaptation of thoughts to observation, and other points, have within certain limits great significance. His mistake is only that these points of view, correct in themselves, are elevated to ultimate principles and are thereby over-estimated with respect to their worth.

In reference to Mach's anti-metaphysical tendency, let us say first, that it does not correctly define the relation of our thought to experience. If his view were correct, then thoughts would have neither an independent significance nor an independent validity. Without doubt, however, they have both in large measure. Very often science is for us a supplementing of experience, not merely a portrayal or a generalisation of it. When we reconstruct a lost period of history, or trace the outlines of the development of the earth's 


\section{PHILOSOPHY OF THE PRESENT}

surface; when we connect the tides with the action of the moon upon the earth, or consider the sun as a fiery, molten body; when, on the basis of historical evidence, we paint a picture of times long past, or speak of the conservation of energy in a closed system,-in all these ways we have something more than a mere portrayal of facts; we enlarge experience in thought and by its means. We even correct experience when we sharpen and refine our means of observation. According to Mach, a visual phenomenon, like sense-phenomena in general, is a fact like any other. But to apparent size, form, and duration we oppose the "real," that is, the measured and objectified size, form, and duration. When we discover mistakes of observation and eliminate them; when we distinguish the empirical rule from the theoretical law; when from a number of observations we strike an average, and declare this to be the most probable expression of the facts; and when from signs of all kinds we reason to new events or uniformities, -in all these cases we proceed on the assumption of a sovereign mastery over experience, not in the spirit of slavish dependence upon it. 
None the less important is it to emphasise, that thoughts have an independent validity and by no means find their only norm in the facts which they are supposed to represent. This independent validity reveals itself not only in the particular logical principles which place our concepts and judgments in a definite relation to each other, but also in this, that by research and description we develop a great spontaneity. Without the guidance of thought and intelligent preparation, every experiment would be meaningless. Reflection and calculation often lead to new paths in knowledge. The facts themselves do not tell us in what relation they should be placed, or how they should be exhibited. The "portrayal" theory, if it were taken seriously, would reduce knowledge to an absurd and puerile affair. The very fact that we actively approach the empirical facts, master them and complete them ; that we systematically elaborate the contents of consciousness with methodical aim-in one word, that we create knowledge-allows us to think of science as a work full of charm, worthy the sweat of nobles.

The "portrayal" theory does not at all do justice to the content of knowledge, when it 


\section{PHILOSOPHY OF THE PRESENT}

limits us to the mere facts of reality-that is, to the occasional sensations given in consciousness and their interconnections. For these are full of gaps, fragmentary and narrowly limited, without well-marked time and space connection. Even according to Mach, science does not have for its task to describe this kind of experience, that is to say, the observation which is possible within an act of consciousness. Even he does not scruple to make earlier experiences of equal importance with those of the present; and the observations of others, of equal value with our own. Indeed, he speaks of physical objects just as the realistic scientist does, to whom mass and motion are by no means expressions for sensations and their changes. So that even here it is evident that there has been an essential enlargement of the "facts" by means of thought.

In truth, there is no avoidance of this supplementary activity of thought, because the colours, tones, and pressures which we perceive, the contents of consciousness dependent upon us, cannot be the vehicles of those changes in our experience which we know to be independent of us. That the pendulum of my clock moves, 
that some of the stars twinkle, that over there in the church the organ-tones are sounding, and that the voice of a visitor strikes upon my ear ; for these things I can make neither myself nor my visual and auditory perceptions responsible. Since natural science assumes bodies to be vehicles of such phenomena, it seeks to connect those changes which are independent of us, who experience them, with a changing something independent of us, which is equipped with the necessary properties to make those changes cognisable. It would be contrary to all logic, if, instead of real bodies and forces, we should allow the sensations to be responsible for those sensuously apprehended changes which are demonstrably independent of them and of us.

Sense-experience is without doubt a basis for scientific investigation, but scientific research does not attempt to provide us with a phenomenological description of sense-impressions nor to set forth their empirical properties or their relations as given in consciousness. It seeks rather, first of all, to eliminate that which is dependent in experience upon the experiencing subject; and this includes not only feelings, ideas, thoughts, after-images, contrast- 


\section{PHILOSOPHY OF THE PRESENT}

phenomena, fusions, and the like, but also the peculiar qualities of colours, tones, pressures, \&c. ; that is, it tries to separate by analysis phenomena which are abstract and only thinkable, from concrete sense-perception. Thereupon it attempts to arrange these phenomena in an independent system or to conceive some plan of nature in which such phenomena occur. The goal of natural science is therefore not sense-experience, but the real system of nature which is built up by using the given data. The laws of nature are relations between factors in this system, not between the sensations, all of which reveal subjective influences. The magnitudes of Ohm's law, $I=\frac{E}{R}$, are not sensations, nor are sensations in any way contained in any other formulated laws of physics, chemistry, or physiology, although they may have furnished indispensable aid in establishing them. This is apparent even from the fact that the laws of nature take account neither of the individual manifoldness of sense-impressions nor of their temporary validity. Mach speaks of phenomenological laws into which the whole science of physics will sometime be resolved. Up to this 
time he has not found them, and in the nature of things it is not to be expected that he ever will find them. An economy which is engaged in such elimination of indispensable thought-matter would be the bankruptcy of science. ${ }^{1}$

Mach has indeed another ground for his anti-metaphysical tendency. This consists in our natural trust in the certainty of sensations -a trust which in itself is perfectly reasonable. Sensations are as they are; we cannot twist or trifle with them. We have them, or we do not have them; and if we have them, we have them in a definite, incontrovertible form, by virtue of which they are as they are. The white which I see here, no one can argue away. It is simply given with unanswerable certainty. But if I speak of atoms of oxygen or vibrations of ether, these are objects just conceptually apprehended, whose significance and necessity may be questioned; they are only of indirect validity, assumed merely on the ground of observations and mental operations. Therefore it seems that they cannot at all be placed on

1 Compare the similar and illuminating views of Max Planck : Die Einheit des physikalischen Weltbildes (1909), and my work, Erkenntnistheorie und Naturwissenschaft (1910). 


\section{PHILOSOPHY OF THE PRESENT}

the same plane with the incontrovertible facts of sense-perception.

But now let us inquire more carefully into the meaning of this "certainty." Examined closely, it consists simply in having sensations. For just as soon as I go beyond them and attempt to describe them, picture them, communicate them, or assert that I have them, there enters at once a new factor into the game, namely, a relation of words, or modes of thinking, to the sensations, which, as psychological experience teaches, has absolutely in no way the character of evidence, but which may be deceptive, erroneous, or doubtful, as may be proved. If this relation also is regarded as merely given, then we abolish the difference between fact and assertion, and in general lose sight of the logical character of relation, and take our stand on the merely actual, without proof, demonstration, or critique. Thus we could speak of certainty only where we renounce all verification, evaluation, or intellectual activity, and content ourselves with simply having states, processes, and facts. This kind of certainty comes in precisely the same manner to the snail, which creeps laboriously over the 
ground and moves his feelers in all directions, or to the fly, which, by reason of the warmth of the room, awakes from its winter sleep and seeks lazily and uncertainly for food. Indeed it is characteristic of the whole sense of reality of our age, an age averse to all speculation, to lay great stress on this kind of certainty and to hold it as a pattern and aim for all scientific research. Certainty of this kind is, of course, unshakable; but this is not because it stands the test in conflict, not because it holds its ground in the face of contradiction, but merely because no conflict or contradiction is here possible. True and false, right and wrong, contradiction and agreement, pertain only to thoughts, judgments, assertions-never to mere facts. A precisely similar limitation of the applicability of the category of certainty is to be recommended. For that reason the bare fact of having sensations has as little value in determining the certain and the uncertain as it has in determining the true and the false. The sensations as such are a rudis indigestaque moles, out of which everything or nothing can spring, but which are in themselves neither a final absolutely reliable ground nor a deceptive mockery of sense. 


\section{PHILOSOPHY OF THE PRESENT}

So, then, we must consider that this so-called certainty only applies to the individual who by chance has such a conscious content. Beyond this sphere it does not extend. As the basis of a universally valid science, which should be independent of the experiences of the individual, it is wholly inadequate. Only that which exists for everyone could serve as universal, but sensations are only for him who has them. Since, now, all science strives to present universally valid propositions, science cannot be based upon the certainty in question.

Finally, the question may still be raised: What, then, really forms the content or object of this certainty? To this it is answered: The sensations. But modern psychology teaches that the sensations are products of scientific analysis. Elementary contents, like simple colours or brightness, tones or noises, in fact elements in general, we do not find at all in our investigation of what is given in consciousness; nor do we obtain them at all apart from the processes of isolation and comparison. Not sensations, nor complexes of them, are immediately given to the mind which has passed through the school of experience, but contents of conscious- 
ness, of perception and memory, of feeling, imagination, and understanding, together with the processes, actions, and functions which adjust themselves to these contents or determine them. Both are found in manifold intricacies and complications, from which the elementary contents and functions are separated only with great difficulty. As a rule, however, we find definite attitudes, theoretical or practical, æsthetic or religious, \&c., in which certain points of view predominate and certain ends are to be fulfilled. Our mental organisation is not planned primarily for the pursuit of science nor to conform to the severe demands of scientific knowledge, but to satisfy the needs of life. No single component part of experience is in itself adapted to be forthwith incorporated into science, nor to become a vehicle of unconditional certainty. Again, nothing would be gained by designating sense-perception, instead of sensation, as the content of this certainty. For senseperception, according to the teaching of scientific psychology, is a kind of resultant, in which the manifold experiences of a longer or shorter development and history of the individual unite with the momentary excitation of our sense- 


\section{PHILOSOPHY OF THE PRESENT}

organs to produce a definite result. How can we separate the primal material which is prior to all empirical connections from the additions which the individual on account of his own peculiar development has unintentionally made? Does this perceptual product, like the originally given material, belong to the "facts" which are invoked to carry certainty in themselves? If we exclude it, then there must be some kind of preparation of the sense-material before we can speak of immediately given facts, and in that case we deny the immediacy of what is merely given. If we do not exclude it, then we embrace in what is given a fullness of relations which demands, and possibly does not admit of, logical scrutiny. In either case, in the determination of the bases for such an affirmed certainty, investigation and knowledge are already presupposed.

Recently Mach has published a more comprehensive work: Erkenntnis und Irrthum (1905, 2nd ed. 1906). In this new work his earlier point of view, of which we have here been speaking, is modified by many important changes and supplemented by certain additions. From his new standpoint the goal of scientific thought is seen to be the supplementing of a partially 
observed fact, and this is held to be attainable not only through adaptation of thoughts to facts, but also through their adaptation to each other. Furthermore, a new criterion is proposed for distinguishing the physical and psychical. The physical is the totality of that which is present in space for all. The psychical, in the sense of the narrower ego, excluding one's own body and the contents of sensation, is what is immediately given to only one, but is accessible to all others only by analogy. So, then, the elements from which the contents of experience arise-the pressures, tones, colours, \&c.-are classed as at present not capable of further analysis, and are reduced to abstractions provisionally established, awaiting the progress of science. Finally, in his new book there is developed a much more penetrating psychology and biology of knowledge, since sensation is regarded as the foundation of all mental life, and the attempt is made to deduce truth and error, concepts and judgments, from the sensations and their memory traces, as well as from the laws of reproduction and association; and at the same time the biological purposiveness of all knowledge and knowing functions is emphasised. 


\section{PHILOSOPHY OF THE PRESENT}

Owing to these changes the criticism which we have directed against the position taken in the Analysis of the Sensations (the new edition of which maintains essentially the old standpoint) is in part no longer applicable. That is to say, if now he expressly attributes to scientific thinking the function of supplementing observation, although, to be sure, he does not clearly formulate thereby either a necessary or sufficient condition of scientific work, still he at least recognises that his former theory of "portrayal" is insufficient. And his emphasis of the special significance which belongs to the adaptation of thoughts to each other shows that Mach does not deny the independent character of thought which we have maintained in opposition to him. More than this, when he looks forward to a further analysis of the elements, and holds concerning sensations as well as concerning concepts that they come about through a process of abstraction, then that immediate and unconditional certainty of facts as simply given, which they formerly seemed to enjoy and deserve at Mach's hands, is denied to them.

On the other hand, the distinction which he 
now prefers between the physical and psychical is less clear-cut and positive than the previous one, ${ }^{1}$ and does not at all yield the same distinction between the two concepts. For that which is immediately given only to one subject, while to all others it is inferable only by analogy, embraces the totality of experience, namely, all contents of consciousness, certainly not simply the narrower ego ; and what is immediately present in space for all exists only under the presupposition of a real outward world, which Mach, now as before, rejects as a metaphysical speculation.

The standpoint of his new book, so distinctly based on historical development, deserves full recognition, and lends a great charm to his views on scientific method. Here Mach dispenses rich treasures from his abundant historical knowledge. But genetic description and theories must not lay claim in matters of knowledge to give the only judgment, or the decisive one. We must guard against allowing pure construction to take the place of empirical research. He who shows how the formation of concepts, the determination of the laws of nature, the genesis of scientific opinions, have 1 Compare p. $39 \mathrm{f}$. 


\section{PHILOSOPHY OF THE PRESENT}

arisen, has thereby determined nothing with reference to their value or authority. And he who says that a correct judgment is always something which either directly or indirectly is of service to us, or that the laws of nature are limitations of expected possibilities, has emphasised, even if these assertions should prove correct, only a special and by no means an essential side of these subjects. Science has become an independent power (" absolute spirit," according to $\mathrm{Hegel}$ ), which no longer simply takes the standpoint of biological advantage or disadvantage to the individual and the species, but makes and fulfils its own peculiar demands. It is not, therefore, a happy description to designate the inner connection of knowledge-that is, truth-as an adaptation of thoughts to each other, nor to designate the appropriate representation of objects - that is, scientific accuracy -as the adaptation of thoughts to facts.

But apart from this, the axiom should hold good here that in empirical matters reliable results can be gained only by empirical methods. The way in which Mach, for example, traces back concepts to sensations and representations, or builds up the ego from simple elements, shows 
that he has entirely lost sight of this axiom. $\mathrm{He}$ has had as little success in deducing the peculiar quality of thought and the spontaneity of the subject from sensations as in reducing the objects of natural science to pressures, tones, colours, and their reciprocal relations. Critical caution in transcending actual facts of consciousness and in the assumption and determination of realities is, within certain limits, surely wholesome and necessary; but in this case it has degenerated into a radical anti-metaphysical attitude fatal to the proper interpretation of facts.

We conclude, then, that Mach's philosophy rests upon an entirely unsafe and insecure foundation, in so far as it finds its support solely in sense-data, in immediate experience, and in that which is given in consciousness. The certainty of scientific knowledge-in particular, the certainty of the uniform relations prevailing therein-can in this way neither be understood nor established. Such a limitation of science to sensations, to conscious elements, such a renunciation of realities, delivers science over to accident and caprice. Phenomenological descriptions take the place of exactly formu- 


\section{PHILOSOPHY OF THE PRESENT}

lated laws among objective events. Even psychology is not feasible as a pure science of consciousness (compare the general criticism upon Idealism below); how, then, as such should natural science be possible? Instead of following impartially the spirit of scientific knowledge, and showing its necessary factors, Positivism has preferred to construe itself as an ideal of science and to measure real science thereby. Instead of lopping off speculative excrescences and seeking sound criteria for the determination of realities, Positivism has poured the baby out with the bath, and in its simplified procedure brought upon all reality the reproach of illegitimacy. Instead of recognising experience as an indispensable point of departure, and as a control which no real scientific research could neglect, it is here represented as the only object and the real goal of investigation and description, and is thereby elevated to a throne never intended for it. In the presence of much prevalent obscurity concerning the difference between speculative additions and real scientific results; between purposive but doubtful assumptions and necessary presuppositions; between metaphysical fancies and 
scientific insight,-we can both understand and appreciate the bearings of Mach's labours. But, on the other hand, it is just as true that this critic of modern science has not succeeded either in discovering or exhibiting the real limits between the two.

\section{EUGEN DÜHRING. (Born 1833)}

The Positivism of Eugen Diihring is of a different character from that of Mach. Diihring's Natuirliche Dialektik (1865) contains important epistemological investigations on the principle of identity, the principle of sufficient reason, infinity, continuity, \&c. He has given a comprehensive exposition of his standpoint in his Kursus der Philosophie als streng wissenschaftlicher Weltanschauung und Lebensgestaltung (1875). This book was fully revised in 1895, and published under the title Wirklichkeitsphilosophie. But since in the new edition a large number of theoretical scientific discussions have been omitted, it is necessary, for a correct knowledge of Dühring's views, to go back to the earlier work. With him the conviction became more and more firmly established that 


\section{PHILOSOPHY OF THE PRESENT}

the thing which is of primary importance is to pave the way for a kind of mental guidance or mental economy, in which we must take our start from comparatively easily communicable fundamental views. This conviction greatly restricts the purely scientific part of his work. Among the other philosophical writings of Duihring, we would emphasise his Wert des Lebens, published in 1865 (6th ed. 1902).

Philosophy, according to Diihring, is the development of the highest form of our knowledge of the world and of life. It aspires, hence, to be a coherent world-theory and at the same time the groundwork for the most noble and perfect conduct of life. While the understanding rules supreme in the building up of a theoretical view of the world, in the sphere of ethics, on the contrary, feeling holds a dominant place. The method which should be followed in philosophy is a positively dogmatic and categorical one, finally also a dialectic method, which proceeds according to the universal laws of our thinking. As the organ of philosophy he brings forward the "rational imagination," a kind of constructive fancy used also in the natural sciences, particularly in 
mathematics, in carrying out operations and making combinations. This works in intimate connection with the understanding and is guided by it, while limited to the sphere of possible reality. As the philosophical impulse, Dühring designates universal passion, the feeling of the individual as opposed to the totality of his experience, by virtue of which he is aroused to a knowledge of what is empirically given and to the practical transformation of the same.

The starting-point of all philosophy is reality and the science of reality, i.e. natural science. Diihring therefore calls his system a philosophy of reality, or a natural system. As predecessors in his school of thought, he praises Schopenhauer and Feuerbach and also Comte. Concerning reality, the problem of philosophy is to comprehend it as it is, not the impossible goal of explaining it and deriving it from something which is not real. If we limit ourselves to such a schematic exposition of what is given in reality, then complete knowledge is possible and spasmodic periods of skepticism or criticism are unnecessary.

Now, in our thinking there are certain principles which are valid quite independently of 


\section{PHILOSOPHY OF THE PRESENT}

the question whether they apply to objects which are real or only represented. In this sense we can speak of a coincidence between thinking and being, and it is quite possible for us on the basis of our concepts and judgments to arrive at a definite form of the world, of nature, and of being. From this standpoint, dialectic has the problem of establishing beyond all doubt the powers of the understanding and of schooling it in its task of apprehending reality. Diihring believes also that senseperception is in general reliable and fit to gain objective knowledge. The outer world in space and time exists as we represent it to ourselves, even although allowance must be made for the qualities of sense.

The fundamental law, which, according to Dühring, is to guide our apprehension of reality along safe and viable paths, is the law of determinate number. According to this law, any number which is thought of as in any way complete, is determined; that is, it excludes the notion of infinity. To speak of a countless number that has been counted, or of an infinity of units, Dühring calls a most impossible contradiction. According to this law, the number 
of events in time which have taken place up to the present, in spite of an eternity lying behind us, must be closed and limited. Likewise, the number of heavenly bodies in space must at any moment be finite and perfectly definite, even although continuous space may extend outward boundlessly. Thus, it further follows that the world-process must have had an absolute beginning in time, and that all divisibility of a material body is finite, and that a body can be reduced to a definite number of parts.

If, now, we desire to go beyond that first event in which the cosmic process had its beginning, we arrive, according to Dühring, at a changeless being in which no longer any succession of single occurrences takes place. This primordial being, since we should be able to determine it only by the negation of the properties appropriate to the existing world, is and remains like itself. In this we must seek the roots of everything that we designate as an event, or apprehend as determinate existence. This is not to say that every form of distinction must have ceased in it. It is true that we cannot suppose that there was in this primordial being a succession of separate events, but this 


\section{PHILOSOPHY OF THE PRESENT}

is not to say that simultaneous differences in space, which require no origination, may not well be assumed. Approximations to this primordial condition are revealed to us in astronomical cosmogony and in the historical development of the earth and of living beings, in so far as we trace them back in time to ever simpler and less evolved forms and processes. All consciousness, all vital movements must indeed have had a beginning, and what lies further back in time must without these important distinctions have formed a more homogeneous condition. We may, therefore, conceive of nature as a quite definite totality of existences and processes, which, so to speak, empty backward into a primordial being, while at the same time they flow forward and expand into the unlimited.

Now the actual is always the present. What has been, what is past can no longer be conceived as reality. It follows that the primordial state is no longer existing, since we live and stand within the world-process. But it may have left traces in the sphere of reality; so that in its transformations into the actual, moving, self-developing nature, certain persistent and 
immutable factors, eluding the changing play of events, have penetrated the real. Matter and atoms, as well as those uniformities which we regard as the laws of nature, may be looked upon as a kind of dowry from the primordial state. But if the transition from this to the world-movement is something new, an absolutely first beginning, then it is possible that further acts of nature may be initiated, and still again other new beginnings. This assumption of absolutely first appearances, events, existences, which, within the causal series beginning with them, we may designate as last (relatively as first) causes, is especially characteristic of Diihring's world-scheme. 'To these new beginnings belong, not only the appearance of motion, but also the phenomena of life and of consciousness.

The ground-form of all change is the ceaseless replacing and substitution of one process by another. In this, the unity of nature is as little annulled as it is in the fundamental difference between nature and the primordial being. But we must think of it as a unity in multiplicity, or a uniform coherence, which must not be hypostatised nor regarded as a kind of 


\section{PHILOSOPHY OF THE PRESEN'T}

personal being. Among changes, only that which constantly recurs, which is constantly repeated, can be formulated as a law. But the establishing of laws does not interfere with the appearance of new phenomena. As Dühring says: "It would be a denial of productive and creative activity, if we should think of the ground and consequence of events as if nothing more than a combination of all known causes contributed to their production." Much more is the self-development of nature revealed in new processes and new existences. All we can say, therefore, is that if certain types or forms are already present in nature, then certain uniformities will be found present in them; but that these types shall themselves appear is not included in the necessity of events, nor in the repetition determined by uniformity. Thus the laws of nature do not stand in opposition to the assumption of absolute beginnings.

Our knowledge fails, therefore, wherever we have to do with the appearance of new phenomena. Here the best we can do is the concise formulation of our ignorance, as Diihring thinks. $\mathrm{He}$ attaches no importance to fantastic attempts to formulate a complete system of cosmic re- 
lations. In spite of this he busies himself with the problem of the future of the world, and finds here two possibilities: either the mechanism of nature goes on without end, or else it changes into a form of being known to us from the primordial being as a limiting concept. According to all previous analogies, as Dühring believes, the continuation of a definite worldform is improbable. For differentiation is a fundamental law of nature, and radical changes must continually follow. Since now the number of these changes, according to the law of determinate number, will sometime be exhausted, there must be either an endless exact recurrence of events (Nietzsche's theory of the eternal cycles), or else a cessation of all repetition. Apparently the conditions of nature, as Dühring thinks, are becoming gradually quieter, the changes less violent and radical, and the differences more moderate, and therefore more favourable to life.

Of Dühring's further views, only a few characteristic ones may be noticed. Between the conscious and the unconscious there exists, as he explains, complete dissimilarity. Nevertheless, the antagonism of mechanical forces 


\section{PHILOSOPHY OF THE PRESENT}

results in the production of consciousness and sensation. The elementary scheme of all reality demands also a single elementary form of subjectivity, an absolutely elementary sensation. This is the sensation of resistance, belonging to the sense of touch, which reveals most plainly its origin in the antagonism of mechanical forces. It is the ultimate element of all senseperception, and finds itself repeated everywhere, even beyond the earth. The difference between plants and animals is marked by the rise of sensation, a difference which can as little be glossed over by hazy transitions, as the transition from an ellipse to a circle can in mathematics. Animal kinds are generalisations or dormant species, in which the higher types are developed through composition of the simplest specific elements, but not through metamorphosis from the lower kinds.

Dühring's philosophy of reality, the theoretical foundation of which we have explained, is distinguished from the Positivism of the immanent philosophy or from Mach's, particularly in this, that it does not regard conscious reality as the only basis and object of our knowledge. On the contrary, it includes in the "given" 
reality an outer world with matter and forces, after the manner of natural science, although, to be sure, it does not give a very exact account of such a world. His philosophy recognises, it is true, " no ghostly soul," but takes the principles of motion and of life seriously as forces. Duihring, therefore, declares that we are on the wrong track when we renounce the concepts of cause and force, and speak only of phenomena; he calls it "a morbid and skeptical aberration." "As soon as one thinks keenly and rightly, he gets beyond effects and phenomena." Between our sense-perception and our thinking on the one hand, and physical reality on the other, there is a parallelism, by reason of which we are able to know the world as it really is. Dühring's philosophy, however, approaches Positivism in its sharp emphasis upon what is not known, upon the limits which are set to our knowledge. All metaphysical assumptions are condemned as phantasms, and Materialism and Spiritualism in like manner are rejected. To be sure, there cannot be wanting a final and comprehensive system of our highest and most universal cognitions, in order that we may win a final vantage-ground for a theory of the world 


\section{PHILOSOPHY OF THE PRESENT}

and for the conduct of life. "In a distinctive system, there must be no point that does not have a clear and firm value of unquestionable significance." But it is only the special sciences on whose account such a work of thought is to be executed. An independent philosophical knowledge, so far as it is not concerned with the reality of nature and its scientific treatment, is not demanded by Dühring, the Positivist, nor does he take it into consideration.

An original colouring is given to his Positive tendency in this, that knowledge is brought into closer relation with life and conduct, and thereby placed in the service of practical problems. The interest which we, as living, striving, perfectible individuals, take in the course of the world, has become with Dühring, especially in the final presentation of his system, a ruling point of view. With this practical tendency, which, by the way, is expressly treated in a special periodical called Personalist und Emanzipator, there is connected the idea that all present ruling conditions in the realm of mind are demoralised through and through, and are in need of reform from the ground up. Religion is rejected as "a cradle of delusions," and the 
whole of modern philosophy is rebuked as "philosophical twaddle bound up with deceit." Emancipation from this philosophy is a necessary precondition of all better conduct of life and mind. The same is true of art in its traditional form. Only an art which expresses "natural feelings" and ideas which conform to reality has any claim to lasting recognition or any prospect of it. Finally, natural science has to-day become "for the most part an idol." "As it is commonly served up, science is one of the most contemptible idols. It is a hodgepodge of superstition, learned ignorance, vanity, emptiness, skeptical instability, apathy, and good-for-nothingness of every kind." "The universal verdict concerning the beclouded, badly learned, and badly taught science of the nineteenth century," he said, "will in the end be like that passed upon the Scholasticism of the Middle Ages. As it was with logic then, so it is with mathematics now." The remedy which Dühring seeks will not be found in theology or philosophy. "It is not worth while to stretch out a hand to save them. They will gradually suffocate from contempt and neglect." "On the contrary, physics has still some solid ground 


\section{PHILOSOPHY OF THE PRESENT}

under it, and we may cleanse the stables here with some hope. The philosophical twaddle can be driven out of mathematics and physics ; there is still some appeal here to sense and reason." These intemperate judgments, in which Diihring indulges in the second edition of his autobiographical book, Sache, Leben, und Feinde (1903), are but an eloquent testimony to the embitterment of the solitary thinker and to his incapacity for objective estimates of relations.

The researches, able and useful in themselves, concerning the relation of logical thought to given reality, lead with Dühring in general to the result that the antinomies, contradictions, and difficulties in which reason finds itself when it seeks to establish any fixed principles beyond the bounds of possible experience, can be settled in a simple manner. For this purpose the law of fixed, determinate number serves in the first rank, as well as the admission of new beginnings, first causes, and the like. It is nevertheless plainly manifest that this law is only valid when it deals, in the first place, with something which can be counted-that is, with objects which are discrete, mutually bounded, and interdistinguishable; and, in the second place, 
when the totality of these objects is thought of as something in some way complete-that is, as something, for the present at least, closed and finished. Whether these presuppositions prove true for the divisibility of matter, for the course of events in time, \&c., concerning this the law says nothing at all. For this reason it loses, of course, the significance of a world-constituting principle, and can assure us no insight into the inner connection of things. Its value consists in its reference to the fact that a distinction must be drawn between the statement, designation, determination of a number, and the number itself as a formal property of real things and events. "Countless," "innumerable," "infinitely many," \&c., are, according to Dïhring, not predicates of reality, but only expressions for our conceptions, for our counting and reckoning. Whether every real event is composed of a number of phases, we cannot in this way determine.

In the same way, also, the demand for completeness of the causal series, and the hypothesis of absolutely new beginnings within the evolution of world-phenomena, lose their binding force. It might indeed be, as Kant teaches, that 


\section{PHILOSOPHY OF THE PRESENT}

the distinction of cause and effect rests upon a primary concept of the understanding, and that it would have no meaning to suppose that processes are themselves divided into causal members with fixed limits. It happens thus that the law of determinate number, so zealously pushed to the front in Diihring's world-scheme, is at bottom a tautology, in so far as under the presupposition of numerableness, he declares a determinate number as a self-evident consequence. If all continuity of events is thus denied, the law is not a law of reality. We shall, therefore, not feel bound to set sudden limits to the unlimitedness demanded by the causal principle, nor to the demands for causes lying even farther back. Indeed, the assumption of absolutely new beginnings within the world of events seems to us purely dogmatic, dispensing quite too readily with any scientific proof. Since there was a time when the conditions upon the earth were such that life could not be sustained, it is evident that the question concerning the origin of life, or of the origin of the organic from the inorganic, will never be without meaning and purpose. And when idealistic metaphysics comes to the conclusion 
with reference to the origin of consciousness or of mental processes, that all existence in its very nature bears this character, it seeks in this way to give a satisfactory answer to the question concerning the empirical difference between the conscious and the unconscious, a difference which seems to be wholly unrecognised by Dïhring.

In spite of these reservations, which in fairness we must praise in Dühring, he launches out, when it fits his purpose, into the boldest constructions. When, for example, he makes the scale of the senses a reflection of the objective stages of the evolution of nature, and thereby immeasurably exaggerates and schematises the thought of a parallelism between knowledge and its outer objects, this is certainly not a philosophy which seeks simply to interpret reality as it is. The same is true of his peculiar theory that the sensation of resistance is the pure elementary form of all subjectivity, and reveals the origin of consciousness from the antagonism of mechanical forces. In this category we must place also his arguments concerning the problematical primordial state, from which nature has arisen, and his 


\section{PHILOSOPHY OF THE PRESENT}

views upon the future of cosmic evolution. However much these views have the appearance of cautious and strictly scientific research, it is not to be questioned that they rest upon very doubtful presuppositions, and that with equal or better right other hypotheses could be substituted for them. So we see that his premature fettering of thought, his attempt to confine it within determined limits which are later disregarded, revenges itself in the case of Dühring.

If in the Absolute Philosophy the centre of gravity was found in the activity of pure thought, Positivism shifts the centre of gravity to the reality given in our consciousness. In this limitation and depreciation of thought, Positivism betrays its deepest impulse, its most characteristic position. Herein it reacts against the boundless confidence in the efficiency of reason characteristic of the Absolute Philosophy, and against the similar, though weaker tendencies in Herbart, Schopenhauer, and other post-Kantian philosophers. Positivism, therefore, is a standpoint of revision-an inventory, as it were, which precedes new enterprises and loads them in advance with a heavy ballast of critical foresight and caution. In order to do 


\section{POSI'TIVISM}

this work thoroughly, it opposes not only the all-too-many answers, but also the all-too-many questions. It is not content with representing the present metaphysical solutions of the worldriddle as untenable, unsafe and superfluous guesses, but it wishes also to suppress the very impulse toward such speculation, the "irrepressible" need of metaphysics, as Kant calls it. But in so doing, Positivism itself falls into a kind of dogmatism, since it starts with certainty instead of establishing it, and fixes in advance the goal of thought at the same time as the method. 


\section{III}

\section{MATERIALISM}

In the first half of the nineteenth century there began that brilliant advance of the natural sciences which has given to that period the name of the scientific or technical century. The progress in method and in matter which took place in all the branches of scientific knowledge was especially marked in biology, the science of vital phenomena. As early as the seventeenth century, the French philosopher, Descartes, taught that life can be explained on purely mechanical principles. After Descartes' time, with the help of the improved and refined methods brought into use by the gradually unfolding natural sciences, modern physiology set to work to confirm by careful research this mechanical conception of vital phenomena, and to explain the activity of muscles and nerves, of glands and sense-organs, according to physical and chemical laws. Mental life thus took its 
place among other vital functions; it was connected with a special organ, namely, the brain, and was therefore classed among material phenomena. Some, to be sure, recognised a fundamental difference between mind or consciousness, on the one hand, and phenomena of life in general, on the other, and claimed a mechanical explanation only for the latter. At a Congress of Natural Scientists held in Göttingen in 1854, the so-called controversy over Materialism sprung up, in which the opposing views of the physiologists clashed. Materialistic views were openly advocated, and a lively war of words followed.

At that time Rudolph Wagner delivered an address upon The Creation of Man and the Substance of the Soul, and professed the belief in an individual, immortal soul-substance, because, without this, the moral basis of the social order would be wholly destroyed. If we assume that the soul is merely a function of the brain, it follows as a practical consequence that eating and drinking must be the highest ideal of mankind. On practical rather than on theoretical or scientific grounds, therefore, Wagner held to the existence of a soul not 


\section{PHILOSOPHY OF THE PRESENT}

destructible with the body. He even declared that faith and knowledge could exist side by side, like a kind of double-entry book-keeping. His opponent, who sought with adroit skill to show the absurdity of this belief, was Karl Vogt (1817-1895). In a work entitled Köhlerglaube und Wissenschaft, Vogt makes a clever attack upon the new path to knowledge, called faith, to which we owe the assumption of an immaterial soul. According to Vogt, the limits of higher thought are one and the same with the limits of sense-experience. But observation reveals to us that the brain is the organ of the so-called mental functions, and to this knowledge we must accord the rank of incontrovertible truth.

Jacob Moleschott (1822-1893), in his work Kreislauf des Lebens, had already advocated similar views in opposition to the celebrated chemist Liebig. In later editions of this work no allusion was made to its original motive; new material was added, greater care was bestowed upon the form, and finally, when the fifth edition appeared in 1887 in two volumes, it became the principal work on Materialism in Germany in the nineteenth century. Moleschott 
sought to clear away the Kantian opposition between the phenomenon and the thing-initself by identifying knowable being with being itself. Being exists only through its attributes, and all attributes consist in relations: "Only the warm hand knows the cold ice; only the healthy eye knows the green trees. Are we to suppose, then, that green is something different from a relation of light to the eye? And if it is not something different, does not the green leaf exist in itself for the very reason that it is green to our eye? In this case, then, the partition wall is broken down between the thingfor-us and the thing-in-itself." According to this, as soon as we have succeeded in finding out all the attributes of bodies which can exert an influence upon our senses, we have at the same time grasped the essence of things. Materialism, as a doctrine of unity, is opposed to the dualistic doctrine of spiritualism; but here the distinction is not clearly made between a monistic view which regards the physical and the mental as two different sides of the same reality, and a materialistic view which traces the spiritual back to the physical. This ambiguity is apparent from the fact that Moleschott 


\section{PHILOSOPHY OF THE PRESENT}

explains, on the one hand, that the materialist professes the unity of force and matter, of mind and body, of God and the world, and, on the other hand, does not hesitate to allow all psychical processes to originate through brainactivity. It is not claimed, of course, that thought is a fluid any more than heat or sound; it is rather a form of motion, a transposition of brain material.

This materialistic doctrine was popularised by Ludwig Büchner, in his widely circulated book, Kraft und Stoff, ${ }^{1}$ the nineteenth edition of which appeared in 1898, shortly before the death of the author. As a good monist, he explains, on the one hand, that force and matter, just like mind and body, are only designation; of two different aspects of one and the same being, or primordial substance, whose real nature is unknown to us; and, on the other hand, he is found soon after inveighing against the "fools in their spiritual blindness" who seem to have forgotten that matter was existent long before mind, that mind exists only by reason of organised matter, and that not a

${ }^{1}$ Force and Matter, by Ludwig Büchner. Translated by $J$. F . Collingwood. Trübner \& Co., London, 1870.-(TR.) 
shadow of proof can be advanced to show that mind has any independent existence apart from matter. Büchner carelessly changes from one to the other of these fundamentally different conceptions quite at will. For instance, he does not wish to be called a materialist, because he regards matter, force, and mind as different aspects of one basic principle. Again, he asserts that spiritual forces as well as physical forces reside in matter, and that there is no matter without mind. In spite of these assertions, which quite exclude any separation of the psychical and the physical, he seriously discusses the question how matter first began to produce consciousness or sensation, and he comes to the conclusion, certainly remarkable for a scientist, that it is quite indifferent to us how sensations arose from matter, it being sufficient to know that it is so.

\section{ERNST HAECKEL. (Born 1834)}

In the year 1899, the year of Büchner's death, there appeared a book which is perhaps destined to put into definite form the Materialism of the present day, and to replace Büchner's work, 


\section{PHILOSOPHY OF THE PRESENT}

Kraft und Stoff: This book, Die Welträtsel; Gemeinverständliche Studien über monistische Philosophie, ${ }^{1}$ was written by Ernst Haeckel, the well-known zoologist of Jena. It has passed through many editions, and has been the subject of wide and lively discussion. This leading work of the materialistic school deserves special consideration in this connection. ${ }^{2}$

Haeckel explains that his researches cannot reasonably lay claim to give " a complete solution " of the riddle of the universe. His object is "rather to offer to a wide circle of readers a critical elucidation of the problem, and to seek to determine how nearly we have at present

1 The Riddle of the Universe, by Ernst Haeckel. Trans. by Joseph McCabe. Harper Brothers, N.Y. and London, 1902.-(TR.)

2 As a sequel tolthis work, the author published, in the year 1904, Die Lebenswunder [Eng. The Wonders of Life, by Ernst Haeckel. Trans. by Joseph McCabe. Harper Brothers, N.Y. and London, 1905], in which the field of organic science, the science of life, receives special treatment. Since the philosophical standpoint taken in this book does not differ materially from that of the Welträtsel, we have not thought it necessary to consider it more at length. $J$. Engert has given, from the catholic-theological side, a detailed exposition and evaluation of this philosophy in his book, Der naturalistische Monismus Haeckels auf seine wissenschaftliche Haltbarkeit geprüft (1905). From the philosophical standpoint the most thorough criticism of Haeckel is that of Erich Adickes in his excellent book, Kant contra Haeckel (1901, 2nd ed. 1906). 
approached its solution." The explanation which he offers concerning the being, origin, and development of the world, of life, and of mind, must " of course be subjective and only partially correct." The only claim which he makes for the theory is that his "monistic philosophy is honest from beginning to end." The book, furthermore, should be regarded as " a kind of sketch-book in which studies of very unequal value are gathered into a whole." It was indeed his desire to construct a complete system of monistic philosophy, but this plan could not be carried out. He declared, too, that he was wholly a child of the nineteenth century, and with its close his life's work would end.

All world-riddles, according to Haeckel, can be traced back to a single universal riddle, namely, the problem of substance. He grants that the real nature of substance, which the realistic scientist regards as the universe, the idealistic philosopher as substance, the devout believer as God, becomes ever more problematical the more intimately we become acquainted with its countless manifestations and their development. What lies behind these 


\section{PHILOSOPHY OF THE PRESENT}

manifestations, as "thing-in-itself," we are not able even now to say. But concerning this final world-riddle, which Haeckel himself so fully recognises, he comforts himself by saying : "How does this mystical thing-in-itself concern us after all, since we possess no means of exploring it, since we do not even know clearly whether it exists? Let us leave to the metaphysicians this fruitless brooding over an ideal phantom, and as true physicists rejoice instead in the wonderful and genuine progress which our monistic natural philosophy has actually made."

In understanding the world, two methods are at our command, says Haeckel, sense-experience and rational thought. Although, to be sure, he sometimes refers the latter back to the former as its source, nevertheless he recognises the two methods as of equal right and mutually complementary, based as they are upon two different functions of the brain. Sense-perception depends upon the activity of the sense-organs, and the corresponding sensory centres in the brain; while thought depends upon the thought-centres lying between these, that is, the so-called association-centres of the cortex. 
According to Haeckel, all the differences in the philosophical systems can be traced back to the opposition between Dualism and Monism. Dualism " divides the universe into two entirely distinct substances, the material world and an immaterial God, who is its creator, sustainer, and ruler. Monism, on the contrary, recognises only a single substance in the universe, which is at the same time God and nature ; body and mind or (matter and energy) are inseparable." This pure Monism is not to be identified either with theoretical Materialism, which denies the existence of spirit and resolves the world into a heap of dead atoms, or with theoretical Spiritualism, which rejects the notion of matter and considers the world to be a specially arranged group of energies or immaterial natural forces. On the contrary, Haeckel holds, with Goethe, that matter cannot exist and be operative without spirit, nor spirit without matter. $\mathrm{He}$ also holds firmly to the unequivocal Monism of Spinoza, according to which matter as infinitely extended substance, and mind (or energy) as perceiving or thinking substance, are the two fundamental attributes of the allembracing divine world-being, the universal 


\section{PHILOSOPHY OF THE PRESENT}

substance. ${ }^{1}$ God and the world are, then, one and the same, and atheism, as a protest against the assumption of a personal God, is included in the monism and pantheism of modern science. Indeed, in the end, the conclusion would seem to follow that the opposition between theism and pantheism, vitalism and mechanism almost melts away. It is in harmony with this assimilation of all possible differences, that Haeckel himself should sometimes speak of his doctrine as materialistic, and in the presentation of his views, true to the traditions of materialistic literature, should be unable to keep separate the monistic and materialistic conception.

The fundamental idea of Haeckel's philosophy

1 In his Lebenswundern, Haeckel's desire to present a striking parallelism between "monistic" and "dualistic" views has led him, in rather bad taste, to oppose a monistic trinity of substance to the trinity of divine persons in Christian dogma. According to this view, substance has three inseparable attributes known to man: matter = substance, energy = force, psychom=sensation. Although the false identification of energy and mind is here avoided, still the difficulty is increased of co-ordinating to each mode of one attribute, corresponding modes of the other. That all matter is bound up with energy will perhaps be granted, but that it is furthermore always connected with sensation, something essentially different, is, to say the least, a speculative assertion transcending the limits of experience. 
is the idea of substance, in which matter and energy are conceived of as inseparably bound together; and the fundamental law which it advances is the law of substance, which includes the older chemical law of the conservation of matter, and the newer physical law of the conservation of energy. After all, both necessarily follow from the law of causality. Without further proofs, the terms energy and spirit, or energy and mind, are constantly used interchangeably, and so Haeckel arrives at a Monism which, after the manner of Büchner, substitutes for the connection of matter and energy, or matter and force, the essentially different connection of matter and spirit, or matter and mind. This fundamental confusion must be kept in mind in order to understand the psychophysical structure of the world in Haeckel's plan.

In the realm of the inorganic we find, as distinct forms of matter, the ponderable mass and the (at least practically) imponderable ether. These are not dead, but are endowed with sensation and will (of the lowest degree to be sure), or, as we might say, with feeling and effort. For instance, the atoms 


\section{PHILOSOPHY OF THE PRESENT}

experience, though perhaps unconsciously, pleasure in condensation, and pain in expansion, and they strive for the former and struggle against the latter. Even in the simplest chemical process there is shown unconscious affinity, which is later manifested in the relations of the sexes.

The soul-life of the lower organisms reveals a similar unconscious character. Every living cell possesses psychic attributes, and the soullife of multicellular animals and plants is nothing more than the resultant of the psychic functions of the combined individual cells. But, while in the lower stages of the organic world all the cells of the body possess psychic functions, in the higher groups only the soulcells, a chosen part, possess them. In these soul-cells, the unconscious ideas have their seat. These cells are also called sensation-cells and will-cells, and are entrusted with the formation of thought, especially of consciousness.

Thus Haeckel distinguishes between the unconscious and the conscious soul-life. The former, which even in the case of man has a much larger field, is co-extensive with all 
matter; the latter is found only in man and in those higher animals which have a central nervous system and sense-organs. Consciousness is an inner perception, and may be compared to a mirroring. The new-born child lacks it wholly. It is only when he says " $I$ " for the first time that his consciousness begins to germinate. 'These two realms of the psychic life, the conscious and the unconscious, are, however, after all closely related and no clearly defined boundaries can be drawn between them.

The soul is, therefore, a natural phenomenon, and psychology becomes a branch of physiology. "The prevailing conception of psychic activity ... considers soul and body as two different entities. These two entities can exist independently of each other and are not necessarily united. . . The soul . . . is an immortal, immaterial being, a spiritual agent, whose mysterious activity is entirely unknown to us." Haeckel declares this hypothetical independent spirit-world to be a product of poetic fancy. In opposition to this, the naturalistic conception of psychic activity sees in it "a sum of vital phenomena which, like all other vital activities, are dependent upon a definite material sub- 


\section{PHILOSOPHY OF THE PRESENT}

stratum." The substratum of this psychic life is called "psychoplasm," because it is shown by chemical analysis to belong to the protoplasmic bodies. The psyche is thus used as a collective name for the totality of psychic functions of the psychoplasm, or as a collective name for a group of brain-functions. Not only are the processes of psychic life in the lower animals determined by the physiological action in the plasma of the appropriate cells, as well as by physical and chemical changes therein, but this is equally true of all higher psychic activity in the higher animals and in man.

It is, therefore, indispensable to a scientific psychology, in addition to introspection, to undertake the anatomical study of the psychic organs and the physiological analysis of their functions. Unfortunately most so-called psychologists either have no knowledge of this kind, or at best their knowledge is very imperfect. This is the reason that "most of the psychological literature of to-day is so much waste paper." In the current text-books on modern psychology, according to Haeckel, instead of a painstaking study of anatomy and physiology, the fancy runs riot concerning the immaterial 
essence of the soul, which no one knows anything about, and to this immortal phantom all possible wonders are ascribed. In these words Haeckel simply betrays the fact that he is not acquainted with modern psychological literature.

In modern psychology, it has been long customary to define the relations between psychical and physical processes according to the principle of psychophysical parallelism. That is to say, it is customary to affirm a coordination between the former and the latter without more exactly determining the manner of this relation, which in the present state of knowledge could only be hypothetical and problematical. This cautious reserve is shown in the fact that psychologists avoid speaking of a causal connection or reciprocal action between physical and mental phenomena. Haeckel, on the contrary, seems to think that this principle establishes a complete dualism of body and mind, and reproaches $W u n d t$ because, in accepting this principle, he refuses to recognise a natural causal connection between psychical and physical processes.

We cannot, within the limits here assigned, enter into a more exact critical examination of 


\section{PHILOSOPHY OF THE PRESENT}

Haeckel's Monism or Materialism. At the close of this section we shall offer a general criticism of Materialism; so that it is scarcely worth while here to subject Haeckel's theories to a real critique, especially owing to the lack of clearness in his arguments. It will be sufficient to point out a few of the difficulties which a merely superficial examination of his work reveals, and we shall not try to decide whether they are referable to a lack of precision in the mode of expression or to unobserved contradictions. One of these difficulties we have already pointed out, in presenting Haeckel's views. It consists in the fact that he uses the concept "energy" quite interchangeably with that of "mind" or "spirit." It is owing to this that mental life, on the one hand, is bound up with every kind of matter, and, on the other hand, appears as a function of a particular form of matter, namely, the psychoplasm. This explains too why it is that " a natural causal connection" is demanded for the relation between psychic and physical processes; while in the relation between matter and energy, as the two fundamental attributes of one and the same substance, there is no mention of causality, as Spinoza, so highly 
revered by Haeckel, plainly taught. A further difficulty of a fundamental nature appears when we try to make clear to ourselves Haeckel's idea of the relation between unconscious and conscious psychic life. Although no sharply defined boundaries between the two are admitted, yet, in spite of this, the appearance of consciousness is connected with a definite organ, the central nervous system. It is evidently, then, of conscious processes that he speaks when the soul is defined as merely a collective term for a group of brain functions. And when consciousness is identified with inner perception, indeed with self-consciousness, there is plainly lacking in Haeckel either the understanding or else the knowledge of the fact that sensations, ideas, and feelings are simply experienced without the additional element of a knowledge of them, or of their relation to an ego in which they inhere. These simple immediately experienced mental phenomena are attributed by modern psychology not to the unconscious but to consciousness. Finally, the idea of the "soul-cell" is incomprehensible if the whole psychic life, including the conscious and the unconscious, is connected with the special organs of the brain. This 


\section{PHILOSOPHY OF THE PRESENT}

would lead us to suppose that there are organisms in which certain cells have no psychic function whatever, so that matter without " mind" exists in rich measure.

In our examination of Haeckel's Welträtsel, we have limited ourselves to those parts which deal with theoretical Materialism or Monism; but we may still indicate in a few words the general attitude of the book, not trusting altogether to the promises of modesty and caution which the author himself holds out in the preface.

The book is written in the same tone of scientific arrogance, ${ }^{1}$ it shows the same hostile attitude toward the traditional and dominant schools of philosophy, it betrays the same inexcusable ignorance in matters of history, whether of philosophy, religion, or the church, ${ }^{2}$ and the same lack of purpose to pass a correct and unprejudiced judgment on such matters, as

1 How little Haeckel is to be relied upon in exact science, the Russian physicist, Chwolson, has shown in his work, Hegel, Haeckel, Kossuth und das zwölfte Gebot. The Twelfth Commandment is : Thou shalt never write about what thou dost not understand !

${ }^{2}$ In the popular edition of 1903 some of the worst sins of this nature are corrected. 
is shown by Büchner in his Kraft und Stoff. The book also bears witness to the same obscurity in thought, failing as it does to distinguish between Monism and Materialism, and the same incapacity to see and follow up the real difficulties and the real problems. We can understand Paulsen's saying that he read this book burning with shame at the condition of general and philosophical culture of our people. That such a book should be possible -that it could be written, printed, sold, read, admired, and believed by a people who possess a Kant, a Goethe, a Schopenhauer, is painful. But, as a matter of fact, every people and every period have the literature which they deserve. Let us comfort ourselves that it is here again the irresponsible crowd which to-day honours Haeckel with blind enthusiasm, while perhaps yesterday it revelled in the Nietzsche cult, and the day-before-yesterday swore by Schopenhauer. The judgment of the crowd is not of much weight, and its applause has ever been untrustworthy and compromising to the philosopher whom it heralded.

As for Materialism, Friedrich Albert Lange, in his fine book, Geschichte des Materialismus 


\section{PHILOSOPHY OF THE PRESENT}

(8th ed. 1908), has treated the subject historically and critically. ${ }^{1}$ Within certain limits, Lange approves of Materialism. For the special sciences, he thinks it is an acceptable standpoint. In particular, scientific psychology may proceed from the presupposition that mental phenomena are wholly conditioned by the states and activities of the brain. But as a worldtheory, Lange finds Materialism wholly inadequate; an Idealism based upon the Kantian theory of knowledge is much better adapted to this end. Knowledge of the transcendent is impossible. Here, only poetry, such as is suited to the moral and religious needs of mankind, can supplement our view. But the ideal world, thus poetically conceived, stands, in Lange's opinion, higher than all objects of scientific knowledge, and is at the same time indispensable to all human progress. Thus, Lange, the neo-Kantian and Positivist, ${ }^{2}$ draws a sharp distinction between scientific knowledge and poetry directed toward the ideal.

In general it is characteristic of Materialism

1 History of Materialism. By Friedrich Albert Lange. Translated by Ernest Chester Thomas. Trübner \& Co., 1880.-(TR.)

2 Compare p. 34. 
that it has no respect for the mental sciences, their methods and results, and that it does not recognise the metaphysical character of its own pronouncements. Psychological judgment, historical researches, criticism of sources, none of these does Materialism consider it necessary to take into account, with reference to the special sciences in question, and it believes that it is able to proceed independently of all of them. There is only one science which it blindly trusts, and which it holds in unbounded respect, and that is natural science. So it comes about that Materialism over hastily sets up its dogma of the exclusive reality of nature, of its forces, laws, and substance; and demands the reduction of all other phenomena, given in experience, to matter and its properties. It is unable to see that this proceeding is itself metaphysical and involves an overstepping of empirical bounds-an anticipation of results which the special sciences have not yet established. Furthermore, it lays claim to the same degree of scientific validity for its assertions that purely scientific theories and laws have won for themselves. Matter and force seem without further proof to be real magnitudes-indeed, 


\section{PHILOSOPHY OF THE PRESENT}

the only realities. Its theory of the universe is, therefore, altogether dogmatic, since the necessary critical basis for such a theory is absent, and since there is lacking that thoughtful reserve of judgment concerning questions of doubt which is characteristic of sound philosophy.

There are three main arguments against Materialism which thus far have put in question its validity and shown it to be neither a selfevident nor empirically proved theory of the world. The first of these arguments is taken from natural science. According to the law of the conservation of energy, which was advanced about the middle of the nineteenth century, and which has since received universal recognition, the sum of potential and kinetic energy in a closed system is constant, no matter what kind of energy this may be. If we distinguish mechanical, electrical, thermic, and chemical energy, then, according to this law, there can take place within any independent whole only an exchange or a transformation of this energy, but never any new creation or any complete disappearance of it. Mechanical work can be transformed wholly or in part into 
heat; chemical energy may replace a corresponding 'equivalent' quantum of electrical energy ; but the total energy at our disposal can suffer no change in amount. By virtue of this law of conservation, the production of any conscious states through material processes would indicate a loss of energy, say in chemical form, without an equivalent amount of any other known form of energy taking its place. The materialistic claims come in conflict, therefore, with a fundamental law of natural science. Numerous attempts, of course, have been made in the interest of other theories to discover a causal relation between body and mind, but of these it is not necessary to speak here.

A second argument comes from psychology. Materialism would be, at any rate, a workable hypothesis for psychology, if it were possible with its help to make even the simplest and most easily apprehended psychical processes intelligible. But it has been repeatedly noted that the sensation of red, or a tone of a definite pitch, is, as such, in no wise more intelligible from the fact that we may trace it back to some particular activity of the brain. To a person born blind, for instance, the most careful de- 


\section{PHILOSOPHY OF THE PRESENT}

scription of the retina, of the optic nerve and optic centre, and the most complete description of all the processes which must take place in these organs in order that a colour sensation shall arise, can give no idea of this elementary psychical process. Mental activities must be immediately experienced or given as facts of consciousness, if actual knowledge of them is to be gained, and they are present and comprehensible only for the subject experiencing them. Thus, it follows that we can gain an understanding of the mental life of others only on the ground of our own experience, and can interpret their expressions in countenance, gestures, and language only according to our personal experiences, as signs of definite states of consciousness. Even Büchner is obliged to admit that we do not know how a nerve-process can bring about a state of consciousness. From this point of view, therefore, Materialism appears to be an impracticable assumption for psychology, because it is incapable of explaining psychological facts. The conditioning of mental phenomena by material processes, particularly by nervous processes, is not to be denied; but in modern psychology this demand is simply 
and satisfactorily met by the concept of a psychophysical parallelism, according to which the mental processes are accompanied by physical processes, without our being able to determine more exactly the manner of this connection. $^{1}$

The most exact study of the structure and function of the cerebral cortex enables us, at the best, to advance only so far as the physics and chemistry of stimuli permit. We know that the sensation ' red' corresponds to light waves of a certain number of vibrations, and we assume that the taste 'sour' is connected with the chemical constitution of matter, to which we trace it back. We hope sometime to know as accurately the nature of the brainexcitations which run parallel to these two sensations; but that 'red' is experienced in the former case, and 'sour' in the latter, remains after all still accidental-that is, it remains a simple fact, which cannot be deduced from the physical premises but which may indeed be something of a wholly different order. The qualities of the contents of consciousness are not deducible from matter, and so psycho-

1 Compare p. 93. 


\section{PHILOSOPHY OF THE PRESENT}

physics contents itself with being the science of the interrelation between psychic and physical processes, to the end that we may bring into connection with a corresponding state of brainexcitations the regular appearance and disappearance, union and separation, expansion and contraction, conservation and change of sensations, representations, and feelings.

A third argument, based on the theory of knowledge, may be added to the ones just considered. If we inquire how it is, after all, that we arrive at the assumption of such things as matter, energy, \&c., we may make the general statement that these concepts serve to represent that in our experience which is independent of us-that which belongs to an independent uniformity of phenomena. It is not simply that we experience blue and yellow, tones and odours, but that we have impressions of this kind in a determinate order of co-existence, an order which cannot be arbitrarily changed by us, - this is the fact which leads us to affirm a real outer world with the help of the abovementioned concepts of matter and energy. It is not, then, the sensations, the psychical processes, the contents of consciousness as such, 
which form the starting-point of all scientific researches and concepts and allow us to speak of a body which we perceive or a force which works upon us, but it is rather the observation that these things come and go, change or remain fixed, are absolutely given in determinate order and grouping without any dependence upon us, without being thought of as our creative act ; in other words, the determining feature is the connection in which they appear, apart from our will and our influence. Such a connection is forced upon the sensations, and is, thus, contingent for them. In the sensations themselves, therefore, we are not able to discover the reason why they stand in certain relations and not in others. And just as little can this reason be found in the experiencing subject who lays claim to the sensations in question as his contents of consciousness. $^{1}$ From this, without further discussion, we can understand that the scientific concepts used by Materialism essentially lack the character necessary to explain conscious processes, in their special and peculiar character. Materialism mistakes completely the

1 Compare p. 45. 


\section{PHILOSOPHY OF THE PRESENT}

purpose and significance of such realities as matter and energy, when it extends them beyond their legitimate field, and considers them capable of generating from themselves the whole psychical life. 


\section{IV}

\section{NATURALISM}

WiтH a fateful regularity the demand is made from time to time, that we should be natural and live naturally, that we should regard ourselves as a part of nature, that we should obey nature's laws and recognise them as norms for our own conduct. Now, when we hold nature up in this way as an ideal in the struggle against the unnatural, or against what is contrary to nature, much depends upon just what we mean by 'nature.' When the Stoics demanded a life according to nature, they had in mind a rational life founded upon the dominance of the highest spiritual faculties of human nature. On the other hand, when Rousseau preached a return to nature, he had reference to the casting off of all the fetters of culture and returning to the child-land of innocent, harmless, and genuine simplicity and happiness. And finally, still another colouring is given to Naturalism in 


\section{PHILOSOPHY OF THE PRESENT}

the hands of its chief representatives of the nineteenth century, Ludwig Feuerbach and Friedrich Nietzsche. As a rule, this school is somewhat polemical and revolutionary, standing in the strictest opposition to prevailing views and combating, as a matter of course, all supernatural tendencies. A theory and critique of supernatural worths in morals and in religion forms the basis for the establishment of a system of natural worths, which are to take the place of the former. Modern Naturalism thus, like Materialism, stands under the dominating influence of the natural sciences.

Ludwig Feuerbach (1804-1872) has summed up the stages of his development in the formula, "God was my first thought; reason, my second; man, my third and last." From the beginning, his efforts were directed to establishing a natural history of religious development. At first, therefore, religion is conceived as an objectification of the human species, as a selfgratification of man, who raises his own being to the infinite, and thus projects himself outward as God. So God becomes the realisation or actuality of human wishes for happiness, perfection, and immortality; he becomes the 
"yea of our desires." Later, Feuerbach finds in this emphasis of that which is typical of the race, after all, merely a remnant of theological and religious conceptions, and demands henceforth of true philosophy that it shall be empirical, that it shall occupy itself only with concrete reality, with the sensuous. Therefore he speaks of the logical concept which gives expression to the universal-that is, to the raceas the despair of the poverty of thought in the presence of the inexhaustible riches of sensuous reality. Philosophy, as the doctrine of the sensuous, must connect itself closely with natural science. Nevertheless, the most important object of sensuous knowledge is, according to him, man; and not indeed the general or ideal, but the corporeal man. The body of man is to be the measure of all things; and physiology, as the science of bodily functions, is to form the basis of philosophy. It is quite comprehensible, as Feuerbach himself incidentally says, that the peculiarity of his philosophy is that it is no philosophy. In religion is found the simple fundamental truth, that man is a child of nature and a part of nature, and has a sense of his connection with nature and the 


\section{PHILOSOPHY OF THE PRESENT}

world, of his oneness with it, of his mortality, and his dependence upon nature and its laws.

Naturalism takes an individualistic colouring with Max Stirner (a pseudonym for Kaspar Schmitt: 1806-1856), who with Feuerbach wholly renounced all supernaturalism, but at the same time proclaimed the most decided egoism. The brilliant success of his book, Der Einzige und sein Eigentum (1845), was, to be sure, of passing significance; but it remains one of the most remarkable works in German literature of the period after Hegel, and is exciting a very lively interest again at the present time. "God and humanity," it reads, "have rested their cause upon nothing, upon nothing but themselves. I, then, shall rest my cause likewise upon myself, I, who am, like God, the nothing of all other things, I who am my all, I who am the only one." The first part of the work contains a clever critique of the various human conceptions which have prevailed in antiquity, as well as in Christianity, and among the "free spirits" in political, social, and humane spheres. In the second part, the ego takes the place of mankind. "In possession of my individuality, I am master of my 
powers, of my intercourse, of my individual enjoyment, and this I attain when I know myself as the only one." "The only one" means, thus, a being-for-one's-self, an individuality, the fact that one lives but once. From this limitation of everything to the self, there follows an egoism which proclaims that each one lives in his own world and is its centre. Self-forgetfulness is not contradictory to this egoism, since it is only a kind of self-satisfaction, an enjoyment of our world and of our possessions. Stirner thinks that we have renounced our individuality in favour of the humanity idea, and have overlooked the fact that in this individuality lies the only possible reality of mankind. My right is that to which I make myself entitled; my possession is that which I can master. As enemies of myself, of my ego, I count every form of community - the family, the state, and society. Toward others I have no duty, and before no power do I humble myself. Truths which claim general validity are just phrases, modes of expression and words; and logic, science, and philosophy are nothing more than these phrases formulated into a system. Far more am I the measure of all; truths below 


\section{PHILOSOPHY OF THE PRESENT}

me, I love; truths above me, I do not know. The earth swarms with fools who imagine that they are sinners, but they live only upon the dreams of their morbid fancy. I know that we are altogether perfect. "If I rest my cause upon myself, the only one, then it rests upon that which is transitory, upon the mortal selfcreator and self-destroyer, and I dare to say:

\section{Ich hab' mein' Sach' auf Nichts gestellt."}

It is doubtful just how far the bold and uncouth utterances of this book are to be taken seriously. Perhaps it all means just this, that we are all, consciously or unconsciously, egoists. Let us examine this standpoint fearlessly, let us seek to determine logically what follows therefrom. Perhaps withal it was aimed at an unmasking of widespread hypocrisy, which in self-denial, compassion, and love extolled the higher powers, which were free from all unholy reference to their own weal and woe, and allowed their adherents to be free, and which yet was not free from egoistic impulses and motives. It must be admitted furthermore that the book betrays an original individualism, an incisive and powerful protest against the petty 
regulation of all the natural impulses and needs of the individual, who knows no duty and no law, but with free and independent will stands opposed to every law and every restraint. This reaction against the levelling influence of society, of the state and of culture, has found its strongest expression in Nietzsche, who knew how to uphold the interest of personality with his peculiar, passionate, and captivating language. The powers of the masses which regulate, equalise, and reduce everything to the average; the reign of lies and conventions; the limitation of conscious desires through the influence of public opinion; the humility, selfrenunciation, and resignation to a higher will which is preached by religion,- these are the tendencies, moods, and forces against which modern Naturalism is directed. Hand in hand with the personal form of the struggle, goes a tendency to paradoxes and exaggerations, a constant agitation for a differently constituted ideal of life, and an unscientific character of argumentation such as aims at persuading, not at convincing; at compelling, not at establishing. In what follows, these general remarks will have ample illustration. 


\section{PHILOSOPHY OF THE PRESENT}

FRIEDRICH NIETZSCHE. (1844-1900)

Friedrich Nietzsche, following Schopenhauer and Richard Wagner, two authorities held in high esteem by him, originally thought and wrote quite in their vein. After the beginning of the eighth decade of the nineteenth century, his own views appeared in various works, ${ }^{1}$ clothed in a half-poetic, half-didactic form. In his great book entitled Also sprach Zarathustra, ${ }^{2}$ his thoughts are mainly poetical. This book was published in 1883-1891, and is rich in thought and sentiment. Jenseits von Gut und Böse, ${ }^{3}$ published in 1886 , presents his views in a strongly aphoristical character. A simpler, more scientific and more systematically arranged presentation is given in his Zur Genealogie der

1 The Works of Friedrich Nietzsche. Edited by Dr. Oscar Levy, 18 vols. The Macmillan Co., New York. T. N. Foulis, London.-( $\mathrm{TR}$.)

2 Thus Spake Zarathustra. Translated by A. Tille, 1896. The Macmillan Co.-(TR.)

Thus Spake Zarathustra. Translated by Thomas Common. Introduction by Mrs. Förster-Nietzsche. The Macmillan Co.-(Tr.)

${ }^{3}$ Beyond Good and Evil. Prelude to a Philosophy of the Future. Translated by Helen Zimmern. The Macmillan Co., New York.-(Tr.) 
Moral, ${ }^{1}$ published in 1887 , which was designed to be explanatory of the works before mentioned. The best account of his whole new philosophy is contained in his book Der Wille zur Macht, ${ }^{2}$ published in 1901, as the fifteenth volume of his works.

Of the extensive literature on Nietzsche, we call attention, first, to the comprehensive biography by his sister, Elizabeth FörsterNietzsche, entitled Das Leben Friedrich Nietzsches (1895-1904). ${ }^{3} \quad$ Further, there is a finely appreciative study by Riehl, entitled Friedrich Nietzsche, der Künstler und Denker (5th ed. 1909) ; a presentation by Lichtenberger, especially recommended by Nietzsche's sister, entitled Die Philosophie Friedrich Nietzsches (1899); the book by Th. Ziegler, following more closely the development of the philosopher, entitled Friedrich Nietzsche (1900); the work of $R$. Richter, a critical exposition of the

1 The Genealogy of Morals. Translated by Horace B. Samuels. The Macmillan Co., New York.-(Tr.)

2 The Will to Power. Translated by A. M. Ludovici, 2 vols. The Macmillan Co., New York.-(Tr.)

${ }^{3}$ A supplementary and partly corrective exposition is found in the work of C.A. Bernouilli, Franz Overbeck und Friedrich Nietasche. Eine Freundschaft (2 vols., 1908). 


\section{PHILOSOPHY OF THE PRESENT}

philosophical content of Nietzsche's teaching, entitled Friedrich Nietzsche, sein Leben und sein Werk (2nd ed. 1909); and the extensive work of $A$. Drews, containing an estimate of Nietzsche's whole literary activity, entitled Nietzsches Philosophie (1904). There is a complete edition of his works in two parts, of which the first in eight volumes includes the writings which Nietzsche himself published; while the second in seven volumes contains fragments, sketches, and notes from his posthumous writings. There is also a pocket edition in ten volumes, which presents the above-mentioned work, Der Wille zur Macht, in a second, fully revised edition.

The task which Nietzsche set himself in the last period of his thinking, he himself designated as the revaluation of all values. "It is my good fortune, after ages of error and confusion, to have again found the way which leads to a Yea and a Nay.

"I teach the Nay to all that makes weak, that exhausts.

"I teach the Yea to all that strengthens, that conserves force, that justifies the feeling of force. 
"Neither the one nor the other has been taught up to this time. Virtue, self-renunciation, compassion, even negation of life, have been taught; all these are values of the exhausted."

Before we fix upon a new valuation, we must have full insight into the uselessness of the old values, we must go through a "pathological intermediate state," which is a simple nihilism of prevailing customs and beliefs.

Extreme positions are not relieved by moderate ones, but only by extremes which are their opposites. Nihilism attains its most extreme form in the assertion that everything is irrational, and that this irrationality is eternal. The pathology of this view consists in its vast generalisation, in passing from a relative to an absolute senselessness.

The current ruling scale of values determining human conduct seemed to Nietzsche to be meaningless. In the evaluation of our times, virtues like veracity, philanthropy, goodness, and helpfulness are highly prized. Even Kant and Schopenhauer, very critical and independent thinkers in other respects, show reverence for these virtues. But with Nietzsche there is no 


\section{PHILOSOPHY OF THE PRESENT}

other objective standard of values than life and vitality. Life is will to power. "What man wills, what each smallest part of a living organism wills, that is a surplus of power." In another place we read, "It belongs to the concept of life that there must be growth, that its power must be widened, and so must take unto itself new powers." Therefore, we can undertake a determination of values only from the standpoint that we estimate the relation of the qualities or activities to be valued to the "quantum of increased and organised power" produced by them. In this sense there are useful, wholesome, normal instincts, as well as injurious, sick, and abnormal ones, of which the former affirm life and the latter deny it. Therefore, veracity, goodness, \&c., are to be opposed just so soon as they become detrimental to vitality, to vigour. Schiller indeed says in his Braut von Messina, "Life is not of all goods the highest"; but directly the opposite view best expresses the standpoint here taken by Nietzsche: "Of all goods life is the highest."

Nietzsche proceeds to subject the moral views and moral judgments which have arisen under the influence of Christianity to a sharp criticism. 
He finds in these "a turning away from willing to being." $\mathrm{He}$ believes that the richest and most pregnant impulses of life have hitherto been denied, so that over life there hangs a curse. In opposition to these rejected morals, Nietzsche, "the immoralist," labours for "the restoration of the egoism of humanity." There are, according to him, two fundamentally different forms of moral evaluation among all people and in all times, which may be designated as the morals of the masters and the morals of the slaves, aristocracy and democracy, individualism and dominance by the masses. The representative of the morals of the masters, the nobleman and gentleman, calls good all those physical and moral attributes which he values in himself and his class : strength, might, boldness, austerity toward himself and others, and even cunning and cruelty. He has duties of thankfulness and fidelity only to his own class, and respects the tradition in which he has been reared. Weakness and cowardice he condemns ; compassion and unselfishness do not concern him. His emotions are pride and the joy of life. His type is characterised as " the genuinely good, the distinguished, the great of soul, the 


\section{PHILOSOPHY OF THE PRESENT}

opulent, those who do not give in order to receive, who do not wish to be exalted because of their charitableness. Lavishness is the type of genuine goodness; richness of person is the presupposition." Again, he praises this type as "the sane, sound, self-seeking, which springs from a strong soul, to which belongs the stalwart body, the fine, victorious, re-creative body."

Quite otherwise is it with the slaves. They are filled with a mistrust of life, and with an instinctive hatred of the mighty who pursue and persecute them. These seem to them like barbarians, the very type of evil; and so the weak regard as evil everything powerful, inflexible, formidable, and strong. On the contrary, goodness signifies to them the virtues despised by the masters; compassion, patience, humility, benevolence, industry. In Judaism and Christianity these morals of the slaves have triumphed over the morals of the masters. Here the instinct of the masses has found a bulwark against the strong and independent; the instinct of the suffering and downtrodden has rebelled against the fortunate; the instinct of the common man has found its justification against the elect. 
The result of this victory of the morals of the slaves over those of the masters is, as Nietzsche believes, decadence, the incontrovertible symptom of which is a lessening of vitality, visible along the whole line of creative and effective activity of life. This degeneracy does not necessarily lead to destruction, to selfdissolution; it may rather be the point of departure for new life, for higher power. The goal of humanity lies not in its end, but in its highest exemplars. To produce such men will be our problem, if we are to rise superior to nihilism. This lofty exemplar of the human race, who represents the type of the master, grand and powerful, Nietzsche calls the superman. For him shall the man who avows the morals of the slaves be a jest and a laughing-stock. The task of this higher race consists not in the guidance of the lower; it is rather that the lower ones form the pedestal on which the superman stands and from which he pursues his own interests. The conditions under which a strong and distinguished species maintains itself are the reverse of those under which the multitude prolongs its existence. What is allowed only to the strongest and most pro- 


\section{PHILOSOPHY OF THE PRESENT}

ductive natures to make their existence possible-leisure, adventure, unbelief, even excess, would, if permitted to the mediocre natures, necessarily destroy them. With the latter class, industry is the rule and temperance and fixed convictions-in short, the virtues of the multitude; by these is the mediocre class of men perfected. Even after the successful production of supermen, the common people remain the quiet and obedient labourers, whose religion alleviates the misery of their pitiful lives. But the superman, the wise one, creating values, must be inflexible toward himself as well as toward others-must renounce for himself comfort, rest, and the quiet enjoyment of life, and yet in all life's conditions he must show the cheerfulness of the good player, the joyful innocence of the romping child, the bright grace of the dancer.

The development of this positive theory of the goal of mankind, the rise of a higher type of the race, alone made bearable to Nietzsche the thought (repeatedly taught in Greek philosophy) of an eternal cycle of events - a thought which at first caused him many sad and heavy hours. According to this view, the world con- 
sists of a limited number of elements, and has at its disposal a limited sum of energy. Therefore, a given combination must repeat itself in an endless period of time. But if a certain cosmic condition which formerly existed is again reinstated, then according to the law that a wholly definite effect must follow upon given determinate causes, it would involve all the other conditions which had previously followed upon it. The eternal hour-glass of being will always be turned again. There is, then, no endless progress, no unbroken ascent to higher and higher goals, but all the steps already mounted must ever be climbed anew ; all the mistakes and weaknesses in the eternal cycle of events must be repeated without end. Hence also the practical consequence follows for me, that this life which I now live is my eternal, my ever-recurring life. This thought, the necessity of which Nietzsche believed he could not escape, was made endurable to him only because he saw therein a problem set for human development. Since in any case we must live again, we should live at every moment as we would wish to live again. And so he admonishes mankind: "Forget not that thou 


\section{PHILOSOPHY OF THE PRESENT}

art acting for all eternity." Has life the highest values to offer? Can it perfect itself according to the morals of the masters? Then it is worth while to live again; then the thought of an eternal return loses its painful sting, its depressing weight.

Nietzsche himself has designated his views as ethical Naturalism. He regarded it as his special work to translate the moral values, which had become apparently emancipated and unnatural, back to their real nature-that is, to their natural "immorality." Hence he is primarily and essentially a critic of existing moral views and an agitator for a new order of values. And in this he proceeds as most agitators do: he caricatures existing conditions and exaggerates in a one-sided way his own point of view, his own ideal. The morals of the slaves which he pictures have never ruled anywhere. And the morals of the masters, as he conceives them, have never existed, and presumably never will.

The thought of a natural selection in the struggle for existence, which he gained from Darwin's doctrine of organic evolution, forms the basis for his theory of the cultivation of 
supermen. The biological point of view, whereby all phenomena fall under the rule of vital fitness, is of supreme significance for Nietzsche's doctrine in its final form. Not only morality, all conduct and behaviour, but also knowledge, and its goal, the truth, must in the last analysis prove their claims before this tribunal. Therefore, everything has a relative value compared with the one absolute essential of life-that is, vigorous health, and the free exercise of the will to power. 'Thus Nietzsche appears as the champion of a renaissance of antiquity, which has so often and in such various forms celebrated its revival. Especially does the opposition between the morals of the masters and the morals of the slaves remind us of the views of the ancients and their social order, and of the flourishing of the bold self-conscious, forceful natures of the period of humanism. Nietzsche may be called the Rousseau of the nineteenth century, although we must not forget that his ideas differ materially from those of his French predecessor. He himself regarded Rousseau as "an exponent of self-contempt and fevered vanity," as the plebeian, with whom he contrasts Voltaire, the aristocrat. He, like 


\section{PHILOSOPHY OF THE PRESENT}

Rousseau, demands a return to nature, but " upward to the high, free, even fearful nature itself and to naturalness, such as plays with great tasks and is well qualified to play."

We cannot here enter upon the numerous difficulties with which Nietzsche's thought-world is burdened. We may refer to only one striking contradiction. On the one hand, he is evidently deeply impressed with the belief in the moral self-determination of man, since he expressly demands that we shall so regulate our lives that we may be willing to be forced to repeat them. On the other hand, his theory rests upon a rigid fatalism (he himself incidentally pleads guilty to an amor fati), which is apparent not only in his theory of the necessary production of higher individuals, but also in his assumption of a mechanical world-cycle. This contradiction between two fundamentally exclusive views becomes more incisive when we consider that Nietzsche could not at all be sure whether his life and that of his associates, the whole creation of which he was a part, had not already been acted out.

'The immoderate way in which he directs his attacks against the religion of love and com- 
passion, against social endeavours and social sentiments, is entirely incompatible with his professed wish that his influence upon mankind should be reformatory, educative, and elevating. Since Nietzsche is described by his sister as one of the most considerate and amiable of men, he himself was evidently not the proud superman whom he longed for, who, remorseless and without scruple, tramples upon the ruined lives of the weary and heavy-laden, of the weak and the sick. But Nietzsche himself, as we know, was a great sufferer, and perhaps for this reason he felt intensely the worth of vigorous health and the joys of life which were denied him, and which he experienced only in hours of overflowing productivity; and this fact may have lent to his ideal a decided colouring.

Without doubt, Nietzsche is one of the most gifted authors of all times, and from resthetic and psychological view-points deserves the very highest esteem. He belongs to those poet-philosophers who, like Plato and Bruno, cultivated philosophy not in a scientific spirit, but rather in the spirit of the poet and artist, who are able to depict life and the world with intuitive clearness, and to present them 


\section{PHILOSOPHY OF THE PRESENT}

in warm and inspiring language. The sterner philosophical disciplines, such as logic and the theory of knowledge, Nietzsche touched upon only casually, and never gave himself up to their problems with original interest; and in the other branches which he liked to cultivate, such as metaphysics and ethics, he has no exact results to offer. We cannot call him, therefore, really a philosopher. Life was his problem, and his heartfelt interest was the determination of life's value and of life's problems. This is the only theme which his thought mastered, and this theme he was able with astonishing versatility of spirit to express in every form of variation, from the lowest to the most ideal. What life and science, religion and art, past and present, really are, and what laws control them-these theoretical questions trouble him only in so far as they are related to his fundamental problem of life.

Nietzsche's greatest and most enduring fame is as an artist and as a highly gifted musical poet. Long after his unjust warfare against Christianity, his contradictory theories which do violence to facts, his clumsy constructions and exaggerations, have been forgotten, he will 
be remembered as one of the greatest German stylists, as a poet of powerful diction, as a master of language and of musical declamation in words; and as such we shall admire him and enjoy him. To be sure, not all registers of the author's art are open to him. He lacks grand simplicity and plainness, he lacks quiet and rich beauty; he lacks the grandeur of deep and blessed peace; he lacks the Olympic clearness, harmony, and serenity. He storms and underscores too much; he is too pathetic and too restless. When we read him, we are moved not by classic but by romantic art; he transfers us to the rococo-mood, not to that of the Renaissance; he incites in us dramatic tension and lyric stress, while he lacks epic calm and exuberance. But he is a master of his art, and we might call him, in a certain sense, the Richard Wagner of German prose. His aphorisms, sure of aim and rich in meaning, stride in pomp and splendour, with effective and surprising turns. And the truth which lives in all poetry thrills us here also. But art solves the problems of reality as little as it does the problems of science. The saga of the superman, of the eternally recurring cycle of events, of 


\section{PHILOSOPHY OF THE PRESENT}

the morals of the slaves and the morals of the masters, have power to stir us and thrill us, when we place ourselves under the spell of his art. But for a revaluation of all values, something more is necessary than prophetic words and personal moods. New values, in order to gain acceptance, must have been lived for and died for, and must be concurrent with the dissolution of the old values. But it is still far from evident that "life" or " the will to power" is the unconditional worth which is to be considered as the goal of all striving and all evaluation. Unless all signs fail, the vitality of the old values is still unweakened and unbroken.

However much we may wish that Nietzsche should be understood and enjoyed in the field in which he has excelled, nevertheless it is true that his influence has not taken those quiet paths where such admiration and understanding would be harmless. His influence tends always to lead astray the immature crowds of his followers, exulting in his phrases and catchwords, which they only half understand. It seems as if it was not for the wise that he wrote his mysterious parables, his pensive poetry, his glittering paradoxes, but for the credulous fools who revel 
in his speeches and make absurd attempts to realise his dream of the superman. But his own time will come, when we shall revere him as a poet, whose original pictures and comparisons, whose enchanting pathos and vital warmth of expression, whose complete mastery over a certain music of language, will give him a place of honour upon the German Parnassus. Then we shall welcome his criticisms just so far as they point to actual evils, and in his fantasies we shall hear the noble song of the rights and the value of personality. Then we shall recognise in his judgments and descriptions the direct expression of an original and significant sensibility, a proud ideal of heroic thought and noble independence, and a stern protest against a barren levelling process and an inward lack of freedom. But in view of the wild eruptions of his unbridled spirit, the cry will be wrung from us as in Hamlet, "What a noble mind is here o'erthrown!" We shall not forget, however, that Hamlet chose the mask of madness in order to ferret out a monstrous truth, and that he made use of the dramatic art in order to force the self-revelation of a secret of the human heart, slumbering in concealment. Nietzsche is 


\section{PHILOSOPHY OF THE PRESENT}

the truth-seeker in the garb of the erring and stumbling man, who with restless, passionate effort sought the ideal goal of understanding, and delayed to test the safety of the ground over which he hastened. "'This passion for the true, the real, the certain, the non-phenomenal, how angry I am with it!" he once cried. "Why does precisely this gloomy and vehement oppressor pursue me? I long for rest, but he will not allow it." Overbeck, one of his nearest friends, declared that the striving after greatness really controlled him, but that his greatest gift was that of a critic, a gift directed not the least against himself. "Anyone who had such a fine and critical talent, and directed it, as he did, so exclusively and vehemently against himself, must end in madness and self-destruction."

Against Naturalism in general the following objections may be urged. It does not follow, because the traditional views as to the origin of religion and morality may be wrong, that religion and morality themselves are wrong. Granting that the description which Feuerbach and Nietzsche give of the origin of religion and of the moral teachings of Christianity is correct, 
it would not necessarily follow that these convictions or principles are themselves incorrect. Furthermore, it is much to be feared that the Naturalism of a Feuerbach or a Nietzsche, if it should become a dominant and successful theory, would not conduce to human progress, but to quite the opposite. We should return to the level of animals, if, according to the last phase of Feuerbach's thought, we were to place our bodily needs above our character and duty, or if, with Nietzsche, we should regard life at any price as the criterion of highest value, by which all other good is to be measured. But the fact is that Naturalism means the end of all real philosophy. With Feuerbach it passes over into empirical observation or natural science; with Nietzsche, into agitation or the unsettling of all standards. In this way, Naturalism renounces not only a comprehensive world-theory, but attacks the foundation of the special sciences, and indeed all attempts at scientific understanding and explanation. Knowing, thinking, understanding become only means to an end; they are only manifestations of life like any other, and lose their distinctive meaning, absolutely fundamental for 


\section{PHILOSOPHY OF THE PRESENT}

the investigator and philosopher. Although a most significant phenomenon in the history of culture, Naturalism in its scientific relations has always been of slight value. It has roused and stimulated, brought thoughts and moods into flux, but it has solved no problems, really answered no questions. It resembles a windstorm which purifies the air, shakes decaying fruit and withered leaves from the trees, but brings with it no life-bearing and fructifying seeds. 


\section{V}

\section{IDEALISM}

When I make the statement: The sun is ninety million miles distant from the earth, I mean that the sun, the earth, and the distance between them are real. The reality which is thereby expressed, and which is ascribed to certain objects, has nothing to do with the truth of my judgment or of my statement, since the latter relates only to my knowledge of an object, not to the object itself. Just as little is it identical with the conscious reality of the fact expressed. For I am not thinking of the dazzling orb, nor of the ground at my feet, nor of the distance measured by my glance between myself and that orb, but of heavenly bodies, whose size, constitution, and distance from each other can only be fixed and determined conceptually in words and numbers.

Precisely the same is true in other cases. If I speak of the vibrations of the ether which 


\section{PHILOSOPHY OF THE PRESENT}

correspond to the colours that we see; or of the chemical analysis of bodies into elements and atoms; or assume, according to the theory of evolution, the development of higher animal forms from lower ones; or refer to character as one of the mainsprings of human action; or speak of Aristophanes as the most important representative of Attic comedy:-in all these cases I am thinking always of realities, not of ideas or sensations, nor indeed of contents of consciousness. All of the concepts and expressions of which I make use in such statements, manifestly imply a reference to independent existences not conditioned by our thinking, hearing, seeing, and understanding-existences whose essential being is only indicated and not exhaustively defined in the contents of consciousness, no matter what the nature of those contents may be.

If we divide all the sciences, according to a current classification, into formal and real disciplines, we can say that in all the real sciences such realities play an important part. With the formal disciplines, logic and mathematics, on the other hand, the question of the real significance of their objects is of no import. The 
meaning of logical and mathematical expressions and laws is as little affected by the conception of magnitude as an attribute of real objects, or of judgments as real thought-processes, as by the opposite view. In the sciences of nature and of mind, however, as well as in metaphysics, a reality is always taken for granted, and an attempt made to determine it more exactly as to its kind. If now, in the field of the real sciences, following the lead of the positivists, we take our stand simply on the conscious reality of sensations, ideas, and thoughts, then we see that the traditional point of view of nature and of mind, as well as of metaphysics, is a gratuitous assumption of an uncritical fancy, unavoidable perhaps, but nevertheless unjustifiable. In contesting all such realities, in eliminating them from scientific knowledge, the antimetaphysical tendency, which we have learned to value in Mach, asserts itself. And in fact, metaphysics has been trying, from ancient times to the present, to determine the reality of the objects of our knowledge and the being of the world. When Plato pictures Ideas as the abiding, the unchangeable, the essential, as opposed to the transitory and illusory images of the 


\section{PHILOSOPHY OF THE PRESENT}

senses; when Leibniz thinks of the whole cosmos as consisting of monads, simple beings, which are equipped with ability to represent the whole world, we are here met by earnest metaphysical efforts to escape from all the deception and instability of the senses, and from all partial or accidental views, and to arrive at a unified and reliable world-theory. If the result of these efforts is the hypothesis that the world in the final analysis is composed of psychic values which are thought of after the analogy of the facts of mental life given in our inner experience, then we speak of an idealistic metaphysics, or of a pure Idealism. An Idealism of this kind is found in Plato and Leibniz; it has also become the foundation of a modern metaphysics.

Of a different nature is the epistemological Idealism represented by Kant and many of his followers, and especially by the modern neoKantians. This Idealism emphasises the fact that knowledge is a product of mind, of reason; that it contains ideal factors, and is therefore not in position to comprehend objects accessible to our experience as these objects are in themselves independent and detached from such factors. Hence the known world is perception, 
intuition, representation, idea, or the totality of such actual facts, but the world in itself remains an empty notion, which cannot be filled with a definite content-just an eternal, insurmountable boundary of knowledge. This doctrine, which is also called transcendental or critical Idealism, naturally shuts out metaphysics, as the science of things-in-themselves, whether it bears an idealistic or materialistic character, and belongs thus far to the circle of Positive theories. ${ }^{1}$ It is by no means true, however, as I have attempted to show in another place, ${ }^{2}$ that this phenomenalism, this limitation of all knowledge to appearances, makes metaphysics, as a real science, impossible.

The difference between the older Idealism and the idealistic metaphysics of the present consists principally in this, that the latter wins its results by an entirely different method. The method which Leibniz, for example, used as a basis for his doctrine of monads, was the analysis of the definition of the idea of substance, and with this definition he begins his

1 Compare p. $33 \mathrm{f}$.

${ }^{2}$ Compare my work on Immanuel Kant (p. 146), in the series, Aus Natur und Geisteswelt. 


\section{PHILOSOPHY OF THE PRESENT}

work. He was fully convinced that if we can establish and carry through non-contradictory judgments concerning a given object, this is entirely sufficient to give reality to the object on which these judgments have fallen. If it were possible to define the idea of God in such a way that no logical contradiction should arise in the concepts used, then the reality of a divine Being would at once be proved. As a result of this obliteration of the difference between formal and real disciplines, a deductive method such as that used in geometry, based on certain definitions and axioms, would be regarded as valid also in metaphysics and as yielding trustworthy results.

This belief in the similarity of metaphysics and mathematics was expressly shattered by Kant. Apart from experience, empirical observation, and research, there is, according to him, no knowledge in the real sciences. Since now any special kind of experience-such, for instance, as intellectual intuition-is not at the command of metaphysics; and since it treats in pure conceptual form of the transcendent, of things which lie beyond the boundaries of possible experience, therefore, according to this defini- 
tion, it could not be a science. In spite of this, in the post-Kantian philosophy there was a return to metaphysical definitions and speculation. Schopenhauer, for example, found the essence of the world in Will, and believed that he had avoided Kant's critique of all metaphysics, in that he proclaimed a special intuitive experience as the empirical point of departure for the fundamental principle of his metaphysics.

About the middle of the nineteenth century, a new method in metaphysics was deliberately demanded and adopted for the purpose of establishing a theory of the world. It rested upon the unreserved recognition of the work of the special sciences, as an intermediary between experience and a theory of the world. It renounced, furthermore, any claim to a special philosophical method, or to any method ignoring the several sciences. The first clear statement of this new standpoint is found in Fechner. It bears the name of a theoretical principle, and is as follows:

"It is necessary to start with the largest possible circle of experience in the field of existence, in order that by generalising, widen- 


\section{PHILOSOPHY OF THE PRESENT}

ing, and extending the point of view which we here employ, we may attain to a view of what prevails in those other, broader, and higher fields of existence, to which, on account of their distance, our experience does not extend; or which reach above and beyond our experience because of their breadth and height. But in this excursion beyond the field of the empirical, we must take care always to employ our generalisations, extensions, and enlargements only in the sense and in the manner in which they have already been employed in the field of the empirical. Thus, we shall claim nothing as valid in the other, wider, and higher sphere which does not become correspondingly more generalised, widened, and extended the wider and higher we direct our gaze in the field of the empirical; and thus we shall make full allowance for the differences which are due to the greater distance, extent, and height of the other sphere."

In his principal metaphysical work, ZendAvesta, which appeared in 1851, Fechner had already employed this methodological principle, and had declared that "generalisation by induction and analogy, and the rational combination 
of the common elements gathered from different sides," was the only theoretical way which could lead to relatively safe and practical results in metaphysics. That he was fully conscious of his divergence from the older method is shown in his declaration that "It is not a preconceived idea of God which determines God's existence, but whatever of God can be perceived in the world and in us."

Thus was gained the notion of an inductive metaphysics, which was safe from the attack of Kant's critique, because it was immediately connected with the special sciences, and made no use of the sharp distinction between the immanent and transcendent which Kant presupposed in his critique of metaphysics. Precisely the same standpoint was taken later by Eduard von Hartmann, in his Philosophy of the Unconscious published in 1869, when he declared that he had arrived at his conclusions by the "inductive scientific method." Wundt is governed by a similar conception, and Erhardt in his Metaphysik, published in 1894, has yielded likewise to the demand for an inductive procedure. According to this demand, metaphysics has the task of carrying further the work of the 


\section{PHILOSOPHY OF THE PRESENT}

special sciences, by anticipating the results of careful detailed researches, by deciding between opposing views, by uniting the separate paths of the different sciences, and in short by seeking to draw a complete world-picture. All of this takes place on a smaller scale and within narrower limits in the special sciences themselves, so that an inductive metaphysics in its scientific character offers nothing especially new. To be sure, with the recognition of the greater uncertainty of such anticipations, decisions, and combinations, there is connected a more modest conception of the validity and significance of metaphysical assertions. But this attitude is certainly to be preferred to the obtuseness and indifference of Agnosticism, or the proud resignation of Positivism, in the presence of the great world-riddles.

Modern Idealism, which in general discerns the reality of the world in something like soul or mind, is fully convinced that natural science and the science of mind have furnished and must furnish the necessary work preliminary to such a metaphysics; and that one must acquire an intimate knowledge of this preliminary work if one proposes to attempt a meta- 
physical extension of its results. At the present time, such an Idealism is represented by a large number of philosophers. We may mention, for instance, Julius Bergmann, who has presented in his System des objectiven Idealismus, published in 1903, certain characteristic features of an idealistic theory of the universe. According to him, the material world is " in the nature ascribed to it by mathematico-empirical science, a content of consciousness embracing in itself as parts of itself all simple conscious beings." Only a being which perceives itself, as Bergmann seeks to show, can have existence, and there exists a multiplicity of things which can be thought of only as parts of one and the same thing. As a consequence, all realities must be conscious unities, and these again members of a universal consciousness. The conviction of the immediate and exclusive self-certainty of all that is given in our consciousness forms the avowed presupposition of this Idealism, developed throughout in a strictly dialectical manner.

Rudolf Eucken has undertaken to construct an objective Idealism in another form. Of his numerous writings, we may mention particularly 


\section{PHILOSOPHY OF THE PRESENT}

Der Kampf um einen geistigen Lebensinhalt: Neue Grundlegung einer Weltanschauung (1896, 2nd ed. 1907). Over against all the limitations of nature and all her laws, which he never disparages or contests, Eucken seeks to show the independence of the mind. For this purpose, he attempts an analysis and evaluation not only of personal striving and realisation, and the peculiar development and tendencies of the individual, but, above all, of the historical objective significance of art, science, and religion. Mind appears as an inner movement of the all, as a universal and endless force which through self-activity generates, maintains, and advances itself. With the multiplicity and antagonism of the separate mental currents, there co-operates a superior unity of the whole, leading and controlling these currents, making possible their progress and determining its nature. The fact of a spirituality overcoming all opposition insures the absoluteness, originality, and independence of mental life. Here Idealism becomes not merely a theory but at the same time a problem, as with $J$. G. Fichte; indeed idealistic reality is nothing but the solution of this problem, the result of a striving after ideal ends. Eucken, however, has 
found the inductive foundations of his Idealism not in the inner experiences of the individual, but rather in those of objective and universal mental life.

In trying to gain a closer acquaintance with this school, we shall limit ourselves again to the study of a few typical representatives. With this end in view, we shall select such philosophers as have formulated a comprehensive world-theory, and thereby have aroused a more universal interest. To this class belong Fechner, Lotze, von Hartmann, and Wundt.

1. GUSTAV THEODOR FECHNER. (1801-1887)

From the literature on Fechner, we may mention the following works: J.E. Kuntze's Gustav Theodor Fechner (Dr. Mises) (1892) ; an appreciation of the life work of Fechner from a very narrow standpoint. Kurd Lasswitz's Gustav Theodor Fechner (3rd ed. 1910); the first volume of the excellent collection, Frommann's Klassiker der Philosophie, and the best complete account of the life and teachings of our philosopher. Wilhelm Wundt's Gustav Theodor 


\section{PHILOSOPHY OF THE PRESENT}

Fechner (1901); a very attractive characterisation of certain aspects of Fechner's personality and work.

In considering the unusually diversified life work of Fechner, which was partly in exact science, partly in art and art criticism, partly in philosophy, let us first call to mind the immortal services he has rendered in the field of scientific psychology. Starting out with a general study of the relation of the physical and psychical, and the relation between body and mind, he arrived at the fruitful conception of a psychophysics, fortified with all the aids of exact method, and marking the memorable beginning of experimental psychology. In connection with this, his most distinguished service, Fechner conceived the outlines of an experimental æsthetics. His poetical gift is revealed especially in his Kleinen Schriften, which were collected and published in 1875 , originally under the name of Dr. Mises, and which deal satirically with questions relating to the older theory of medicine and natural science. Here, for example, he upholds with telling wit the thesis that medicine aims to establish the following proposition:-Every remedy heals all diseases, 
and every disease is healed by all remedies. Of his philosophical writings in the narrower sense of the word, we mention:

1. Zend-Avesta, oder über die Dinge des Himmels und des Jenseits (3 vols. 1851, 3rd ed. 1906).

2. Über die physikalische und philosophische Atomenlehre (1855, 2nd ed. 1864).

3. Über die Seelenfrage. Ein Gang durch die sichtbare Welt, um die unsichtbare zu finden (1861, 2nd ed. 1907).

4. Die Tagesansicht gegenüber der Nachtansicht (1879).

In reference to his predecessors, Fechner himself says, that his starting-point was the natural philosophy of Schelling's school, that he had plucked the best fruit from a branch of $\mathrm{Hegel}$ (a branch, to be sure, bent far from the tree), and that in the ashes of Herbart's fire he had found some coals for his own hearth. Compared with the Absolute Philosophy of a Schelling and Hegel, who had sought to build up a comprehensive system of philosophy, his tendency is not so different as his method, which demands a methodical, careful connection with the results of the special sciences. He has 


\section{PHILOSOPHY OF THE PRESENT}

repeatedly recognised the fact that he shares with the Absolute Philosophy the problem of seeking that which is highest, most universal, and final; and he criticises its efforts solely on the ground that earnest desire has been confused with actual possession, the course with the goal. And, in fact, in his theory of the world we see an attempt, rendered specious by the clearness of his presentation, to bring all the theories and speculations on the universe and its realities into connection with the ideas, thoughts, and results of the empirical sciences.

His theory of the universe is primarily determined by the assumption of a coherent, interconnected psychophysical whole. Just as body and soul supplement each other in the single living being, so in the greater complexes of the world, and finally in the world itself, we have to do with unities of a psychophysical kind. All of these unities, including not only men and animals, but also plants, and, as examples of the more comprehensive forms, the earth and the other heavenly bodies, Fechner places in a relation to each other which becomes plainer from the following illustration:-Let us suppose, 
he says, a great circle and in the great circle many small ones. Each small circle has a soulcontent which it takes up and encloses within itself, concerning which it knows. But since the great circle includes all the small ones, it includes and encloses within itself their soulcontent as well. From the great circle, none of the small ones are distinctly separate, since they are all parts of it; it knows, therefore, the contents of the individual circles. On the other hand, each small circle is distinctly separate from the other small ones, so that none of them know directly the contents of the others, and the great circle, in turn, is distinctly separate from other great circles, while altogether both great and small circles are contained in one greatest circle of all. We are the small circles, the great circle is the earth, the greatest one is God.

Accordingly, Fechner is of the opinion that the earth, as well as the other celestial bodies, has a soul. To the support and proof of this assumption, he has devoted close and clever consideration. $\mathrm{He}$ seeks to show that the earth, in its form and material, in its relations of cause and effect, is uniformly related to the 


\section{PHILOSOPHY OF THE PRESENT}

whole ; that it has within itself individual peculiarities, that it is relatively independent of other similar entities; that through stimulation and influence from an outside world, it evolves out of itself, brings forth out of its own fullness and creative power, an inexhaustible manifoldness of creation; that it changes in detail, but remains an entity. In all these directions, it acts exactly as our body does, except that it is the whole of which our body is only a member ; and it is permanently that which our body is but for the moment. Now, since we can only judge of soul life in others by signs, expressive movements, and the like, Fechner thinks it must be inferred that the earth is possessed of a soul or conscious unity peculiar to itself. Hence, we ourselves belong to the parts and members of the earth, and are included in its more comprehensive consciousness.

Of course, Fechner does not conceal from himself the fact that all these phenomena can be differently interpreted and explained, but he is of the opinion that no better, clearer, more natural, and more beautiful point of view can be found than the one he has proposed. The earth and its neighbours are creatures of God 
with individual souls like ourselves-souls, however, of a loftier nature, on a higher plane of individuality and independence. To understand, thus, that we are all of one spirit, which is of God, will make it easier for every one of us to be of one spirit, in the sense that the higher and highest spirit may have peace in and with us.

The relation of the lower to the higher forms of consciousness, however, can be determined somewhat more exactly by a consideration of our own soul life. In each of us appears a variety of sensations, feelings, ideas and thoughts, which call forth and displace each other, now agreeing, now striving for mastery. This exchange and intercourse between the separate psychical processes depends, according to Fechner, on a fundamental condition-namely, they all take place in one common consciousness. Otherwise they would not find each other, would not affect each other, and would neither check nor advance each other. Furthermore, all that we call unconscious activity in our mind is not without consciousness; it is, rather, a consciousness engulfed in the universal consciousness, but determining very largely the latter's position and conduct. In like manner 


\section{PHILOSOPHY OF THE PRESENT}

we must think of individual minds as partial expressions of a comprehensive, upholding, unifying higher mind, which includes them all. Only in this way can we understand the active intercourse and communication between human minds. We could not understand this give and take, this growth of ideas, and this intermingling of one mind with another, if we did not regard a greater and mightier consciousness as the common point of departure for them. The difference is only-this, that we are obliged to think of this mind which surrounds us as infinitely richer, more efficient, more enduring than our own weak and limited consciousness. But as we ourselves are more than the separate ideas, thoughts, sensations, and feelings which pass through our minds, so must the higher mind be greater than the various individual minds which it embraces. It experiences, to be sure, all that we experience, and as we experience it, but it feels at the same time the way in which the 'what' and the 'how' of our experience enter into relations with each other-relations which are as a closed book to us, and which have a much higher significance than our individual mental processes. 
When, therefore, the earth is held to be something higher than men, animals, and plants, this is not to be understood, according to Fechner, as if it were merely a higher step of the same stairs. On the contrary, mankind is, and will for ever remain, the highest step of the earthly stairs. But the house, into which the whole stairs is built, can be spoken of as somewhat above the highest step, and this house is the earth. "The highest step leading out to the open-that is, the human being-may always be the pinnacle, and the best fitted from all points of view to overlook the whole house and the broad heavens out beyond; but the house that bears this pinnacle will signify something more and higher than the pinnacle itself, which would fall into ruin without the house, while the house without this highest step leading into the open would only lack its highest point of vantage."

This figure of the stairs Fechner brought later into a still closer relation to his psychophysical theories. If we distinguish, for example, between the waking condition and sleep, we can fix an absolute threshold of consciousness which divides the complete unconsciousness of sleep 


\section{PHILOSOPHY OF THE PRESENT}

from the general activity of consciousness in waking. But within the latter, the attention becomes the occasion for establishing a new threshold, which Fechner calls the relative threshold. Everything that in a given moment attracts our interest to itself, raises itself above this threshold, and forms, so to speak, the summit of a wave of mental or psychophysical activity. But, at the same time, there are always a number of unnoticed phenomena, which are lost in the background of consciousness and form a more or less indistinct mass. This unnoticed mass corresponds to the trough of the wave, in the wave-scheme chosen by Fechner for his illustration. Now, all phases of the wave, not the crest alone, belong to the waking state. It forms the whole consciousness, embracing what is noticed as well as what is unnoticed. In like manner, individual minds represent only the waves within a wider consciousness. So Fechner has used induction and analogy in order to be able to conceive of the whole world as governed by similar laws, beings, and forces. The most comprehensive consciousness within this psychophysical stair-building, the being whose body is the world, is called 
God, whose mind, according to the principles of this doctrine, includes within itself all the separate forms of consciousness, but at the same time transcends them and forms above them a unity peculiar to itself.

There exist for Fechner, therefore, no sharp boundaries between individual souls and the bodies belonging to them. They are united by many and firm bonds. This, his synechological view, he opposes to the monadology of a Leibniz or a Lotze, according to which individual souls only apparently affect each other, or are connected with each other, while remaining in fact substantially independent. Finally he regards soul and body as two sides of one and the same being, whose diversity rests upon a difference of view-point. Just as one and the same circle appears to possess a convex or concave periphery according as one stands within or chooses a view-point outside of the circle, so the physical may everywhere be substituted for the outer perception-the mental, on the contrary, for the inner self-perception of the same object. With Fechner, therefore, body is appearance for others ; soul, appearance to one's self. According to this, soul must be understood as the real 


\section{PHILOSOPHY OF THE PRESENT}

true being of an object, inasmuch as we know ourselves doubtless better than others know us. The correlation of body and soul, therefore, cannot be judged as a causal relation, or as a relation of reciprocal action. It is rather a relation of simultaneous dependence, such as obtains, for instance, between the lines and angles of one and the same figure.

Since in individual consciousness, individual experiences do not vanish, but, as daily observation teaches, very often return, therefore we may assume, according to Fechner, that there is an immortality for the individual soul. In his little book, Vom Leben nach dem Tode (6th ed. 1906), ${ }^{1}$ Fechner has given clear and beautiful expression to this thought.

The general significance of Fechner in the history of philosophy rests, on the one hand, upon the fact that he first established a system of metaphysics in connection with the special sciences and their results, proceeding by induction and analogy, and free from a priori construction; on the other hand, it is based on the fact that he has carried through in a peculiarly

1 On Life After Death, by Gustav Theodor Fechner. Translated by $H$. Wernecke. Open Court Co., Chicago, 1906.-(TR.) 


\section{IDEALISM}

striking manner the monistic conception of a unity of God and the world by the illustration of a psychophysical system of graduated stages. Both have contributed new and fruitful impulses to metaphysics.

We have already discussed ${ }^{1}$ the value of an inductive metaphysics, and have seen how much influence it has had. The idea of a pyschophysical system of graduated stages clearly stands or falls with the assumption that the heavenly bodies have souls; and this assumption is very difficult for us to accept. For one of the best established facts in this field of experience is that life and mind belong together, and that the limits of the latter are at the same time those of the former. Now we can of course agree with Fechner in saying that the earth is alive to the extent that it produces, maintains, and nourishes life. But it produces also, and indeed more abundantly, the inanimate, which lacks, so far as can be determined by observation, the characteristic attributes either of life or mind. We have found no occasion thus far to efface the boundaries between the animate and the inanimate, or to regard this difference simply as

1 Compare p. $141 \mathrm{f}$. 


\section{PHILOSOPHY OF THE PRESEN'T}

relative or gradual, or to look upon the transition from one phenomenal form to the other as continuous or fluent. The arguments advanced by Fechner in behalf of his doctrine that the earth is an organism, cannot abolish this distinction. For when one examines them more closely, he discovers that all the characteristics which the earth has in common with the human or animal body depend wholly upon abstract and,superficial analogy. Nevertheless, Fechner's philosophical writings deserve a wide circle of readers, and it is to be hoped that the animated, clear, and attractive form which characterises them, the fine and earnest spirit which prevails in them, and the original blending of science and mysticism which they exhibit, will satisfy the metaphysical impulse and philosophical interest of a large circle of readers in a fuller degree than has hitherto been the case.

\section{HERMANN LOTZE. (1817-1881)}

The following works treat of Lotze's life and philosophy :

Edmund Pfeiderer: Lotzes philosophische 
Weltanschauung nach ihren Grundzügen (2nd ed. 1884), a sympathetic treatment.

Von Hartmann: Lotzes Philosophie (1888), an adverse treatment.

Richard Falckenberg: Hermann Lotze (1901) (in Frommann's Klassiker der Philosophie): a complete, reliable, and impartial presentation of the life and development of this philosopher.

Lotze's writings deal partly with physiology and medicine, and are partly of a philosophical nature. To the former field belongs a treatise on vital energy, fundamental and influential for his time, attacking the vitalistic theory and supporting a strictly mechanical conception and scientific treatment of life processes. Among his philosophical writings we may mention:

1. Medizinische Psychologie (1852, new ed. 1896).

2. Mikrokosmus. ${ }^{1}$ Ideen zur Geschichte und Naturgeschichte der Menschheit (1856-1864, 5th ed. 1896-1905).

3. System der Philosophie. 1, Logik' (2nd ed. 1881); 2, Metaphysik ${ }^{3}$ (1879, 2nd ed. 1884).

1 Microcosmus, by Hermann Lotze. Translated by Elizabeth Hamilton and E. E. C. Jones. T. \& T. Clark, Edin., 1897.-(Tr.)

${ }^{2}$ Logic, by Hermann Lotze. Translated by Bernard Bosanquet. 2nd ed., 2 vols. Oxford, 1884. -(Tr.)

3 Metaphysics, by Hermann Lotze. Translated by Bernard Bosanquet. 2nd ed., 3 vols. Oxford, 1884.-(Tr.) 


\section{PHILOSOPHY OF THE PRESENT}

The general standpoint taken by Lotze is largely determined by his relation to the preceding schools. When Lotze began to work out his metaphysical ideas, Hegel's downfall was not yet final. The spirit of Hegel's method still stood resolutely in the foreground of philosophical effort. Therefore, Lotze sought to come to some definite conclusion concerning the Absolute Philosophy and the dialectic method which it used. This Absolute Philosophy, he believed, had set up a significant goal always to be reckoned with, but it made the great and momentous mistake of believing this goal attainable to finite scientific knowledge. The goal of a rational theory of the world which would satisfy all demands for exactness and thoroughness lies in infinity, says Lotze. We can reach it only provisionally, and we must constantly bear in mind that reality is much richer than our thought which masters it. The problem of metaphysics is to present the sum-total of reality in a logically adequate form, but it has nothing to do with the impossible task of creating or constructing a world. The Absolute Philosophy believed that it possessed, in the dialectic method, an expedient by which it 
could arrive at all facts without particular reference to experience; for Lotze, on the contrary, reality is a given existing magnitude, which we are to understand by pointing out its inner continuity.

To the reality which is presupposed by metaphysics, belong, according to Lotze, things which exist, events which take place with reference to these things, qualities which they have, and relations which subsist between them. Furthermore, we have representations and perceptions, of which all the above elements of reality are to be regarded as objects. The question how it comes about that things exist or happen, instead of not existing or not happening, is put aside by Lotze, once for all, as a question absolutely unanswerable. If we desired to solve such a problem, we should have to be able to take a standpoint outside of all reality, a procedure which is unthinkable. For an understanding of this given reality, which is therefore the only problem left to a philosophy seeking to examine into the essence of things, it is not enough that we should be able to enumerate the laws of its operation and the elements into which it is divisible. A knowledge of the 


\section{PHILOSOPHY OF THE PRESENT}

mechanism of its operation is not sufficient to give us an insight into the progress and phenomenal forms of our present world. Far more must we know the goal toward which the whole machinery of events is working, and we must have a notion of the value which this actual world is to realise in its existence and its development. Hence a teleological consideration necessarily rises above mere mechanism in a metaphysics which understands what is given.

In his metaphysics, Lotze starts with an analysis of the concept of being. What does it mean when we assert that a thing is? To this question, a distinguished English philosopher, Berkeley (1685-1753), answered: “To be is to be perceived." When, therefore, I declare that a thing is, I mean nothing more than that it is perceived. This conception Lotze finds insufficient; that an object exists independently of its being perceived is, as he says, the very thing we wish to indicate by our affirmation of being. Another philosopher, Herbart, has defined the concept of being as absolute "position," thereby excluding not only every negation but also all relativity-that is, 
every relation of one existing thing to another. This answer, again, to the question concerning the essence of being does not satisfy Lotze. For in the notion of absolute "position," a kind of being is assumed which might exist, but which actually does not exist-an abstraction which denotes something possible only in thought, something which, when taken alone, would represent not a being but merely a possibility. If we leave out of consideration all question of relation, and still try to hold fast to the being of things, we find that this unrelated being can no longer be distinguished from non-existence. A thing completely without relations could not be conceived at any place in space, or at any point of time; it could not make itself felt in the world through any effect which it exerted upon others, and could just as little receive any impression from them. But these qualities are the very ones we give to anything which we wish to characterise as non-existent; for, of the non-existent we say that it is never and nowhere, that it does nothing and suffers nothing. If we wish, therefore, to define the being of things with reference to given reality, and at the same time to abstract 


\section{PHILOSOPHY OF THE PRESENT}

from our perception or knowledge, then nothing else remains for us except to identify being with standing in relation. Only under the presupposition of such existing relations, is it comprehensible that being could be ascribed to things even when they are not perceived, or that they can again, under favourable circumstances, become objects of our knowledge.

Now, things of which we say that they exist, cannot be conceived as qualities. Therefore, each thing cannot be conceived as a single quality, because a quality or attribute is never the thing, but is only ascribed to it. Or if we were to consider each thing as the sum of the attributes perceptible in it, then all unity of a being subsisting for itself would be lost to it. Again, we can never determine the final totality of a sum of attributes, but must ever regard such a sum as only relatively complete. Furthermore, we regard a thing as unchangeable even when the attributes, which are perceptible in it, change. Under these conditions, a thing can be thought of only as a unity in multiplicity. But how can these two be brought into harmony--how can the unity of a thing be reconciled with the multiplicity of its attributes? 
According to Lotze, there is only one form in which we can conceive of such a connection of unity with multiplicity existing without logical difficulties. This form is the rule, the law, the formula, as the representative of unity. Just as we can insert various values in a mathematical formula without changing its meaning or without destroying the unity of its logical reference, so all changing attributes are to be thought of as controlled by the unity of the thing in such a way that changes go on between them, which conform to a definite law. When, therefore, an element or an attribute of being changes along certain lines, the other elements or attributes must change along definite lines, determined by the general law governing them. At the same time, it is not of course impossible that such a formula points to an existence independent of us-to an independent reality. Lotze says that reality consists, "according to the manner of its origin, in absolute, incomprehensible, energising actuality, in which there is posited a determinate content of a thing, and by which it is distinguished as a thing from its mere thought-image."

If, therefore, the relations which exist be- 


\section{PHILOSOPHY OF THE PRESENT}

tween individual things, and by virtue of which being is ascribed to them, can firmly establish such being, then they must be real relations, not formal or simply conceived. We know real relations, however, only in the form of reciprocal action. Consequently the whole problem of being narrows down to acquiring an understanding of reciprocal relations. Lotze thinks that these relations are only intelligible when we assume that every being reacts to a given stimulus with an expression peculiar to that being and corresponding to its nature. A passing over of any effect or of any changes from one thing to another, is entirely unthinkable. When a thing ' $a$ ' acts upon a thing ' $b$,' this means : that to the change ' $\alpha$ ' happening in ' $a$,' there corresponds a change ' $\beta$ ' happening in ' $b$.' Therefore, the corresponding states need be in no way like or similar to each other. If, for example, we maintain an attitude of knowledge toward things, and consider this knowledge of things as their effect upon us, this never means that the things simply mirror themselves in us, but that the ideas and thoughts which serve in the acquisition of our knowledge are created by us with the capacity of beings fitted 
for situations of this kind. They may, therefore, be altogether different from the things toward which they are directed, and which they wish to represent and apprehend.

At this point, let us return to the result previously established concerning the concept of an existing thing. We found that a unity can only be thought of as a rule or law, to which the individual elements or attributes must be subject in their variation and relation to each other. If we hold, together with this, that a real unity must be distinguished from a rule which is only conceived, and that the relations existing between separate things are of the nature of reciprocal action, we arrive at the necessary assumption that, at the root of all changes which correspond to each other in conformity with law, and which take place in individual existing things, there must be a substantial unity, an unconditioned, comprehensive substance. The action of thing ' $a$ ' upon thing ' $b$ ' means, then, that the change arising in ' $a$,' which we may call ' $\alpha$,' reacts on the world-cause which comprehends and upholds all things, and excites this in turn to a reaction which appears in ' $b$ ' as ' $\beta$.' Now since the real unity of an 


\section{PHILOSOPHY OF THE PRESENT}

individual thing exists side by side with a multiplicity of changes in its attributes, we must presuppose a world-unity, which insures to all the individual existences the possibility of entering into uniform relations of reciprocal action. If individual beings were absolutely independent or dissimilar, interaction among these beings, according to Lotze, would be entirely incomprehensible. Only when we conceive of them as modifications, parts, or limited existences, can we comprehend the fact that real corresponding relations exist between them. Just how the essential unity of that worldcause manages to compensate ' $\alpha$ ' through ' $\beta$,' we are of course unable to say; we could explain this only if we were that world-cause itself.

We must, therefore, as Lotze thinks, distinguish an Absolute Being and the individual beings comprehended in it, rooted in its unity, and because of this unity acting upon each other. The nature of these individual beings we can determine still more exactly. According to experience, only a spiritual being, a soul, has the property of remaining a unity through all changing circumstances and phenomena-that is, of being a thing which stands in a relation 
of reciprocal action with other things. Consequently all things, whose unity we recognise and for which we presuppose real relations, must be considered after the analogy of our own inner being, as spirits or souls. According to this, our body is regarded by Lotze, as it was earlier by Leibniz, as a multiplicity of individual souls or substances.

The concept of the Absolute which had to be advanced in metaphysics simply with regard to the conceivableness of reciprocal action in the world, receives by a religious-philosophical treatment, supplementing metaphysical considerations, the character of a highest value and of a personal Deity. Only from such a standpoint can the world-mechanism be placed at the service of a teleological relation, and thereby the last task in the explanation of the world be fulfilled. The development, the course of all events in the world according to mechanical laws, tends to a realisation of the good, and becomes thereby an instrument expressing divine intent and purpose. The mechanism is then in fact simply an outwardly appearing regular form of phenomena, whose inner meaning is first revealed through a teleological conception. 


\section{PHILOSOPHY OF THE PRESENT}

Lotze did not found a real school. For this he lacked a closed system, which, elaborated by prophetic fantasy, could answer the bold and persistent demands of the intellect. What is more, the presentation of his views lacked that convincing decisiveness which carries the reader along, and conceals the difficulties in the arguments and deductions. In contrast with Schopenhauer, for instance, a skeptical vein of the shrewdest foresight and reserve prevails in Lotze's writings. It has, therefore, been said that his philosophy resembles the autumn wind, which strips the trees of their withered leaves, while a gleam of the setting sun lights up the bare tree-tops. In spite of this, Lotze has been a source of inspiration even outside the more select circle of his colleagues. This is in part due to his excellent art of presentation, which takes high rank in philosophical literature, and is seen to best advantage in his Mikrokosmus, a book no one should fail to read. The general fineness and acumen of his train of thought are also very attractive, his original turns affording continual surprise and a real intellectual pleasure. Lotze thinks ahead of us, and leads us to 
think after him. He who does not allow himself to be blinded or caught napping, but who seeks the truth honestly and profoundly, finds in Lotze an excellent guide. He belongs to the philosophers who, without following the fashion or flattering the interests of the day, have quietly helped to give to philosophy a recognition in wider circles, scientific in its spirit, earnestly and carefully elaborated.

In his metaphysics, the theory of reciproca action is the most original and most important point. It differentiates itself from an outspoken Positive conception of facts, such as we found in Mach, only by the assertion, that what it conceives as unity, or as law, is real. If we hold to the view that in all reciprocal action, regular changes are involved which correspond to each other and can be expressed by a formula, by a law, then we renounce a realistic interpretation of the concepts of cause and effect, the metaphysics of which, according to Mach, is akin to the fetichism of primitive races. Hence Lotze's theory of reciprocal action can be considered an independent result essentially different from the Positive view only on 


\section{PHILOSOPHY OF THE PRESENT}

the hypothesis of a solution of the problem of reality. This fundamental problem, however, Lotze dismissed with few words. Here, then, we find the greatest defect in his philosophy.

The method of his thought is, as we have seen, decidedly modern in content, but not in form. He handles the separate problems much as Herbart had done before him. We could say of him, also, that he strives to make the concepts of experience thinkable without giving up or questioning their validity. Nevertheless a stronger emphasis on the significance of an empirically given reality for our philosophising, lends to Lotze's Idealism an inductive character in the main closely related to that of Fechner.

\section{EDUARD VON HARTMANN.}

(1842-1906)

Eduard von Hartmann has himself written an account of his life and mental development in his Gesammelten Studien und Aufsätzen (1876), and in Gesellschaft, in its annual publication of 1887. There has recently appeared a very exhaustive presentation of his views by a warm 
admirer, Arthur Drews: Eduard von Hartmanns philosophisches System im Grundriss (1902, 2nd ed. 1906). There is also a more condensed and more critical review in Frommann's Klassiker der Philosophie, by O. Braun : Eduard von Hartmann (1909).

Hartmann is one of the most productive and many-sided philosophical writers, and is distinguished for his clear flowing style, which has a certain elegance and pleasing diffuseness. No other philosopher has so often quoted and commented upon himself, or tried by means of historical and critical references to make his own standpoint clear and bring it into relation with others. Of his very numerous writings only the following need be mentioned:

1. Philosophie des Unbewussten ${ }^{1}(1869,11$ th ed. 3 vols. 1904). As with Schopenhauer's Die Welt als Wille und Vorstellung, all succeeding editions contain the text of the first edition almost unchanged, but have additions and supplements.

2. Die Phänomenologie des sittlichen Bewusstseins (1879, 2nd ed. 1886, under the new title: Das sittliche Bewusstsein).

1 The Philosophy of the Unconscious, by Eduard von Hartmann. Translated by William Chatterton Coupland. 3 vols. Macmillan and Co., New York, 1884.-(Tr.) 


\section{PHILOSOPHY OF 'THE PRESEN'T}

3. Das religiöse Bewusstsein der Menschheit im Stufengang seiner Entwicklung (1881), to which is joined (1882) a positive philosophy of religion under the title, Die Religion des Geistes (3rd ed. 1907).

4. Ästhetik (1886-87). The first volume contains an historical-critical review of German æsthetics since Kant, while the second volume deals in an original manner with the philosophy of the beautiful.

5. Das Grundproblem der Erkenntnistheorie (1890).

6. Kategorienlehre (1896), in which the author treats of the most important and most universal forms of relation between perception and thought, such as time, space, causality, finality, \&c., in their various spheres of application.

The Ausgewiihlten Werke, published since 1885, contain thirteen volumes. From the posthumous works there has been published a System der Philosophie im Grundriss, in eight volumes. It includes Theory of Knowledge and Natural Philosophy (1907); Psychology, Metaphysics, and Axiology (Theory of Values) (1908); Principles of Ethical Theory, Philosophy of Religion, and Fisthetics (1909).

Hartmann has repeatedly set forth his rela- 
tion to earlier philosophers. He asserts that he is most closely related to Schelling, Hegel, and Schopenhauer. To Schelling's first system, the so-called negative philosophy, he refers his idea of the Unconscious, and the construction of matter out of immaterial centres of force; while the second system of the same philosopher, the positive philosophy, serves as the immediate basis of his metaphysics, since it strives to connect the one-sided principle of a rational Idea and the principle of a blind Will, which Hegel and Schopenhauer respectively raised to world realities. Hartmann's indebtedness to Schopenhauer is mainly, as he says, in respect to the philosophy of nature; nevertheless his pessimism, his leaning toward the religion of the Hindus, as well as his conception of the relation in which will and intellect stand to each other, have been strongly determined by this philosopher. Hegel has influenced Hartmann principally by his philosophy of spirit ; by the historical character of his system, which considers all the preliminary stages of knowledge as relatively essential moments of the same; and by his demand for speculative syntheses to reconcile opposite views with each 


\section{PHILOSOPHY OF THE PRESENT}

other. In the method of his research, however, Hartmann thinks that he has followed exclusively the rules and proceedings of induction, as they are used in the modern, natural and historical sciences.

Hartmann himself, accordingly, characterises his system as " a synthesis of Hegel and Schopenhauer, with a decided preponderance of the former, carried on under the guidance of the doctrine of principles from Schelling's positive philosophy, and the idea of the Unconscious from Schelling's first system; the first abstract result of this synthesis is then joined with the individualism of Leibniz and with modern scientific realism and thus fused into a concrete monism, in which the real-phenomenal pluralism has become of less moment, so that the resulting system is established upon an empirical basis by the inductive method of the modern natural and historical sciences." Doubtless Hartmann, through such easily multiplied data concerning the origin of the separate elements of his philosophy and of their relation to other systems, has greatly lightened the task of the future historian.

In his metaphysics, which is the part of his 
philosophy of chief interest to us, Hartmann prepares his way by stating certain epistemological principles, the tendency of which he characterises by the name of transcendental realism. Kant represented the opinion that only phenomena, that is, objects to which the forms of our perception and thinking had contributed an indispensable share, could be known ; but that things-in-themselves, conceived and determined independently of our perception and thought, could not be known. In opposition to this transcendental Idealism, ${ }^{1}$ Hartmann undertakes to show that things-in-themselves, their properties and reciprocal relations, can be considered not only as really existing, but can be known, if only mediately. Phenomena, that is, the contents of our perception, are connected with those realities through transcendent causality, and things-in-themselves are looked upon as causes of phenomena. From this it follows that, to the diversity of objects of perception, there must correspond a diversity of realities producing them; and so we are able not only to posit things-in-themselves, but also to make more exact statements concerning their nature.

${ }^{1}$ Compare p. 138. 


\section{PHILOSOPHY OF THE PRESENT}

As operative, the thing-in-itself must have reality and existence, and, in order to explain a change of phenomena, it must itself be changeable and thus determined in time. At the foundation of its changing being there must be a changeless essence, a substance. Both unity and multiplicity, as well as necessity of action, must be predicated of things-in-themselves. If, as Kant assumed, space and time as forms of perception, together with the primal concepts of the understanding, are first of all subjective, they must at the same time have a transcendent meaning, because otherwise we should be obliged to renounce all knowledge of the real. The essential forms of things and the thought-forms of our intellect agree with each other. But such a harmony between our knowledge and the real objects to which it is directed can only be accounted for by assuming that the same allembracing, all-controlling reason is active in both.

What, then, is the nature of the reality to which we are justified in reasoning from the facts of our experience? Hartmann designates it at the outset as the Unconscious, and by this he understands first the unknown positive 
subject to which the predicate "to be unconscious" belongs. He then institutes a search throughout the realms of nature and of mind for the facts which shall point out to us the significance of the Unconscious. Take, for example, the purposiveness exhibited in the reflex movements of animal organisms, in socalled instinct, or in the healing power of nature ; or, again, the unconscious productivity in thought and in artistic creation; the instinctive attraction of sexual love; the unconscious intellectual activity which manifests itself in the genesis of sense-perception, and many other facts of a similar nature-all these may be cited as material for our knowledge of an unconscious principle. All the processes here mentioned point, as Hartmann thinks, to the law of a transcendent causality, to a universal ground which is called the Unconscious, and which is identified at the same time with the Absolute, the World-cause, and the All-one. Spinoza's Substance, Fichte's Absolute Ego, and other like concepts of earlier philosophers were the dim half-true anticipations of the knowledge of the new world-principle, the Unconscious. Consciousness appears accordingly as secondary, 


\section{PHILOSOPHY OF THE PRESENT}

but in a certain sense it represents a higher stage, inasmuch as "all progress consists in the enlargement and deepening of the sphere unfolded in consciousness."

In the Unconscious, will and representation (or idea, reason, intellect) are bound together in inseparable unity. "What is not represented cannot be willed, and what is not willed cannot be represented." In the latter respect the Unconscious is distinguished from consciousness, in which the emancipation of intellect from will is possible, as Schopenhauer indeed had taught. Now, since will and idea stand in unmistakable antithesis within the Unconscious, but at the same time reciprocally advance each other, they form an absolute unity. Neither through spatial nor other differences can a plurality of being be imputed to the Unconscious.

We must think of the world-process, according to Hartmann, in the following way: The original peace and self-sufficiency of the Absolute, which depends on the undifferentiated unity of will and idea and upon the lack of an activity of the will, is disturbed by the blind rousing of the potential will to volition. The 
origin of the world, the result of this movement, is hence irrational, because it goes back to an unmotived act of the will. But since the Unconscious is not simply will, but also idea or representation, the world, which is its product, must bear in itself the character of the rational. The world as it now is may, therefore, be called the best of all possible worlds. Owing, however, to the disparity between the infinity of the will, which can never be fully satisfied, and the finite contents of the world and its representable nature, there results an unhappiness or pain in the world-principle, in the Unconscious itself. This impels to ever further striving and activity, whose purpose is the escape from pain, that is, the restoration of the original harmony between the will and the idea, or the dissolution of the world. So the whole world-process becomes a purposive development corresponding to the tendencies of the Unconscious.

If now the world-process is the necessary means to the destruction of the world, we must hold it good and desirable, and in spite of the universal pessimism which prevails with regard to the origin and existence of the world, we must cherish an optimistic attitude with refer- 


\section{PHILOSOPHY OF THE PRESENT}

ence to the work of world-development and to our own part therein. So there arises for us the obligation to live and to work for the furthering of consciousness, because this alone can negative the creative will, caught in the stream of endless activity. In other words, we have to regard ourselves as means, in that we take up the purposes of the Unconscious in our conscious end-affirming reason. Every cowardly personal renunciation must therefore be regarded as an immoral method of action. Morality consists rather in nothing else than the working together to shorten the way of suffering and the way of redemption of the Unconscious.

Clearly, blind will, the principle of irrationality, can only be overcome through the growing self-knowledge of the Absolute, through the final mastery of the idea. A very powerful help in attaining this end is the individualising of the Absolute. For the separate individuals, in which the Unconscious objectifies itself, are each to the others simply an idea, that is, a "not will." The control of the logical over the will becomes so much the greater as the individuals are more numerous. The individual, A, for example, is simply an element of will. If we 
add now a second individual, $B$, the number of will-elements is increased by one, while at the same time every individual is an idea for another. With three individuals we have three units of will, and, at the same time, six ideas. In general terms, the number of will-units is to the number of idea-units as $n: n(n-1)$, or, if we include the idea of his own body that each individual has, as $\mathrm{n}: \mathrm{n}^{2}$ And so the Unconscious creates a legion of individuals. The most rudimentary of such simple will-fragments are the "atoms" of natural science, which are to be conceived, according to Hartmann's dynamic views, as individualised discrete forces.

Consciousness arises within an individual mind in this way: the latter is amazed at the sudden emancipation of the idea from its will, as the result of the existence of other individual minds, and seeks to deny it. This wonderment of the will at the rebellion against its recognised mastery, this surprise that the invader of an idea impregnated from without, calls forth, is consciousness. Now the opposing will in the presence of the idea is too weak to carry through its intention of negation. Such an impotent will is associated with unhappiness, and this 


\section{PHILOSOPHY OF THE PRESENT}

appears therefore at every awakening of consciousness as an expression of the anger of the Unconscious at the intruder whom it must endure and cannot displace. But if the selfknowledge of the Absolute has become great enough through the growth of consciousness, then, says Hartmann, the negation of the will appears. The necessary condition for this end is the existence of a universal human culture, whose insight alone makes possible a unified action. If all humanity is impressed by the folly of volition and the misery of existence; if it is filled with a deep longing for peace and for the painlessness of non-being; if the wasting of old age has seized upon all or at any rate the greater part, then, yielding to one simultaneous resolve, as sick, exhausted, and useless cripples, we shall all take leave of existence and plunge ourselves and the world into nothingness.

Such, then, are Hartmann's metaphysical theories. Let us turn now to a short criticism of these views, since it is not practicable, if we remain true to our general plan, to enter upon a more detailed study of his contributions in the field of the special philosophical disciplines, 
although some of them might be well worth our attention. Hartmann himself has called his standpoint monistic, and, in relation to the theory of knowledge, realistic; nevertheless we may still count him among the representatives of modern Idealism, since the reality which he espouses and whose nature he seeks to determine more exactly, is conceived as mental or spiritual reality. The Unconscious is an intimate unity of will and idea, so that we must remember that Hartmann recognises in these functions real forces, which rule and act independently of our knowledge of them, and hence independently of consciousness. Moreover, his method is pronouncedly inductive; from a very large number of facts he seeks to arrive at the most comprehensive conception of a world-theory.

But certainly the method which he employs in his philosophy of the Unconscious is at bottom only apparently induction in the sense of modern empirical science. Perhaps he himself meant to recognise this when, in explaining the special characteristics of his system, he placed in the foreground his relation to the theories of earlier philosophers, and mentioned only at the close 


\section{PHILOSOPHY OF THE PRESENT}

the empirical basis upon which the resulting system was established. Hartmann, the metaphysician, may be regarded rather as a late offshoot of the Absolute Philosophy, a late Hegelian or late follower of Schelling. The strong influence of Hegel and Schelling shows particularly in the way he proceeds in historical discussion. He prefers always the abstractlogical evolution, which treats ideas as magnitudes standing in peculiar relations to each other; always the dialectic-speculative method of careful regard for chronological relations; always the arrangement of historical facts according to the clue given within themselves; always the explanation and motivation of separate modes of intuition according to historical findings. In metaphysics, with Hartmann as with Schelling, the difference between research and speculation, between science and myth is obliterated and misunderstood, while the real meaning of Schelling's positive philosophy is not grasped. ${ }^{1}$ And he uses experience just as Schopenhauer did, as a mere springboard for a flight into the realm of things-in-themselves, and is not dissuaded as to the certainty of his results

1 Compare p. $245 \mathrm{f}$. 


\section{IDEALISM}

by the knowledge that he can deal in his speculations only with hypotheses of greater or less probability. We may, therefore, say that he uses the inductive method, which he asserts to be fundamental, only in a very superficial way. All he has used of it is the empirical point of departure, and the merely probable validity of its results. As for his metaphysical specula. tions on the beginning and end of the world, there is lacking any deliberate connection between them and the special sciences in the form of a generalisation or enlargement of the knowledge and results gained by these. There is sadly lacking, also, any critical safeguarding of the steps of his argument through a careful weighing of all instances. The system of Hartmann, like that of Schopenhauer, may be styled a philosophical romance, a half mythological speculation, like the myths of Plato, rather than an extension and completion of scientific knowledge.

How little the method of Hartmann is to be considered inductive in the sense of the natural sciences can easily be shown by the fundamental idea of his system. Although he repeatedly emphasises the fact that the Unconscious signi- 


\section{PHILOSOPHY OF THE PRESEN'T}

fies something positive, yet the grounds are wholly lacking for the determination and definition of this principle as a coherent worldcause. The examples which Hartmann submits as inductive arguments for his theory are all of them taken from the sphere of vital phenomena. It is, furthermore, not easy to understand what positive meaning the idea of the Unconscious could have when it is not limited to the sphere where alone consciousness has a part. In spite of this scantiness of inductive material, the Unconscious is raised to the Absolute, to the All-one, to a world-principle outright. Perhaps the disparity between the facts supporting this world-theory and the theory itself has some connection with the fact that an epistemological tendency has determined the choice of the concept of the Unconscious. The opposition between the world which appears in consciousness and the world which is independent of consciousness, and therefore in a way "unconscious," has doubtless played a part in Hartmann's metaphysics. In this way the idea of the real, in distinction from the phenomena of consciousness, may have become the Unconscious. 
The argument for the existence of an Unconscious, as the real cause for all phenomena, logically considered, has of course no conclusive force. That which is common to a group of phenomena can be applied only to the constitution of their generic idea; it cannot be used for the determination of their cause. If one wishes to study the common features of a class of phenomena with respect to their causal relations, such a study can lead of course to the demand for a cause for just these common features and nothing more. With the same right, or possibly with a better right, we might, after Hartmann's example, draw the conclusion that time is the universal cosmic principle, following the myth of Chronos, since all phenomena in the world have in common a time-character, and so time could be postulated as the worldcause, and hypostatised. In such an argument the inductive material would be far more complete and comprehensive than that offered by Hartmann in his argument, and the conclusion to a world-cause would be a safer one.

In passing, we wish to call attention to the inconceivability of Hartmann's conception of the end of the world. It is not very consistent 


\section{PHILOSOPHY OF THE PRESENT}

with the principles of modern science, as laid down in the laws of the conservation of matter and energy, nor with Hartmann's own doctrine of "realism," to suppose that the decision of cultivated humanity to destroy itself would result in the annulling of the whole world. In this matter, Schopenhauer, with his idea of the negation of the world, was much better able from his standpoint of transcendental Idealism to protect his argument from obvious objections. However, we place no weight on this difficulty, since Hartmann himself afterwards reckoned with it, when he characterised the end of the world-process as a supernatural act, "in which the world-essence withdraws itself from its former manifestation of will, and with the world of phenomena annuls also its laws and apparent substance (matter)." But this elucidation certainly does not lessen the mythological character of his metaphysics.

Nevertheless, Hartmann has done one service to metaphysics in that he has clearly shown that the reality of consciousness and the reality which we recognise and seek to determine in the real sciences, are two entirely different things. The system stands, therefore, in strik- 
ing opposition to the Immanent Philosophy, to the phenomenalism and Positivism of our day. To be sure, the epistemological foundation of transcendental realism is inadequate, and the application of the principle of transcendent causality, as our earlier arguments have shown,1 misses the real point of departure for the formation of a concept of reality. But Hartmann is without doubt one of the most energetic and clearest defenders of "realism," against the anti-metaphysical tendency common among scientists and philosophers of the present.

\section{WILHELM WUNDT. (Born 1832)}

Wilhelm Wundt took up the work of Fechner and carried it further. $\mathrm{He}$ established, in the year 1879, the first laboratory for experimental psychology, and founded a school, whose scope and scientific activity mark him as the most efficient philosopher and psychologist of the present day. A thorough presentation of his main doctrines may be found in Frommann's Klassiker der Philosophie:-Wilhelm Wundt, seine Philosophie und Psychologie (3rd ed. 1909),

${ }^{1}$ Compare p. 44 f. and p. 104 f. 


\section{PHILOSOPHY OF THE PRESENT}

by E. König; also in Rudolf Eisler's Wilhelm Wundts Philosophie und Psychologie (1902). Wundt's literary contributions reveal an astonishing versatility and productivity. Together with a great number of works in natural science, chiefly of a physiological nature, he has published a large number of philosophical works upon most varied themes. We can mention here only the most important of these:

1. Vorlesungen über die Menschen- und Tierseele (1863, 4th ed. 1906). ${ }^{1}$

2. Grundzüge der physiologischen Psychologie ${ }^{2}$ (1874, 6th ed. in 3 vols. from 1908).

3. Logik (1880-83, 3rd ed. in 3 vols. 1906-8).

4. Ethik (1886, 3rd ed. in 2 vols. 1903). ${ }^{3}$

5. System der Philosophie (1889, 3rd. ed. 1907).

6. Völkerpsychologie. (So far 5 vols., published since 1900, partly in 2nd ed.)

Wundt's ability to familiarise himself thoroughly with all fields of knowledge, and to enrich them all by his ingenious combinations,

${ }^{1}$ Lectures on Human and Animal Psychology, by Wilhelm Wundt. Translated by J. E. Creighton and E. B. Titchener. Swan Sonnenschein \& Co., London.-(TR.)

${ }^{2}$ Principles of Physiological Psychology. Vol. i. Translated by E. B. Titchener. Swan Sonnenschein \& Co., London, 1904.-(Tr.)

${ }^{3}$ Ethics. Translated by E. B. Titchener, J. H. Gulliver, and M. F. Washburn. 3 vols. Swan Sonnenschein \& Co., London.-( $\mathbf{T}$. $)$ 
by his inspiring ideas and researches, and by a rare gift for systematic-architectonic analysis, has made him not only the greatest all-round scholar of our time, but also the most successful representative of those who aim at a mediation between philosophy and the special sciences. In this respect he may be called a modern Aristotle or Leibniz. Wundt, if anyone, has aided in fostering a greater respect for philosophy, its efforts and results, and in restoring a more lively interest to the queen of the sciences in the higher sense of the word. He has not only projected and carried through a comprehensive and detailed system of philosophy, but through exhaustive researches in the sphere of the separate philosophical disciplines, he has also been able to preserve the connection everywhere with the results of the separate sciences. Chronologically also his philosophy is the final step in the series we are here considering. But above all, it is in the writings of $W u n d t$ that we first find the process of approximating and assimilating the methods and results of the natural and mental sciences, brought to a provisional conclusion-a conclusion, indeed, which may for a long time serve as an example. 


\section{PHILOSOPHY OF THE PRESENT}

Philosophy, according to Wundt, is based upon all the separate sciences, and forms a general supplement and completion of them. Its task is to unite into a consistent system the general knowledge contained in these various sciences, and to trace back to their principles the general methods and presuppositions of knowledge used by science in general. Therefore, the division of philosophy is dependent upon the logical arrangement of the separate sciences-that is, upon their system. Without further discussion, we shall give in the following table the main divisions of his general conception of philosophy.

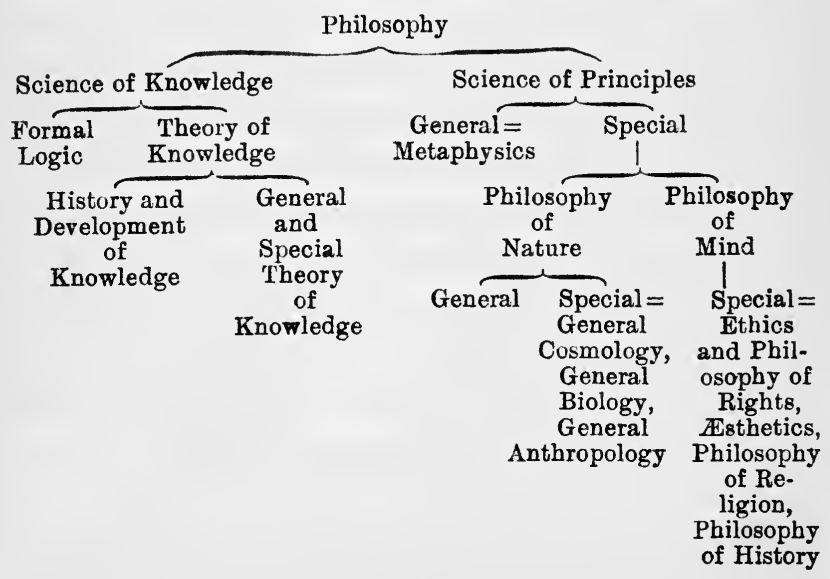


Among these philosophical disciplines, the science of knowledge deals with the origin of the contents of knowledge, with knowledge in the making; while the science of principles deals with the systematic combination of the principles of the contents of knowledge-that is, with completed knowledge. For our purpose we need not consider formal logic, on the one hand, nor the special forms of the science of principles on the other. Our immediate purpose will be rather to give a brief presentation of the epistemology and metaphysics of this philosopher.

Now, according to Wundt, while our thinking in its application has nothing whatever to do with the question as to whether the ideas to which it relates have a real objective significance or not, knowledge, on the contrary, is determined by this relation of thought to a reality of its contents. If we isolate this reality of a thought-content, there arises the idea of experience, which is to be conceived as immediate, so far as it precedes all deliberation, reflection, and logical relation, while the contents of knowledge in which the determinations of our 


\section{PHILOSOPHY OF THE PRESENT}

thought have in any way intervened must be considered as mediate experience. Accordingly, we can classify all of our affective processes, ideas, and voluntary actions as immediate experience. To them, then, we can apply the term 'data of experience.' Among these, ideas first engage the interest of the knowing subject. These ideas, however, are originally not different from the objects of our perception, and can therefore be characterised on account of this unity as 'objects of idea.' The separation of our ideas from the objects to which they refer is a subsequent step, a later result of logical analysis. The elaboration which thought performs on these 'data of experience' cannot, to be sure, destroy their original unity, but can only remove it conceptually. The concepts formed in this way by reflection must never be mistaken for or confused with the original experience. Moreover, the motives which lead to a discrimination in the 'data of experience' must in every individual case be carefully examined, because the value of these motives alone determines whether or not the distinctions made by them have any real significance. 
Among these 'data of experience,' the ideas first of all call for an important and penetrating analysis. These seem to be the elements of our immediate experience, which once for all must be accepted as given. From the ideas we naturally distinguish 'willing' and 'feeling,' as processes which involve a spontaneous activity. Examined more closely, however, our whole inner being seems to have this double nature: "There is no voluntary nor ideational process which is not at the same time both active and passive." The will can always be made the real centre of those relations by virtue of which an ego separates itself from a nonego. The motive for this lies in the constancy with which the will is represented to us as present in consciousness. The feelings and sensations in states of tension and excitement, which are characteristic expressions of the activity of will, are distinguished by a great constancy, and offer, by the gradation of their intensity and quality, a standard by which the objective results of any activity of the will may be measured. But this special relation of the will to the subject is only a secondary process of knowledge, which changes nothing 


\section{PHILOSOPHY OF THE PRESENT}

of the original unity of all 'data of experience.' In reality, subject and object remain inseparably bound together. The separation spoken of, just as every other, can therefore lead only to different thought-determinations of one and the same real fact, not by itself to different facts. Hence the problem of epistemology is not to create objective reality out of elements which in themselves are not as yet objective, but rather the only problem capable of solution, namely, that of preserving objective reality wherever it is present, and of deciding the question of its existence wherever there is any doubt.

If we distinguish now in any given 'object of idea,' between an idea, on the one hand, which is referred to the subject, and, on the other, an object that must be conceptually determined as free as possible from contradiction, then it follows that everything which belongs to the subject can be immediately experienced, is given intuitively. On the other hand, the world of objects, which out of regard for a consistent presentation must do without many attributes assigned to the subject-as, for example, sense-qualities-is consequently given 
to us only conceptually. Even if, however, the mere being of objects, the character of objectivity as such, may be found given in the 'data of experience,' nevertheless the nature of the objects, owing to the corrections which are necessarily made in scientific knowledge, is to be considered only as conceptual and belonging to so-called mediate experience. If we set apart the 'data of experience' relating to the subject for treatment in a scientific psychology and entrust natural science with the task of examining the objects, then, according to what has been said, the world of the psychologist is perceptual and immediately given, while, on the contrary, the world of the investigator in natural science is conceptual and mediately given.

How far, in the conceptual working over of experience, one can and may depart from it cannot be stated concretely off-hand. But among the principles which govern our thinking, we know one which has the possibility in itself of transcending a given content of experience. This principle is that of the connection of our ideas according to cause and effect. Since the content of our experience is 


\section{PHILOSOPHY OF THE PRESENT}

always limited, the universally valid application of the principles of cause and effect must of necessity demand a transcending of given empirical bounds, since we have to seek outside of real experience for the cause and effect appertaining to certain beginnings and termini within our experience. Cause and effect, however, stand in a necessary conceptual relation only when they are conceived as members of one and the same whole. From this the idea can be developed that because of the assumption of such a whole, any change in one member must be bound up with a corresponding change in the other. Therefore, the idea of an unlimited progress, to which the application of that principle forces us, will at the same time carry with it the further idea of a totality of all being, in which all progress is to be conceived as completed.

If we understand by transcendence, a knowledge which leads out beyond the limits of any given experience, then there are, as $W u n d t$ shows, using mathematics as an example, two kinds of transcendence-a quantitative and a qualitative. A quantitative transcendence is present, for example, when the given space- 
idea is extended out beyond the limits empirically established. Such a transcendence has the character of real experience, because in this process the contents of what is given are carried over into the realm beyond the limits of experience. On the other hand, we have a qualitative transcendence when one passes from a distinctive experience, as, for example, from the data given in consciousness, to qualitatively different ones, thereby introducing an imaginary transcendence. In this manner, the former procedure results in the construction of a reality not given in experience; the latter, however, in nothing more than a possibility of thought. Where we have to do with such things as space, time, and the number of objects, a transcendence of the mathematical kind encounters no real difficulties. Qualitative transcendence, however, can at best yield only lasting hypotheses, which, however, serve as a supplement in making of experience a consistent unity. Progression into the transcendent, which in the science of mathematics is of mere formal significance, has to do in metaphysics not only with the form, but also with the content of experience. 


\section{PHILOSOPHY OF THE PRESENT}

Metaphysical problems are three in number -a cosmological, a psychological, and an ontological problem. Transcendence leads in cosmology to the idea of an absolute, indivisible unity, and to the idea of an infinite totality of external experience. This same twofold progression we must carry through in psychological transcendence with regard to inner experience, and in ontological transcendence with regard to the totality of knowledge. In the field of cosmology, the ideas of infinite space and infinite time arise in the form of a quantitative transcendence; while the ideas of unlimited matter and eternal causality appear in the form of a qualitative transcendence. The concept of a quantitatively endless universe divides into two concepts which are necessarily related: namely, the idea of endless progress, and the idea of an infinite totality. The final unity of outward experience finds its expression in the concept of the atom. Empirical science, however, knows only relative atoms. The idea of a final absolutely indivisible element of matter demands absolute singleness, which one can only reach in this field when one limits one's self to a merely formal idea, to a material 
point. This, to be sure, reduces matter itself to a mere 'thing of thought.' Furthermore, in regard to the totality of the world-contents and world-phenomena, our thought wavers between an unlimited and a limited or circumscribed transcendence.

The psychological problem leads likewise to the ideas of an individual unity and a universal totality. In this case, however, the quantitative and qualitative transcendence cannot be separated from each other. "The mental must have some quality." Therefore the psychological concepts become lasting hypotheses, which, apart from the satisfaction that our reason, owing to its love of unity, finds in their formation, have in addition a practical significance, because the questions which refer to the final conditions of our own being have a disproportionately greater value for us than cosmological considerations. All subjective conditions can be referred back to two diametrically opposite states, activity and passivity. All feelings in particular bear this character, and with them, and at the same time because of them, ideas and acts of will. Withal, activity and passivity are reciprocal processes, for 


\section{PHILOSOPHY OF THE PRESENT}

passivity itself is repressed activity, and both are experienced by us successively or simultaneously. Still we always conceive activity as something more immediately characteristic of our ego than passivity, because we refer the latter to objects which affect us, and which thereby hamper us and our activity. If we designate as our will that pure activity which is characteristic of the ego in contrast to the objects affecting it, then we can say: "There is absolutely nothing outside of man, nor in him, which he can call fully and wholly his own, except his will." Thus there remains, as the goal of a transcendent process aiming to arrive at a psychical unity, the pure will.

On the other side, empirical relations of mental unities reveal themselves to us in the form of ever more comprehensive communities of will. The final term of this series can be nothing other than a collective human will, which unites all human nature in the conscious performance of definite will-purposes. Now the idea of such a community is not merely a theoretical construction; it is at the same time a practical ideal. It is not to be doubted " that if any meaning, intelligible to our rational 
minds, is to be given to the whole course of human history, it can only be found in the development of the ideal of humanity. For this, to be sure, the empirical evolution of the totality of mind offers only incomplete beginnings, but nevertheless beginnings from which, on the one hand, the progress of our theoretical rational knowledge can emanate, and to which, on the other hand, all of our practical humanitarian efforts must ultimately refer."

From this point, the approach to the ontological ideas opens before us. For the realisation of this ideal of humanity demands at once an adequate basis in some comprehensive ontological idea. But the real point of departure for the treatment of the ontological problem lies in the fact " that the original 'object of idea' is divisible into its two parts, the object and the idea, to be kept separate from each other, and yet belonging together." As a result of this unity of the 'object of idea,' reflection is directed from the beginning toward a subsequent abrogation of the separation which was effected by it. For this reason, the attempt is made to unite the cosmological and psychological ideas of unity. Such a proceeding is permissible only 


\section{PHILOSOPHY OF THE PRESENT}

on the one condition that the already completed partial transcendences lead out beyond themselves, "whether it be that they demand the postulate of an absolute being different from both contents of experience, or that the one process merges into the other, so that the resultant furnishes the idea of unity which is common to both series." Only the second of these possibilities seems to $W u n d t$ a real solution of the ontological problem. The first would yield an idea wholly indefinite as to content and form, with which one could do nothing. Consequently the world must be conceived by us either as a material or a spiritual unity. Now all idea of objects rests upon an effect which the will experiences; the will is passive when it is acted upon, and it is active when this passive condition stimulates it to ideational activity. But the thing which limits the ego is in itself unknown. We can only conclude from our own experience that whatever occasions passivity must in itself be active. Now since there is absolutely no other activity known to us excepting that of our wills, we can, in every case, refer our own passivity only to another will, and can trace back all phenomena accord- 
ingly to a reciprocal action of different wills. From the reciprocal determination of the individual wills there emerges in consequence the idea. Hence the world can be conceived as the totality of will activity, which through its reciprocal determination-i.e. the ideational activity-arranges itself in an evolution series of will-unities of different compass.

The universal ontological idea of an absolute totality was foreshadowed in the reference to the practical ideal of humanity. Since this presupposes a completed spiritual unity of mankind, an adequate basis for it can in turn be conceived of only as a unit. There is no obstacle to extending this last world-ground beyond the measure demanded by these results, and regarding it as infinite and thereby subordinating to it the idea of the moral human ideal as something only relatively infinite. By reason of this, to be sure, the idea of an absolute world-ground is indeterminable. If we identify it with the idea of God, then metaphysics is not in position to endow it with any concrete content. This gap can only be filled by religious faith, when it takes the content of its idea of God from the moral ideal. God is therefore 


\section{PHILOSOPHY OF THE PRESENT}

conceived of as the World-will, but cosmic evolution is to be thought of as the unfolding of the divine will and activity. To be sure, all rational ideas are indemonstrable, but, as history teaches, they are of an empirical universal validity. Since philosophy seeks to trace them back to the generally valid nature of reason, it discloses the genuine kernel of those ideas, and proves them in themselves to be necessary. "To accomplish more is neither in its purpose nor in its power. In particular it must refrain entirely from showing, in addition to that necessity of the idea, the necessity of a reality corresponding to the idea."

When we compare the metaphysics here briefly presented, with the corresponding teaching of a Fechner, Lotze, or von Hartmann, the great differences in methodology and content cannot escape us. Here experience and the laws of rational thought are the only guiding stars, the only foundation, and the only aids to investigation. Experience supplies the facts, the empirical sciences the provisional results of a systematic examination of these facts, and metaphysics starts from these results in order to carry them further and perfect them from a 
logical point of view. In all this, Wundt abstains from all fantastic analogies, all purely dialectic treatment and interpretation of scientific ideas, all independent encroachment upon the facts worked out by the separate disciplines. Philosophy with him limits itself primarily to a presentation of the presuppositions which form the foundation of the sciences, and to a systematic correlation and final summary of their results. His philosophy is at the same time free from that ontology in which realities are made to correspond without further ado to concepts dialectically deduced, and in which the logically necessary continuity of our knowledge is confused with a necessity of being and occurrence.

This explains that wise reserve which causes Wundt in his metaphysics to avoid all superfluous or baseless speculations and to renounce all specious reasoning which does not agree with strictly scientific method. In his reverence for facts and for the sciences which deal with facts, he is not excelled by any positivist. Although in his specific labours-such, for example, as those in the field of psychology-he exhibits an inclination toward the large comprehensive 


\section{PHILOSOPHY OF THE PRESENT}

things, nevertheless he has lost neither his interest in, nor his appreciation for the small and modest advances which are made in ordinary research in the field of empirical knowledge. And yet, at the same time, Idealism, with its transcendent realities of spiritual life, receives at his hands a complete and undiminished vindication. Will and Idea are the ultimate elements of all reality ; spiritual communities are the final goal of all evolution; while in the establishing of this goal, and in making the assumption of a divine being which vouches for its realisation and makes it possible, ethical motives have been of essential moment.

But although Wundt's philosophical system is so grandly planned and so rich in original applications, although he has turned to account most completely and carefully the inheritance of the modern special sciences, and although he has appreciated most fully the value of a philosophy directed toward the sum total of a unified world-theory, nevertheless his system forces upon us certain questions, a few of which we must now consider.

Idealism, as we have seen, is characterised in general by the fact that it uses self-know- 
ledge, the essence of the knowing mind, as the key with which to unlock the world-secret. Although this principle in itself may arouse opposition, we must not stop here to establish its validity, depending as it does upon somewhat involved arguments, incapable of brief formulation. In the general critique of Idealism at the close of this section, we shall make some statements with reference to it. But in this connection we wish simply to raise the question, whether Wundt, with his belief that the will expresses our being most exactly, and that the world, therefore, consists of will-units, has discovered the most probable solution of the world-riddle among all theories of qualitative transcendence. There are certain critical considerations which, as it seems to us, make the affirmation of this question doubtful.

First, let us point out that our study of mental life has revealed to us a large number of elementary contents none of which can be traced back to other contents, any more than all can be considered manifolds of a single elementary phenomenon. Red cannot be reduced to blue, heat to cold, pleasure to pain; nor does the claim that they are all combinations of 


\section{PHILOSOPHY OF THE PRESENT}

simpler homogeneous elements rest upon any better ground. A metaphysics, therefore, which in connection with scientific psychology seeks to establish the nature of the soul, has no occasion for positing an ultimate element of all soul life, following, for instance, the example of natural philosophy. We are of the opinion, therefore, that on this point there is no parallelism of method between the cosmological and psychological problems, and that the essence of individual personality on its mental side cannot be grasped when we try to discover or assume such a problematical unity. The problem of the psychic ego, as experience reveals it to us, and as scientific psychology elaborates it with all the aids of detailed research, is rather the problem of the unified connection of the coexistence and succession of a great manifold of elementary processes differing among themselves. There exists, therefore, so far as we can see, no necessity for considering one element as more fundamental than another.

The difficulty of the position becomes more apparent as soon as we make clear to ourselves the result of Wundt's attempt at transcendence in the matter of a final psychic unity. For 
the chief difficulty with his theory of individual activity of the will lies in the fact that it does not explain the empirical manifoldness of psychic processes. The activity of every will-initself, he says, is pure volition, but through the reciprocal action of different wills, it becomes real or ideational volition. Just how from the reciprocal action of pure wills, ideas may arise it is difficult to see, and up to this time scientific psychological analysis has not made the assumption probable, nor has it made clear how such pure activity of will taken alone by itself could exist anyway. When, in general, we characterise our inner states as an opposition of activity and passivity, then we have, by the use of two abstract concepts, whose applicability reaches out far beyond the psychic sphere, defined them from one point of view only, and we must not forget that our mental life shows other sides, which can likewise through abstraction be made objects of special consideration and be made generally applicable by corresponding generalisation. It seems to us that by no logical procedure can we pass from such an abstraction to the demand for an actus purus which would be "the inmost being of the 


\section{PHILOSOPHY OF THE PRESENT}

individual subject," and indeed of all things in general.

To be sure, it is really to further my understanding and evaluation of myself, that I regard myself not simply as a link in a chain of mechanical events, but as self-active, having power to influence the course of events, hindering or helping, hastening or retarding, increasing or diminishing. Moreover, my share in the world of events depends upon my talents, upon my whole past and my whole course of development, all of which, as compared with the casual grounds determining my actions, take precedence and can assert their authority. But the activity which I develop by reason of these conditions results from an innumerable and quite incalculable variety of factors. I am a cause of changes in the world, not as pure will, but as an indeterminable multiplicity of capacities for action, each of which has its own law and history. Here, then, we are once more led to look upon the individual as an independent complex of conditions, no matter how complicated, and for that reason to regard unity in multiplicity as the real problem of the psychic ego.

Finally, let us point out in Wundt's meta- 
physics a difficulty in regard to the oft-mentioned problem of reality. The point of departure for investigation in epistemology is the idea that our immediate experiences-that is to say, the ' data of experience' - are simply a given reality which, in spite of all the determinations of thought practised upon it, cannot be set aside, divided, or otherwise changed. Therefore, let scientific and psychological reflection speak, if it will, of an object and of subjective conditions - as a matter of fact both are inseparably connected with each other. For that reason, the problem of epistemology is not to create objective reality, but rather to preserve it where it is present, and to come to a decision in doubtful cases. Therefore, all reflection should from the beginning be directed to the elimination of the division into object and subject which is practised upon the original unity of the 'object of idea.' Therein lies the real point of departure for the treatment of the ontological problem.

One asks himself involuntarily after the above discussion of Wundt, What then exactly is reality? Positive and metaphysical tendencies clearly conflict with each other here. It corre- 


\section{PHILOSOPHY OF THE PRESENT}

sponds to Mach's standpoint, when the reality of the original experience is emphasised, and only a secoudary significance is given to the thoughtdeterminations. But in that case every metaphysics, especially a metaphysical transcendence, would have to be excluded, or entrusted with the merely negative task of unmasking all realities created by thought as mere shams, as more or less purposive expedients and the like. On the other hand, Wundt is evidently endeavouring, in opposition to Mach, to seek reality, and is not willing to stop with the original actuality of the 'object of idea.' The doctrine of the units of will, standing in reciprocal relation to one another, can in no way be regarded as simply a renewal of that which the data of experience in themselves are and signify prior to all reflection. It is, therefore, not quite clear in $W u n d t$ just what relation the reality, unreservedly granted to experience, to 'objects of idea,' has to the reality of objects of thought, or thought-things, which is established by the rational working over of the facts of experience. It cannot be that there are two such realities existing side by side, in so far as they relate to the same empirical matter of fact. Either only 
that which is empirically found in experience is real-if so, then plainly all metaphysical creation and aspiration are futile; or, our thought has the power to posit and to determine realitiesif so, then experience, even if it is the point of departure and guide to research, is in itself unreal. In any case, it becomes apparent that it is again the problem of reality that deserves a penetrating study, before we shall be able, after the manner of idealistic metaphysics working in connection with the existing reality of consciousness, and in connection with the real sciences, to establish the true nature of the world.

The metaphysics of Wundt is certainly to be regarded as the most imposing, most systematically matured form of Idealism of the present time, and conforms most nearly in method and content to scientific demands. His System der Philosophie, with its pure and natural style, is therefore to be most highly recommended for study to those who wish to obtain a deeper insight into the nature and tendency of modern philosophy. One's esteem and admiration for this work and its author are not diminished by one's many doubts about the correctness or 


\section{PHILOSOPHY OF THE PRESENT}

probability of this or that assertion or hypothesis, no matter how fundamental these may be. Should only Kantians be able to esteem and recognise a Kant, or Herbartians a Herbart, in his greatness and significance? Contact with the special sciences in their totality, which is characteristic of the development and peculiarity of the philosophy of the present, has reached, at least in Germany, its greatest scope and intimacy in Wundt. In this respect, only Comte and Spencer can be really compared with him. But the former is not to be considered in this discussion, since he belongs to an earlier period, and Spencer, guided as he was by a one-sided scheme of philosophical disciplines in which the mental sciences did not come into their rights, performed a corresponding service only in biology and sociology. Eduard von Hartmann, however, who might come into consideration in this connection, never himself engaged in research in the sphere of the special sciences, and so lacks that close relation to them which in Wundt meets us at every step, and which betrays not only the man who knows, but the independent seeker and discriminating scholar. Therefore, he seems to us to deserve most of all 
the title of " a modern Leibniz," for to him as to the earlier philosopher no human knowledge is foreign, and he, like Leibniz, strives after a theory of the world which shall give full weight to the claims of both the formal and the real sciences. Wundt also arrives at a monado-logical system, although, to be sure, he substitutes units of will for units of perception, and has changed a scale of monads quietly resting side by side into an actual community and reciprocal determination of creative beings.

Aristotle placed the dianoëtic virtue, directed to insight and knowledge, above the ethical, devoted to action and behaviour. Later, Spinoza found in the intellectual love of God, which is the epitome of all wisdom, and in adequate knowledge, which rightly interprets and utilises the phenomena of the world, the content and basis for an existence worthy of mankind, and for a "human freedom" unaffected by all the sad and confusing influences of blind passions. Similarly, Wundt in his ethics has characterised the creation of spiritual goods and values as the highest task of the aspiring will. In so doing, he goes beyond the purely personal activity of intellect satisfying to each individual 


\section{PHILOSOPHY OF THE PRESENT}

as such, and arrives at an objective teleological conception which presupposes the community and is planned to meet its demands. Here, as everywhere else, he has endeavoured to emphasise the social forces of the state, of society, and of humanity as of surpassing significance in comparison with the doings and dealings, the hopes and wishes, of the individual. In this very point $W$ undt echoes the traditions of the post-Kantian Idealism of a Hegel, and, we may venture to add, he has in high measure justified this ideal.

\section{GENERAL CRITIQUE OF IDEALISM}

Concerning Idealism in general, it remains to present the following considerations. Idealism tends to the view that a knowledge of the mental is, by virtue of inner experience, easier, safer, and more profound than a knowledge of the outer world through the medium of so-called outward experience. According to Kant's opposition of outer and inner sense, both are equally easy or difficult, possible or impossible. The inner being of the mind could be as little known, he taught, as that of things outside 
ourselves. In both cases we have to do with phenomena in which factors of our knowing, perceiving, and thinking mind are always in some way present. Just how the ego and the non-ego are independent of these factors is not determinable. But Schopenhauer believed that he had an entirely different and more immediate way of approach to his own inner being than he had to the outer world. The latter can be known only through the medium of the idea, but we know ourselves as willing immediately by an act of pure intuition. Similarly Beneke declared that our inner experience is absolutely and completely trustworthy ; we experience ourselves as we are. According to him, then, the opposition of phenomenon and thing-in-itself has no significance.

Some modern psychologists, and among them Wundt, hold similar views. Wundt characterises consciousness as the sum-total of what we experience, and sets psychology the task of comprehending psychical processes as they are. In regard to content, consciousness coincides exactly with mental facts. To experience a psychic state, and to have a consciousness of it, are therefore the same thing. Psychology will 


\section{PHILOSOPHY OF THE PRESENT}

be diverted from its real task, if that which is given in consciousness is conceived as nothing more than a phenomenal expression of a being different from this expression. Similar also is the view of Brentano, another influential psychologist of the present. He ascribes to inner perception, when directed toward psychic phenomena, a trustworthiness which is lacking to outer perception when directed to physical phenomena. But this trustworthiness belongs to inner perception for the reason that it coincides with its object. Therefore, to perceive a psychic process and to have it are again one and the same thing. In striking contrast to this prevalent view, we read in Nietzsche, "I hold firmly also to the phenomenal character of the inner world: all that is known to us is first completely arranged, simplified, schematised, and interpreted."

The fact is that this view must be considerably restricted, if we wish to present the true facts. First of all, it is clear that the alleged superiority of our knowledge of the psychical is true only when the knowing subject and the object of knowledge belong to the same individual. Only a subject, $A$, who is sad over 
some disappointment or other unhappy event, can say of his experiences that they are absolutely as he conceives them or as he knows them. To every other individual this statement is completely denied-that is to say, in so far as the psychic processes of the other are concerned. If the one who knows and the phenomenon known are not of the same subject, then the one has no immediate knowledge of the psychic processes of the other, but, as is generally understood, only a mediate knowledge obtained by the interpretation of expressions, words, and the like. Since psychology is not based, and cannot be based, upon the consciousness of the psychologist alone, therefore, it is often able to apprehend that which is 'given' as a mere phenomenon of an existence which is different from it. Now this is true in so far as the mental life of others is nothing else than a form of being different from the perception or opinion of myself, the psychologist. Scientific psychology makes no essential difference between the mental life of the knowing subject and that of his fellow-man; it is indeed justly proud of that participation or community in its work and research, by virtue of which the mental 


\section{PHILOSOPHY OF THE PRESEN'T}

life of others is not very differently valued from that which is found in the psychologist's own consciousness.

Furthermore, this claim concerning the selfcertainty of inner experience can have reference only to the experiences immediately present. Every psychic phenomenon of the past is known only by means of memories or other representative acts. That I stood yesterday in this place, spoke, observed, and thought_-of these facts I have no immediate knowledge ; that is to say, the contents of consciousness at that time are not the present ones. Now psychology has no scruples in making use of such remembered psychic phenomena, of which it is evident that the coincidence of the object and the knowledge of it cannot be affirmed. In every collection of observations extending over a certain period of time, in every statement of general uniform relations, in every formation of class-concepts reaching out beyond the single phenomenon just experienced, in every methodically conducted research, earlier experiences are taken with present ones without thought of any fundamental differences, and are treated as of equal value. A psychology which did 
not proceed in this manner would soon end in ridiculous self-limitation. For the scope of the contents which may be experienced in an act of consciousness is exceptionally small. Scientific psychology is, therefore, compelled to go far beyond the circle of immediate experience, if it wishes to gain a knowledge of psychic life which shall be at all complete.

But even in the case of experiences immediately present, the unity of consciousness with its object cannot be asserted without restrictions. For example, facts such as justobservable sensations and just-observable differences between sensations indicate that there are sensations and differences of sensations which we do not notice, of which we know nothing. If we let a visual impression of a somewhat complex nature act upon the eye of an attentive observer for a period of time not of sufficient length to mark all of its peculiarities, then the observer is unable to give an account of all that he has seen. A good example of this is that of letters thus displayed; the observer can tell their number, to be sure, and even name a few of them according to their phonetic nature, but he has no idea 


\section{PHILOSOPHY OF THE PRESENT}

of their colour. Since it is evident that he has seen all the letters coloured, his consciousness, which is able to give no account of their colourcontent, must certainly be called inadequate. In the face of this fact, if one should persist in the view that the psychical processes are identical with that which is given in consciousness, then one would arrive at the absurd conclusion, that under certain circumstances visual sensations are present which have no quality, are neither white nor black, red nor green, \&c.

These facts, which have been established by experimental investigation of mental life, could easily be multiplied. The examples given will suffice, however, to show to what extent the assertion, that the psychic is what we meet with in consciousness, needs limitation and modification. Nor is it difficult to explain how this comes about. Consciousness, inner perception, self-observation, are, according to the views of modern psychology, to be traced back to the combining of earlier experience with new psychic excitations. This uniting process has been called, since the time of Herbart, apperception. To perceive a psychic process, to have a consciousness of it, and to apperceive 
it, are accordingly synonymous expressions or equivalent concepts. We cannot ascertain immediately what sort of a process it would be if it were not apperceived-that is, if no earlier experiences, voluntarily or involuntarily, spontaneously or on demand, came forward to meet it and prepare a welcome for it. This can be learned only indirectly by the aid of special scientific research. It is evident, then, that psychic phenomena are not as we experience or know them, because apperception in an a priori incalculable form modifies them, or, as Nietzsche says, "simplifies" and "arranges" them.

From all these considerations, it follows that psychology as a science is not in its broad scope a knowledge of what is given in consciousness. The establishing of facts, the knowledge of their uniformity, the explanatory theories, indicate on every side the insufficiency of consciousness. It is precisely this that we have in mind when we say that self-perception or self-observation is neither the richest nor the purest source of psychological knowledge, and that it needs supplementing and critical sifting. How far psychologists may or should 


\section{PHILOSOPHY OF THE PRESENT}

deviate from original experience cannot be determined a priori. Perhaps the qualitative existence of separate phenomena, such as red, pleasure, \&c., is something unchangeable, independent of apperception. If we survey, however, the development of modern psycho$\log y$, we discover, even in the field of simple qualities, progress in analysis, which can only be understood as progress in scientific knowledge. How, then, can one hope to establish limits universally valid, and not simply provisional, within which consciousness or inner perception, mediates an adequate knowledge of the psychic phenomena to be observed? Rather must we reckon with the possibility that these phenomena are qualitatively different from the form in which they present themselves to us in consciousness. The materialist gives expression to this possibility, when he calls our psychic life a brain function concerning which inner perception tells us nothing. Metaphysicians, again, like Herbart and Leibniz, Spinoza and Wundt, have substituted for phenomena of consciousness psychic realities which differ essentially from them. In particular, a qualitative transcendence, such as 
Wundt undertakes in his treatment of the psychological problem, could only be justified on principle from the standpoint here taken.

Clearly, inner perception, as to its claim to trustworthiness, is in a bad way. In the first place, the mere 'being given' is as such neither certain nor uncertain, neither reliable nor unreliable. ${ }^{1}$ If we judge on the basis of our 'data of experience,' if we announce what is found in consciousness, such testimony must always show by research, and in the face of it, what our final judgment shall be concerning it. Of course psychology, as an empirical science, everywhere depends upon this testimony, but if it proceeds cautiously, it never accepts this testimony as pure and unconditionally valid knowledge without proof. The experimental method has shown, among other things, that we may question the testimony of some observers, without questioning their subjective reliability or their honesty. Under exactly identical conditions of observation, the conclusions of one investigator may be meagre and incomplete, or wavering and contradictory; while those of another may be rich and

${ }^{1}$ Compare pp. 48 and 49. 


\section{PHILOSOPHY OF THE PRESENT}

complete, reliable and consistent. When we take such distinctions into account, and give preference to the conclusions of the second observer, in so far as it is not practicable to determine more closely the individual nature of the former, it means clearly nothing else than that we doubt the validity of the evidence from inner perception as such. The best possible observers are not always reliable. Their reports change according to mood and disposition, practice and fatigue, interest and preparation. Even in very simple matters, such as the comparison of sense impressions, how uncertain are the judgments of the observers! Only in very rough determinations, when we are not seeking final and decisive results, is inner perception a wholly safe guide.

Since self-perception is of scientific value only when properly reproduced, characterised, and described, so the testimony as to what is experienced forms the immediate foundation of psychological research. Now, there exists not only a disparity between the subjective certainty of the person giving testimony about his inner states and processes, and his objective reliability, which is ascertainable by an exact 
control of his conclusions through experimental proof, but furthermore, the relation between his experience and his testimony is not simple and immediate. The arbitrary symbols of speech used in description have no similarity with the conscious contents described. They are frequently insufficient to make possible an entirely fitting report; they may be inadequate, and there often cling to them different meanings, which cause misunderstanding or uncertainty in the interpretation of what is meant. Those contents which attract the attention are made unduly prominent; while that which goes on in the background of consciousness is generally omitted in the testimony of the experiencing subject. Psychological knowledge and preconceived opinions, the desire to find and report as much as possible in the experiment, have a determining influence on the testimony of the subject.

It is necessary, therefore, that psychological method shall be rather complicated and refined, in order that it may avoid the pitfalls so dangerous to the unskilled, and that it may disclose the psychical in its real nature and uniformity. It is for this reason that the experimenter collects observations and strikes 


\section{PHILOSOPHY OF THE PRESENT}

averages, and uses unexpected methods not known to the observer; it is for this reason that he struggles against the influences of expectation and surprise, which as experience teaches modify our consciousness of psychic phenomena. All this would be to no purpose, if every act of inner perception were absolutely evident and infallible, if the host of constant and accidental factors in such observations were not able to bring disaster and failure. Modern psychology, which aims to become a science having the same general validity as natural science, approximates to this goal because it divests inner as well as outer perception of a supposedly self-evident trustworthiness. 'The true task of psychology, as of every real science, is knowledge, which is on the one hand under the law of accuracy - that is, agreement with facts, and on the other hand under the law of truth-that is, freedom from contradiction in our thoughts. Neither accuracy nor truth, however, is assured in simple experience nor in the mere fact of being given in consciousness.

It might indeed be well, with the aid of modern psychological science, to revive Kant's doctrine of the inner sense (now, of course, old- 
fashioned and inadequate as to its form), which presents to us only phenomena, not the egoin-itself. The complete knowledge of psychic reality forms, then, the ideal goal of psychological science-a goal, to be sure, lying in infinity, exactly as the complete knowledge of physical reality forms such a goal for natural science.

We can thereby judge whether Idealism has a right to determine total reality after the analogy of the supposedly better known mental life. The immediate and undiscriminated experience, however, which fills our consciousness previous to all reflection, is neither physical nor psychical, and nothing real at all, although, to be sure, it suggests both realities, and forms the point of departure and material for the investigation of both. Not with regard to the unity of immediate experience, but in answer to the demand for a unified world-theory, metaphysics will have to pursue the paths of natural science and of psychology, and bring these into connection with one another through the numerous reciprocal relations yielded by these disciplines. Whether such a metaphysics will have an idealistic character, however, cannot of course be finally determined in this connection. 


\section{VI \\ CONCLUSION}

WE have presented the four main schools of philosophy in Germany at the present timePositivism, Materialism, Naturalism, and Idealism-and have allowed them to give an account of themselves through a few typical representatives. Of these, Positivism and Idealism have been considered more in detail. These two schools, moreover, occupy the foreground of the present philosophical movement, and are on good terms with each other so long and in so far as the anti-metaphysical tendency of Positivism is left out of the question. Both are, and seek to be, scientific philosophy, which stands fundamentally opposed to arbitrary speculation rooted in free pure thinking alone.

Such, indeed, in our opinion, will be the philosophy of the future. Only such a philosophy will be able to satisfy the demands which we have sketched in our Introduction, 
and be able to extend the light of knowledge and to increase the power of its rays, so as to dispel the darkness of ignorance. Only such a philosophy is secure from the danger of becoming an ignis fatuus or a careless torch-bearer which shall lead us upon the shoals. Such a philosophy is not promoted by servile adherence to authorities and leaders of schools, but only by subjecting every brilliant fancy, no matter how happy it may appear, to strict investigation and independent thought. I have not, therefore, considered it my task to determine and fix the opinion of my readers, but to make a survey of the present lively and noteworthy activity in philosophical fields, and in this way to encourage independent judgment and selection.

In general, the course of development of German philosophy reveals the gradual unfolding of two fundamentally opposite views. Originally, with Leibniz and his school, the belief prevailed that reality, the essence of all things, could only be comprehended and determined by the aid of reason or of thought, while experience is merely of subordinate significance. Sense-perception can give us no adequate knowledge of the world as it really 


\section{PHILOSOPHY OF THE PRESENT}

is, and beyond the region of its applicability thought alone can give us information. God's existence and nature, as well as the view that the world is made up of monads which are furnished with the faculty of perception, are deduced by Leibniz by an essentially conceptual method, by means of ontological speculations. In this he believed firmly that the freedom from contradiction in a concept or judgment is in itself sufficient to guarantee existence or reality to the conceptual content. Possibility and reality differ from each other only as two ideas of which the one is more general, the other more specific, much as the ideas "living being" and "man." Thus it is only necessary to add the attribute of reality to a concept in order to endow its content with existence. But this attribute can be given at any time as soon as freedom from contradiction in the concept allows it. In this way, metaphysics becomes an activity of pure thought, a sister science to mathematics. In its a priori realm it is not disturbed by the claims and encroachments of experience, and the distinction of "formal" and "real" is set aside.

Such a trust in the power of reason inspired 
even the philosophers of ancient and mediæval times. It was not the Eleatics alone who indulged in conceptual reflections and repudiated the senses as deceptive and inadequate. Other philosophers of a wholly different school, such as the founders of the atomic theory, depended ultimately upon thought in their attempt to explain the structure and functions of the world. Democritus expressly characterised senseperception as obscure knowledge, and in opposition to it lauded the results gained by the understanding as true knowledge. It remained for the later philosophers, who were no longer sufficiently interested in the theory, to obscure by their inconsequence the real facts, which indicate clearly the close relation between metaphysics and rationalism. When, for example, in the eighteenth century, Lamettrie, one of the leading representatives of those who held materialistic conceptions of the universe, declared: Le sens . . . voild mes philosophes, and held the psychic life to be a function of the brain, this was a plain contradiction. The senses certainly do not teach us this theory, if it is a theory. So almost all philosophers, up to the beginning of the eighteenth century, have given the highest 


\section{PHILOSOPHY OF THE PRESENT}

place to thought, and have recognised that a metaphysics, or the discovery of realities which do not coincide with "what is given in experience," is achievable only on rationalistic lines by the aid of thought.

Even the more modern natural science of a Galileo and Newton shared this view. When they stripped the outer world of colours, tones, pressures, \&c.-in short, of sense qualities in general-and gave to bodies only the attributes of space and time and dynamic attributes, they made of outward reality a world no longer immediately given in experience but comprehensible only in thought. Matter and its atoms, energy and the chemical elements, ether and the vibrations of the air, are all 'things of thought,' not elements of what is experienced. So we see that their view also rests upon the rationalistic presupposition that in all matters of knowledge, reason has the final word, and that we must think of a real world beyond the bounds of our perception, of our experience. Even if the natural scientists managed as a rule to avoid pure $a$ priori construction, such as that of Leibniz, nevertheless, in their acceptance of real things of thought, they were, like him, filled 
with a sense of the superiority of the understanding over mere sense-perception.

But at the present time a quite opposite conception has arisen and obtained a relatively wide acceptance. According to this, the immediate experience of the knowing individual is his only reality, and the activity of thought is reduced to a more or less purposive auxiliary function, having a certain "economic" value in making 'what is given' intelligible. Every concept has its significance only in so far as it serves this purpose: it is not an indication of reality. Atom, mass, energy, are figures, symbols, and signs, which can be used in so far as they represent reality to us, and in so far as they make reality more easily understood; but to attribute existence to them, and to substitute for the visible world of sense a real world of this kind, is a naive unwarranted procedure, and indeed has been a hindrance to the progress of science. Science is nothing more than a simple complete picture of experience, of which one need only ask what outlines and shadings are necessary and sufficient to make the picture a true reproduction. We have had a good illustration of this view in the case of 


\section{PHILOSOPHY OF THE PRESENT}

Mach, but we find also that philosophers like Avenarius and Wundt incline to it also. With the latter we have seen the influence of this standpoint become a criterion for the evaluation of the 'data of experience,' 'the objects of idea.' We have found that, as a result, a certain inconsistency appeared in his arguments. ${ }^{1}$

Leibniz attributed to all thought, in so far as it takes place without contradiction, a real significance, an objective validity. According to this modern doctrine, on the contrary, all thought is merely formal. In both cases the difference between mathematics and metaphysics ceases to exist, but in the first case mathematics becomes metaphysics, while in the second, vice versa, metaphysics becomes mathematics. There, figures and space forms have become significant attributes of reality, or at least phenomena bene, that is, realiter fundata; here, all realities have become concepts, symbols, numbers, among which no higher law rules than the elegance and certainty of mathematical operations. There, all that is purely formal ceases; here, all that is real vanishes.

This second conception of philosophy does 1 Compare p. 218 f. 
not follow immediately upon the other. Kant with his illustrious work stands most conspicuously between them. According to him, thought has a real significance only together with and in experience, and there is, therefore, in this sense only an empirical reality. Beyond experience, thought can accomplish nothing further, except to set up the absolutely empty and indefinite concept of the thing-in-itself, a wholly unknowable reality, which is useful as a limiting idea to curb the presumption of sense-perception. As a matter of fact, perception is and remains a necessary ingredient of all knowledge of reality, but we must realise that this limitation is actual and not grounded in reality itself. If, for instance, there were an intellectual intuition by which thought could gain immediate access to the world, then a knowledge of things-inthemselves would be possible. But this is denied to us because of a lack in our mental make-up, because of the organisation of our knowing mind.

In this way Kant sought to do justice to the claims of both experience and thought. To pure thought, which Leibniz had entrusted with such noteworthy powers, nothing remained 


\section{PHILOSOPHY OF THE PRESENT}

but the recognition of the thing-in-itself. On the other hand, however, Kant was far from recognising immediate experience, or senseperception, as a pure reality; he insisted rather that all thought-determination which had to do with experience belonged necessarily to empirical reality. The known and the knowable world are composed of both factors. Then Hegel, with this as a basis, undertook the construction of a grand system of empirical reality, by showing the rational in all that is real, and the real in all that is rational. In his panlogism all phenomena of the empirically-given world had found a place; in his panempiricism all categories and laws of thought had received their correlate in reality. The method of thought movement was at the same time recognised as the real process of development, the necessity of an advance from concept to concept became a real necessity of transition from stage to stage. Thus in principle, reason and experience became of equal scope and of equal value. Pure being became just as much an empty limiting concept as pure thought. In principle the old struggle between rationalism and empiricism seemed thereby to have been terminated; in reality, 
however, the line which separates formal thought and thought which posits and defines the real was only once more wiped out. An $a$ priori scheme, which called itself the dialectic method, although indeed it was handled with great skill, served as an all-too-willing tool by means of which to stamp reality with the mark of reason.

In the belief that reality is richer and contains something more than our thinking, which generalises so easily and classifies so mechanically, we find the cause of the gradual rise of modern empiricism. Schleiermacher, and Schelling in his positive philosophy, admit that definite limits are set to our constructive thinking. Personality and individuality are not capable of conceptual derivation; they remain a secret which must be experienced. The dialectic process halts in the presence of such final facts. To this view of Schleiermacher we find a parallel in the later doctrine of Schelling, according to which our thinking can show only that which is possible but not that which is real. All construction, therefore, leads only to a negative philosophy, which waives the question as to whether there is a reality corresponding to 


\section{PHILOSOPHY OF THE PRESENT}

its deductions. It can only say, if there is a reality it must and will take this form; but it is unable to prove existence. Thus the new standpoint appears, which limits thought to the portrayal of given experience and which recognises experience as an absolute reality to which no other can be opposed. So one extreme replaces the other.

In our opinion we have in this way merely exchanged one untenable position for another. Certain it is that thought which follows solely its own laws, the laws of formal logic, is not forthwith to be recognised as able to establish and determine realities, or to be considered as objectively valid thought. But it is equally certain that immediate experience, in its unpurified, untested actuality, is not the reality with which we have to abide once for all. Even though a final theory concerning the existence and nature of reality still lies far afield, nevertheless the real sciences may make the approach to this goal a part of their programme and their work. But the task of investigating how far and with what right thought-things shall be considered valid as realities will be the chief problem of a theory of 
knowledge which will oppose a naïve metaphysics on the one hand and a radical antimetaphysical tendency on the other. A renewal and revival of Rationalism is of course involved in this, in so far as we grant to thought the ability and authority to establish and determine realities.

In spite of its frequent reappearances, it is generally believed to-day that rationalism has in principle been disposed of by Kant and the positivists. Concepts without perceptions are empty, taught the Königsberg scholar. But with his elastic idea of possible experience whose scope extends far beyond that of the real, Kant won for his theory of knowledge the assumption of thinkable realities to which in perception no real facts correspond. Of living beings on another planet, we plainly have no real experience; but if certain conditions of observation were fulfilled, we could gain a knowledge of them as well as of those who surround us. They belong, therefore, to the realm of possible experience, and it is easy to see that, with the help of this concept, an opening is made for a certain kind of rationalism. The real opponent of rationalism is therefore 


\section{PHILOSOPHY OF THE PRESENT}

not Kant, of whose inclination in this direction other instances could be cited, but rather Positivism, like that of Mach, which sees in the reality of immediate experience all the objectivity of real scientific knowledge. 'The new rationalism cannot therefore avoid a direct conflict with this school, whose position we may call the standpoint of reality.

In the struggle against this standpoint the neo-rationalism can fall back upon two incontestible facts. These are the affirmation and determination of the mental life of others, and of historical reality. The mental life of others, and historical personages and events, are supersensuous values entirely outside of experience. If the concept of possible experience has any distinct meaning at all, it must here find its limits. Psychology and every branch of historical science completely lose their meaning if we interpret these facts in the spirit of the standpoint of reality. They necessarily lead out beyond this standpoint and demand a more positive evaluation of thought and its results. The mental life of others is thinkable and can be constructed, but it can never become the content of my experience. 
In the same way historical reality can be constructed from reports and other evidence, and can therefore be established in and by thought; but as surely as time does not turn backward, so surely can historical reality never become an object of perception or of immediate experience. A theory of knowledge which sets out to understand the presuppositions of the special sciences and not to master and mould them, will have to keep these facts in mind.

With this the new rationalism at once clears the way for metaphysics as a science, and for an inductive completion of real scientific knowledge. In the sixth decade of the nineteenth century, philosophy, in order to free itself from a metaphysics which had led it astray, raised the cry: Back to Kant! But after Kant, followed Fichte, and then Schelling and Hegel. It was thought, therefore, that neo-Fichteanism must follow neo-Kantianism, and at present voices are loud in demanding a neo-Schellingism and a neo-Hegelianism. But, on the contrary, the opinion might just as well be held that it is a question of returning to still older views; we ought to go back to the pre-Kantian philosophers, and take up the traditions of the great 


\section{PHILOSOPHY OF THE PRESENT}

metaphysicians of the seventeenth century, Descartes, Spinoza, and Leibniz. Cleansed by a critical purgatory, and supported by the modern special sciences, we should again enter upon the golden age of ideas. But of course the naiveté of those speculations is for ever past. If they are revived now, we must win our right to them. The whole development of the Berkeley-Hume-Kant philosophy down to modern Positivism must be surmounted in order that metaphysics may celebrate its resurrection in and above the sciences of reality.

We have no wish to ignore or set aside the incisive and indeed just critique of the old metaphysics. We must rather adopt it and transcend it. Its well-grounded motives, its relative truth, should be taken over into the new standpoint; while at the same time the absolute significance of the critique must be questioned. With full consciousness of the infinite goal of science and the temporal limits of our existence ; in careful employment of thought dedicated to attainable tasks, we must venture out again into those waters of which Kant so impressively warned us, since banks of mist and icebergs may be mistaken for new lands. 
The gate of metaphysics does not open to him who seeks to surprise the garrison by "insight," "intellectual intuition," and other mysticism; but only to him who in open, honourable struggle seizes and holds the causeway. Spinoza once said: A passion can only be overcome by a passion. So we may say: A philosophy will only give way to a philosophy. In the "pathological interlude" of philosophical anarchy which at present still seems to prevail, a glimpse of a possible fruitful unison of philosophical efforts and results inspires our hope and awakens our strength. A new realm is already rising slowly but surely from the receding ocean of the future. We have sought to picture its preparation in these pages. But on the threshold of this philosophy of the future stands the problem of reality. 


\section{INDEX}

Absolute Philosophy, 26 f., 76, 149 f., 162

Esthetics, experimental, 148

Agnosticism, 33, 144

Antinomies, 72

Apperception, 228

Aristophanes, 136

Aristotle, 19, 196, 221

Art, 71, 129

Atom, 241

Avenarius, 35, 242

Bacon, Francis, 31

Being, Lotze's theory of, 164 ; absolute, 170 ; primordial, $63 \mathrm{ff}$.

Beneke, 223

Bergmann, Julius, 145

Bernouilli, C. A., 115 note

Body, 91, 109 ; soul and body, $157 \mathrm{f}$.

- and mind, 93, 157

Bosanquet, Bernard, 161 note

Brain, 92, 95, 103

Braun, O., 175

Brentano, Franz, 35, 224

Bruno, 127

Büchner, L., 82 ff., 89, 97, 102

Causality, $73 \mathrm{f}$.

Certainty, criterion of, $48 \mathrm{ff}$.

Christianity, 110, 120, 132

Chwolson, 96 note

Cohen, H., 34
Commandment, twelfth, 96 note

Common, Th., 114 note

Comte, 29 ff., 61

Consciousness, 65, 67 f., 75, 90 f., 95, 102 f., 223 ff. ; Fechner's theory of, $153 \mathrm{ff}$.; Harimann's theory of, $185 \mathrm{ff}$.

Coupland, W. C., 175 note

Cortex, 103

Creighton, J. E., 194 note

Cynics, 19

D'AlEM Bert, $27 \mathrm{f}$.

Darwin, 124

Deduction, 14, 140

Democritus, 19, 239

Descartes, 78, 250

Dialectic, 62

Drews, A., 116, 175

Dualism, 87, 93

Düring, Eugen, $59 \mathrm{ff}$.

Earth, soul of, $151 \mathrm{f}$., $159 \mathrm{f}$.

Economy, mental, 60

Eisler, Rudolf, 193

Eleatics, 239

Empiricism, $244 \mathrm{f}$.

Energy, 94, 100 f., 104, 240 f.

Epicureans, 20

Epistemology, 14, 16, 217

Erhardt, 143

Ether, 89, 135, 240

Eucken, R., 145 ff.

Evolution, 33, 124 


\section{PHILOSOPHY OF THE PRESENT}

Experience, 11, 41 f., 56, 201, $235,241,243$

Falckenberg, Richard, 161

Fatalism, 126

Fechner, 141 f., 147 ff., 210

Feuerbach, 61, $108 \mathrm{ff}$.

Fichte, J. G., 146, 181, 249

Force, 33, 82 f., 99

Galileo, 240

Gellert, 4

Goethe, 11, 97

Gottsched, 4

Gulliver, J. H., 149

HAECKEL, 3, 4, $83 \mathrm{ff}$., $93 \mathrm{ff}$.

Hamilton, Elizabeth, 161 note

Hartmann, Edward von, 143, $147,161,174$ ff., 210, 220

Hegel, 4, 11, 12, 26, 56, 149, 162,177 f., 188, 222, 244, 249

Herbart, 76, 149, 164, 174, 220, 228,230

Hönigswald, Richard, 36 note

Hume, 20, 31, 34, 250

Huxley, 33

IDEALISM, $18 \mathrm{ff}$., 58, $135 \mathrm{ff}$; critique of, $222 \mathrm{ff}$., 236 objective, 145

Immanent Philosophy, 34, 68, 193

Individuality, $110 \mathrm{f}$.

Induction, 10, 14, 32, 143

Inductive metaphysics. See Metaphysics

Intuition, 140

- intellectual, 243, 251

Jones, E. C., 161 note

Judaism, 120
KANT, 9, 11, 34, 73, 77, 97, $117,138,140$ f., 143, 176, 179 f., 220, 222, 234, 243 f., $247 \mathrm{ff}$.

Kaufmann, Max, 35

König, E., 193

Knowledge, 43, 53, 56

Kunze, J. E., 147

LAMETTRIE, 20, 239

Lange, F. A., 34, 97 f., 98

Lasswitz, K., 147

Leibniz, 138 f., 157, 171, 178, $195,221,230,237$ f., 240 , 242 f., 250

Levy, Dr. O., 114 note

Lichtenberger, 115

Liebmann, Otto, 34

Life, conduct of, $60,70 \mathrm{f}$., $118 \mathrm{f}$., 130

Logic, 14, 16, 136

Lotze, 147, 157, 160 ff., 210

Ludovici, A. M., 115 note

MACH, 35 ff., 68, 137, 173, 218, 242, 248

Marty, Anton, 35

Masters, morals of the 119,125

Materialism, $19 \mathrm{ff}$., $78 \mathrm{ff}$., $98 \mathrm{ff}$.

Nathematics, 136, 140

Matter, 33, 39 f., 65, 82, 87, 89, 99, 104

McCabe, Joseph, 84 note

Metaphysics, 40 f., 141

- Inductive, 16, 143, 159, 189

Mill, J. S., 32

Mind, 82 f., 94, 96

Moleschott, Jacob, $80 \mathrm{ff}$.

Monadology, 138, 221

Monism, 81, 87 f., 89, 94, 96 f.

Morality, 125

NAtorp, Paul, 34 
Naturalism, 19 ff., $107 \mathrm{ff}$.

Nature, laws of, $66 \mathrm{f}$., 107

Neo-Kantianism, 34 - Rationalism, $248 \mathrm{f}$.

Newton, 27, 240

Nietzsche, 3, 4, 67, 97, 108, 113, 114 ff., 224, 229

- Mrs. Förster, 114 note, 115

Nihilism, 117

Number, determinate, $62,72 \mathrm{f}$; law of, 74

OнM's Law, 46

Ontology, Wundt's theory of, $207 \mathrm{f}$.

Overbeck, Franz, 115, 132

Panlogism, 244

Pantheism, 88

Parallelism, psychophysical,93, 103

Paulsen, 97

Pfleiderer, Edmund, 160

Philosophy, its present position, 1 ff. ; relation to special sciences, 8

- Absolute, 26 f., 76 ; schools of, 8 ; task of, 35 ; Wundt's division of, 196

- Immanent, 34, 68

Phenomenalism, 139

Planck, Max, 47 note

Plato, 19, 127, 137 f., 189

Poetry, 98, 129

Positivism, 8, 18 f., 19 ff., 26 ff., 137, 193, 236

Psyche, 92

Psychical, definition of, 53, 55

Psychological method, 101, 225 ff., 229 f., 233

Psychoplasm, 92, 94

RationalisM, 247

Realism, 193
Realism, transcendental, 179

Reality, 21, 68, 164 f., 217 f., 238,251 ; Lotze's theory of, $162 \mathrm{f}$.

Relations, Lotze's theory of, $166 \mathrm{ff}$.

Religion, 28, 70, 96, 113

Richter, R., 115

Riehl, 34, 115

Rousseall, 20, 107, 125 f.

Samuels, H. B., 115 note

Schelling, 4, 26, 149, 177 f., $188,245,249$

Schiller, 118

Schleiermacher, 245

Schopenhauer, 3, 4, 61, 76, 97, $114,117,141,172,175,177$, $182,188,192,223$

Schubert-Soldern, Richard von, 35

Schuppe, W., 35

Schmitt, Kaspar, 110 ff.

Scholasticism, 71

Schools of philosophy, 8,18

Science, $13 \mathrm{ff}$., 38, 71, 195 f. ; Mach's view, 36 ff.; relation to philosophy, 8

Sensations, 44 f., 49 ff., $104 \mathrm{f}$.

Sense-perception, 86

Skeptics, 20

Slaves, morals of, 119 f., 124, 125

Sociology, 30

Soul, 79, 91, 93 ; of the earth, $152 \mathrm{ff}$. ; Fechner's theory, 157 Soul-cells, 90, 95

Space, 62

Spencer, 33, 220

Spinoza, 87, 94, 181, 221, 230, $250 \mathrm{f}$.

Spirit, 87, 94

Spiritualism, 81

Stirner, $110 \mathrm{ff}$. 


\section{PHILOSOPHY OF THE PRESENT}

Stoics, 20

Substance, problem of, 85,89

Superman, $121 \mathrm{f}$.

Theologr, 71

Thing-in-itself, 81, 86, $179 \mathrm{ff}$., 244

Thomas, E. C., 98 note

Thought, 44, 54, 197 ; economy of, 37

Tille, A., 114 note.

Time, 62

Titchener, E. B., 194 note

Touch, sense of, 68

Transcendence, 98; Wundt's theory of, $202 \mathrm{ff}$.

Treitschke, 2

Turgot, $27 \mathrm{ff}$.

Unconscious, 67, 95, $177 \mathrm{ff}$.
VALUES, $116 \mathrm{f}$.

Vitalism, 88

Vogt, Karl, 80

Voltaire, 125

WAGNER, Richard, 114, 129

- Rudolf, 79

Washburn, M. F., 194

Wernecke, H., 158 note

Will, 89; Wundt's theory of, 199, $206 \mathrm{ff}$; Hartmann's theory of, 174

Williams, C. M., 36 note

Wolff, 4, 9, 11

World-cycle, 123, 126

Wundt, 93, 143, 147, $193 \mathrm{ff}$., 230 f., 242

Ziegler, Th., 115

Zimmern, H., 114 note 


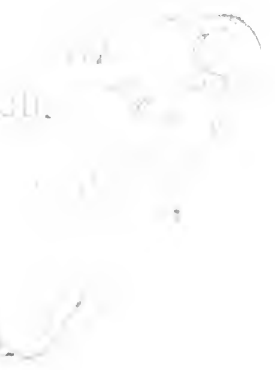

$\sqrt{11 / 80}$ 


\section{PLEASE DO NOT REMOVE CARDS OR SLIPS FROM THIS POCKET}

\section{UNIVERSITY OF TORONTO LIBRARY}



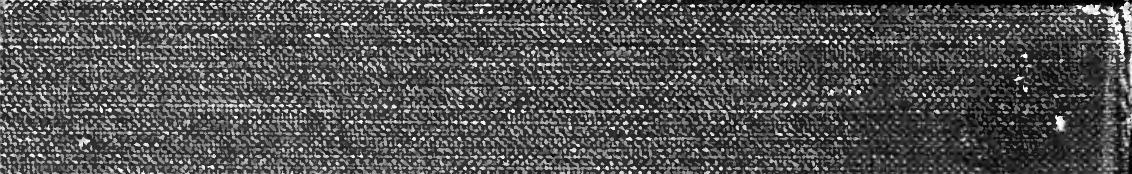

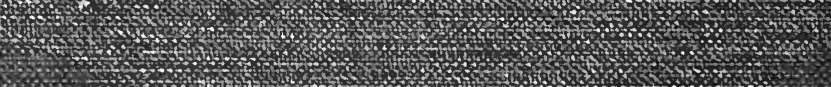

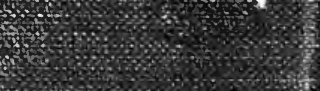

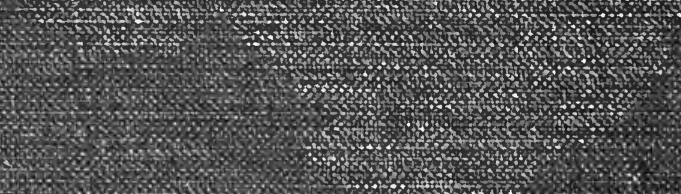

\begin{tabular}{|c|c|c|c|c|}
\hline & & & & \\
\hline
\end{tabular}

37 30

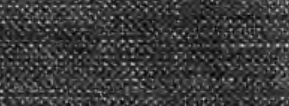

(x)

\%

$7 \sin ^{2}$

80

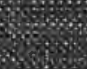

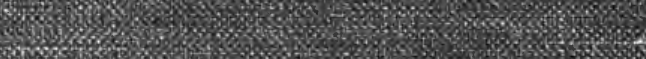

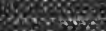

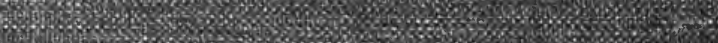

